\title{
WestVirginiaUniversity
}

THE RESEARCH REPOSITORY @ WVU

Graduate Theses, Dissertations, and Problem Reports

2011

\section{Analysis of Systematic Risk: Decomposition and Portfolio Efficiency}

Rudolf F. Klein

West Virginia University

Follow this and additional works at: https://researchrepository.wvu.edu/etd

\section{Recommended Citation}

Klein, Rudolf F., "Analysis of Systematic Risk: Decomposition and Portfolio Efficiency" (2011). Graduate Theses, Dissertations, and Problem Reports. 3459.

https://researchrepository.wvu.edu/etd/3459

This Dissertation is protected by copyright and/or related rights. It has been brought to you by the The Research Repository @ WVU with permission from the rights-holder(s). You are free to use this Dissertation in any way that is permitted by the copyright and related rights legislation that applies to your use. For other uses you must obtain permission from the rights-holder(s) directly, unless additional rights are indicated by a Creative Commons license in the record and/ or on the work itself. This Dissertation has been accepted for inclusion in WVU Graduate Theses, Dissertations, and Problem Reports collection by an authorized administrator of The Research Repository @ WVU.

For more information, please contact researchrepository@mail.wvu.edu. 


\title{
Analysis of Systematic Risk: Decomposition and Portfolio Efficiency
}

\section{Rudolf F. Klein}

\author{
Dissertation submitted to the \\ College of Business \& Economics at \\ West Virginia University \\ in partial fulfillment of the requirements for the degree of \\ Doctor of Philosophy \\ in \\ Economics
}

\author{
Approved by \\ Victor Chow, Ph.D., Committee Chairperson \\ Ronald Balvers, Ph.D. \\ Arabinda Basistha, Ph.D. \\ Alexander Kurov, Ph.D. \\ William Riley, Ph.D.
}

Department of Economics

Morgantown, West Virginia

2011

Keywords: Systematic Risk, Asset Pricing, Orthogonalization, Decomposition, Fama-French

Model, Investor Sentiment, Portfolio Efficiency, Stochastic Dominance, Foreign Exchange

Copyright 2011 Rudolf F. Klein 


\section{ABSTRACT \\ Analysis of Systematic Risk: Decomposition and Portfolio Efficiency}

\section{Rudolf F. Klein}

This dissertation comprises three essays that tackle various aspects of linear asset pricing models. The first essay, recognizing the dependence problem between factors, in the context of linear multi-factor models, proposes an optimal procedure to find orthogonalized risk premia, which also facilitates the decomposition of the coefficient of determination. Importantly, the new risk premia may diverge significantly from the original ones. The decomposition of risk allows one to explicitly examine the impact of individual factors on the return variation of risky assets, which provides discriminative power for factor selection. The procedure is experimentally robust even for small samples. Empirically we find that even though on average, approximately eighty (sixtyfive) percent of style (industry) portfolios' volatility is explained by the market and size factors, other factors such as value, momentum and contrarian still play an important role for certain portfolios. The components of systematic risk, while dynamic over time, generally exhibit negative correlation between market, on one side, and size, value, momentum and contrarian, on the other side.

In the second essay we apply Marginal Conditional Stochastic Dominance (MCSD) tests to returns on sentiment-beta sorted portfolios and sentiment-arbitrage portfolios, constructed using the Baker and Wurgler (2007) index of sentiment levels. The theory of MCSD demonstrates that, if one (mutually exclusive) subset of a core portfolio dominates another, conditional on the return distribution of the core portfolio, then the core portfolio is inefficient for all utilitymaximizing risk-averse investors. Based on returns on the U.S. equity market, we show that both positively and negatively sentiment sensitive stocks are conditionally and stochastically dominated by sentiment insensitive stocks. Moreover, we find dominance among sentimentarbitrage portfolios, constructed with positively sensitive vs. insensitive, insensitive vs. negatively sensitive, and positively vs. negatively sensitive stocks. Therefore, we conclude that the market portfolio is stochastically inefficient.

The third essay builds on the theory of the FX market, which shows that investing in a high yielding currency would generate zero average returns, due to its depreciation with respect to the home currency. Empirically, it has been shown that high yielding currencies actually appreciate. The Consumption CAPM applied in the FX market argues that a high yielding currency also exposes investors to more consumption risk, hence the positive excess returns. The literature on the FX market proposes different strategies that generate abnormal returns based on the "forward puzzle". This paper investigates whether the returns obtained through a specific strategy that combines mean reversion and momentum in the FX market, are a compensation for risk. We find that the risk factors corresponding to an extended version of the Consumption CAPM can explain $99 \%$ of the variation in currency excess returns. We compare this model with other asset pricing models and conclude that none of them can provide a similarly good explanation. 


\section{Dedication}

Two people, very dear to me, cannot receive my thanks: Alina's father,

Lucian and my father, Rudolpf. To them I dedicate this work. 


\section{Acknowledgments}

I owe a debt of gratitude to all those who, along the way, have helped me get to where I am now. My sense of this debt can partially be relieved by addressing THANKS to:

My mom, Elena, and my brother, Silvius, whose financial and moral support was indispensable.

My best friend, 'Omu', and his family for being so good to me.

Alina's family: Cornelia, Anca, and Maricel for allowing me to steal Alina away from them.

The Admissions Committee that accepted me into the Economics Ph.D. Program at West Virginia University.

Prof. Ron Balvers for being a great coordinator: he always gives excellent suggestions and knows how to encourage you when you need it.

Prof. Victor Chow, my academic advisor, for fulfilling his duties above and beyond what was needed, to ensure that I am able to become an independent and successful researcher.

My dissertation committee members - Dr. Ron Balvers, Dr. Arabinda Basistha, Dr. Victor Chow, Dr. Alex Kurov, and Dr. Bill Riley - for their useful comments and suggestions that made this dissertation significantly better.

The faculty, staff, and fellow graduate students in the Economics department at WVU for all their support throughout the entire program.

The wonderful people of West Virginia, in general, and Sun Ki Fowler, in particular, for embracing newcomers so kindly.

Craig Ferguson for the stress-relieving, before-going-to-bed show, and for inspiring me on how to write this section.

My wife, Alina, for love, support, and patience. 


\section{Mulțumiri}

(Translation of Acknowledgments into Romanian)

Datorez mulțumiri tuturor celor care, de-a lungul timpului, m-au ajutat să ajung unde sunt acum. Nu pot decât să adresez MULȚUMIRI:

Mamei mele, Elena, și fratelui meu, Silvius, al căror ajutor material și moral a fost esențial.

Celui mai bun prieten al meu, 'Omu', și familiei lui pentru că au fost atât de buni cu mine.

Familiei Alinei: Cornelia, Anca și Maricel pentru că mi-au îngăduit să o fur pe Alina de lângă ei.

Comisiei de admitere pentru că m-au acceptat în Programul de Doctorat în Economie al West Virginia University.

Prof. Ron Balvers pentru că este un coordonator excelent: mereu dă sugestii foarte bune și știe cum să te încurajeze când ai nevoie.

Dr. Victor Chow, profesorul meu îndrumător, pentru că și-a îndeplinit sarcinile dincolo de ce era necesar, pentru a se asigura că pot deveni un cercetător independent și de succes.

Membrilor comisiei mele de dizertație - Dr. Ron Balvers, Dr. Arabinda Basistha, Dr. Victor Chow, Dr. Alex Kurov și Dr. Bill Riley - pentru comentariile și sugestiile lor, care au îmbunătățit considerabil această lucrare.

Corpului profesoral, administrației și colegilor doctoranzi din departamentul de Economie din WVU, pentru tot sprijinul din timpul întregului program.

Oamenilor minunați din Virginia de Vest, în general, și lui Sun Ki Fowler, în particular, pentru că ne-au primit cu atâta căldură.

Lui Craig Ferguson pentru că ne-a făcut să râdem noapte de noapte, înainte de culcare, și pentru inspirația în scrierea acestei secțiuni.

Soției mele, Alina pentru dragoste, sprijin și răbdare. 


\section{Table of Contents}

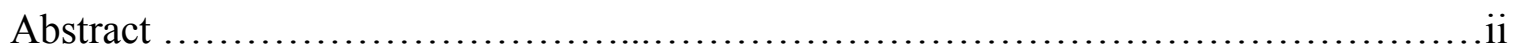

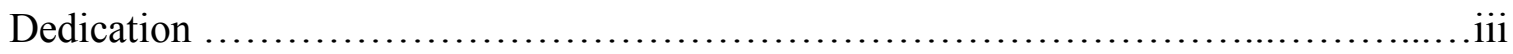

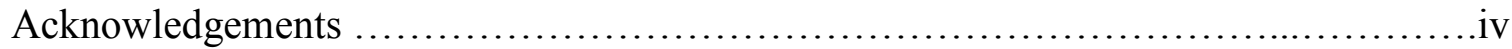

Multumiri (Translation of Acknowledgements into Romanian) ..........................v

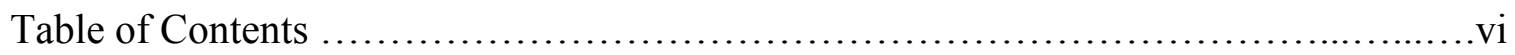

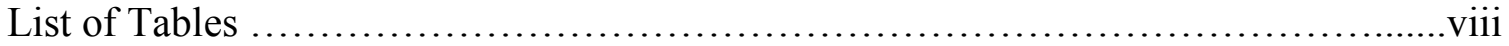

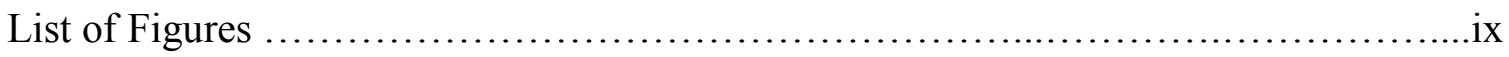

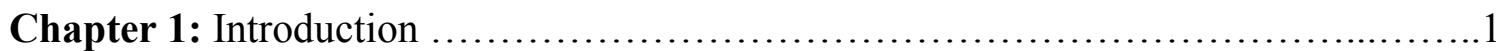

Chapter 2: Orthogonalized Equity Risk Premia and Systematic Risk Decomposition

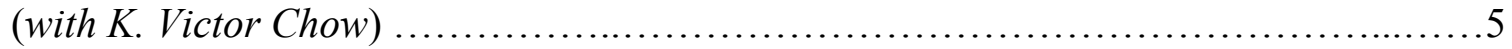

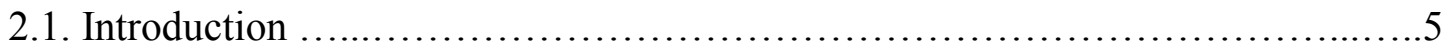

2.2. Orthogonalization Procedure …......................................... 9

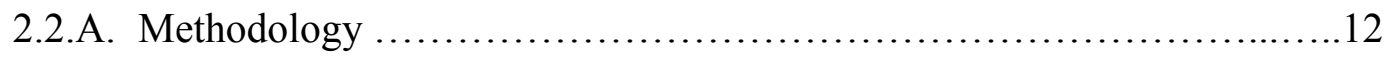

2.2.B. Monte Carlo Simulations ................................................18

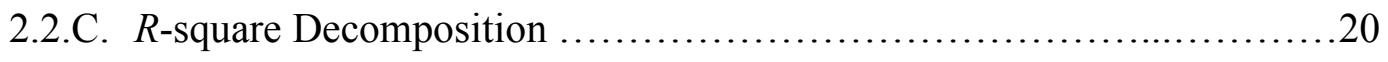

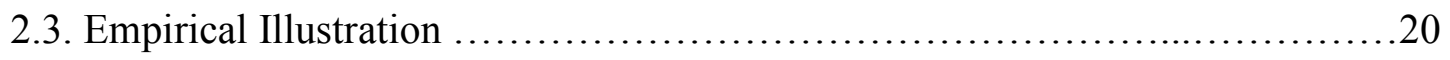

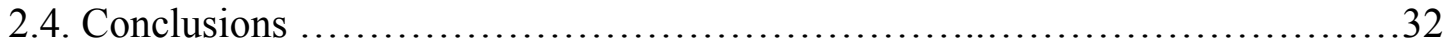

Appendix to Chapter 2: The nature of the relationship between the original and the orthogonalized factors ...............................34

Chapter 3: Sentiment Effect and Market Portfolio Inefficiency

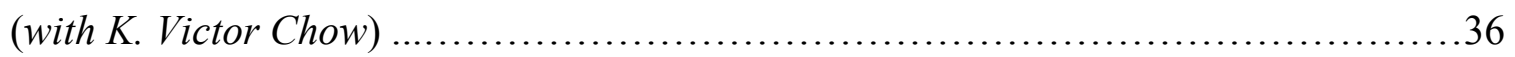

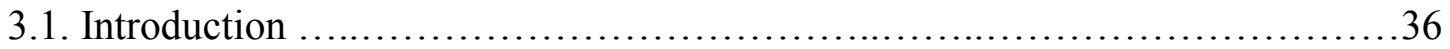

3.2. Marginal Conditional Stochastic Dominance Test .............................41

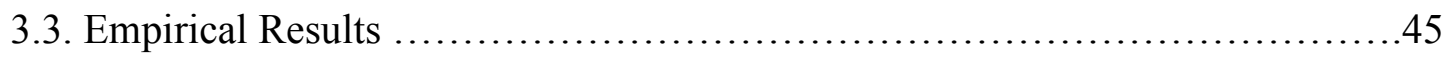

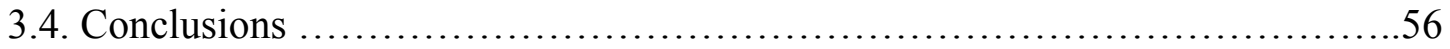


Chapter 4: Consumption Risk and FX Trading Returns

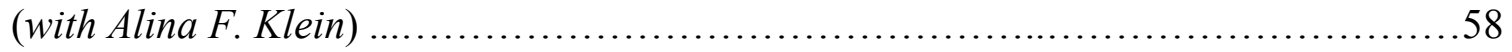

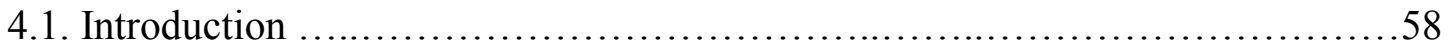

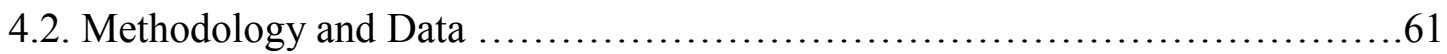

4.2.1. Combining Mean Reversion and Momentum Strategy ..................61

4.2.2. Econometric Procedure .........................................62

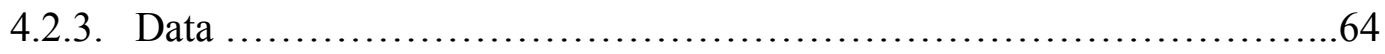

4.3. Testing the CCAPM, Yogo's CCAPM and Their Alternatives ...................67

4.3.1. Asset Pricing Models in the FX Literature ............................66

4.3.2. GMM Estimation ......................................................69

4.3.3. Model Comparison ............................................... 74

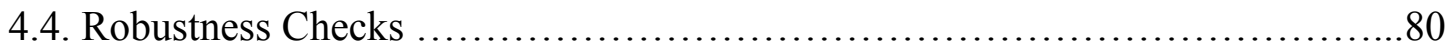

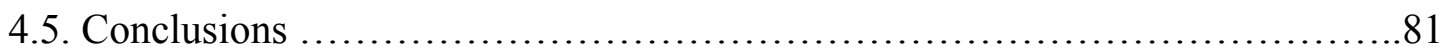

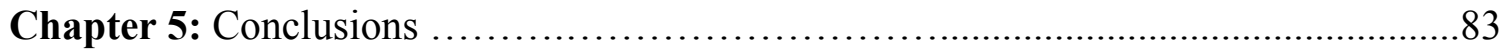

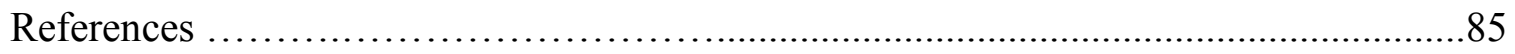

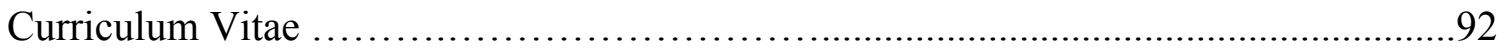




\section{List of Tables}

2.I Method Comparison with Respect to Resemblance Criteria ........................11

2.II The Mean Squared Errors (MSE) of the Decomposable Systematic

Risk Estimates ......................................................... 18

2.III Sampling Errors of Individual Decomposed Systematic Risk Estimates ............19

2.IV Distribution Properties of Factors' Sample Returns: Original vs. Orthogonal .....20

2.V Non-orthogonal vs. Orthogonal Beta Estimates .............................23

2.VI Orthogonal Transformation and Systematic Risk Decomposition .................25

2.VII Risk Decomposition for Style Portfolios ...................................27

2.VIII Risk Decomposition for the 30-Industry Portfolios ...........................29

3.I Distribution Properties of the Factors' Returns: Non-orthogonal vs. Orthogonal ....46

3.II Summary Statistics for Sentiment-Beta Sorted Portfolios .......................48

3.III MCSD Test for Sentiment-Beta Sorted Portfolios ...........................50

3.IV Summary Statistics for Sentiment-Beta Sorted Portfolios Conditional on the Level of Sentiment .......................................... 51

3.V Summary Statistics for Sentiment-Arbitrage Portfolios ........................53

3.VI MCSD Test for Sentiment Arbitrage Portfolios ...............................55

4.I Descriptive Statistics ...............................................66

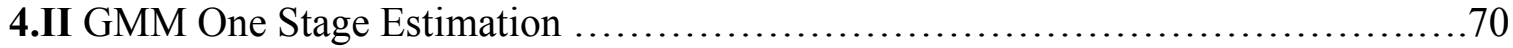

4.III Models Comparison .................................................... 75

4.IV $J_{T}$ Difference Test ................................................. 79

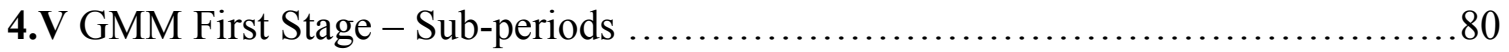




\section{List of Figures}

2.1 Decomposed Risk over Time ............................................. 31

4.1 Durable and Nondurable Consumption ...................................60

4.2 Mean Estimated Returns vs. Mean Realized Returns for the FX Portfolios

Obtained through GMM First Stage Approach .................................. 72

4.3 Mean Estimated Returns vs. Mean Realized Returns for the FX Portfolios

Obtained through GMM Second Stage Approach .............................73

4.4 Mean Estimated Returns vs. Mean Realized Returns for the FX Portfolios and the 25 Fama-French Portfolios (GMM First Stage) ........................ 76

4.5 Mean Estimated Returns vs. Mean Realized Returns for the FX Portfolios and the 25 Fama-French Portfolios (GMM Second Stage) .........................77 


\section{Chapter 1: Introduction}

This dissertation gravitates around linear factor models, which are at the core of asset pricing. Often, the market beta is not enough to explain the cross-sectional variations of average equity returns. That is why researchers have proposed alternatives to the traditional single-factor Sharpe (1964) and Lintner (1965) Capital Asset Pricing Model (CAPM). For instance, Fama and French $(1992,1993,1996,1998)$ document that the company's market capitalization (i.e. size) and the company's value, which is characterized by ratios of book-to-market (B/M), earnings to price $(\mathrm{E} / \mathrm{P})$ or cash flows to price $(\mathrm{C} / \mathrm{P})$, together predict the return on a portfolio of stocks with much higher accuracy than the market beta alone. Moreover, the Carhart (1997) model extends the Fama-French model, by including a fourth factor: momentum. The momentum effect of Jegadeesh and Titman (1993, 2001), Chan, Jegadeesh, and Lakonishok (1996), Rouwenhorst (1998), and others, indicates that average returns on the prior best performing stocks (the socalled winners) exceed those of the prior worst performing stocks (the so-called losers), and thus short-term past returns have predictive power over future returns. Conversely, DeBondt and Thaler $(1985,1987)$ reveal a contrarian effect such that stocks exhibiting low long-term past returns outperform stocks with high long-term past returns. DeBondt and Thaler $(1985,1987)$, Chopra, Lakonishok, and Ritter (1992), and Balvers et al. (2000) suggest a profitable long-term reversal strategy of buying the losers and shorting the winners. Lately, a number of papers have been inspecting the effect of investor sentiment on common stock returns. Baker and Wurgler $(2006,2007)$, for example, examine investor sentiment as another determinant of stock returns. Glushkov (2006) tests whether exposure to sentiment is a priced factor that is, whether investors demand premium for holding stocks with more exposure to sentiment. He finds that the 
relationship between sentiment betas and returns is inverse U-shaped, meaning that low and high beta stocks tend to underperform the near-zero beta stocks. The Consumption CAPM, originally developed by Lucas (1978) and Breeden (1979) is extended, for instance, by Yogo (2006) who introduces in the equation the nondurable consumption, the durable stock, and the market premium. An extension of the CAPM to a multi-country case is the widely known International CAPM, attributed to Solnik (1974), Stulz (1981), or Adler and Dumas (1983). The list of possible macro-economic factors can also include monetary determinants such as: the growth rate of M1 per capita, the federal funds rate, liquidity premium, or term spread. The first proponents of the monetary explanations in the case of currency risk premia are Hodrick and Srivastava (1986).

The first essay (Chapter 2) considers five of the factors enumerated above as inputs in an empirical application to a theoretical procedure of symmetric orthogonalization. These factors are: $R M$ (i.e. market risk premium), $S M B$ (i.e. Small minus Big, market capitalization), $H M L$ (i.e. High minus Low, book-to-market ratio), Mom (i.e. momentum), and Rev (i.e. long-term reversal, or contrarian). Since these variables are returns, or spreads in returns on well-diversified portfolios, they cannot be independent to each other. To be able to examine the impact of each individual factor on the return variation of risky assets, and to able to gauge each factor's premium (free of their mutual dependence) we need to find the underlying, uncorrelated components of these factors. To accomplish the task of finding the orthogonalized factors, we use a procedure developed initially in the quantum chemistry and in the wavelet literature. This symmetric procedure has clear advantages over other methods used so far in economics and finance: it is optimal, in the sense that it maximizes the resemblance with the original factors. Plus, it is both democratic and simultaneous, in that it doesn't have a sequence bias, meaning that 
it doesn't matter which factor is transformed first and which one follows next. Due to the general nature of this algorithm, it can have several important applications. One of them, which we are pursuing in this paper, is to decompose the coefficient of determination, which is a standardized measure of systematic risk. Thus, we can asses the attribution of risk to each individual factor. Consequently, we can now answer some very important questions that arise in the asset pricing literature, like for instance: does a high $R$-square imply a proper diversification; does a higher beta of one factor imply its relatively higher importance; or, which factors should be included in the analysis for a specific type of portfolio? Empirically we find, for instance, that even though on average, approximately eighty (sixty-five) percent of style (industry) portfolios' volatility is explained by the market and size factors, the other factors (i.e. value, momentum and contrarian) still play an important role for certain portfolios.

In the second paper (Chapter 3), after controlling for the market, size, value, and momentum factors, we examine the impact of investor sentiment on the cross-section of equity returns. For that purpose, we use Marginal Conditional Stochastic Dominance (MCSD) tests to prove the existence of a sentiment effect in the US equity market, and to show that the market portfolio is inefficient relative to sentiment-beta sorted portfolios (i.e. portfolios formed by sorting common stocks on their sensitivity to the index of investor sentiment). As a measure of sentiment we employ the Baker and Wurgler (2007) index of sentiment levels. The theory of MCSD shows that, if one sub-portfolio of a core portfolio dominates another, conditional on the return distribution of the core portfolio, then the core portfolio is inefficient for all utilitymaximizing risk-averse investors. Empirically we find that, considering the returns on all common stocks listed on the NYSE, AMEX, and NASDAQ, from January 1966 to December 2007, both positively and negatively sentiment sensitive stocks are conditionally and 
stochastically dominated by sentiment insensitive stocks. Moreover, we find dominance among sentiment-arbitrage portfolios, constructed with positively sensitive vs. insensitive, insensitive vs. negatively sensitive, and positively vs. negatively sensitive stocks. Consequently, we conclude that the market portfolio is stochastically inefficient. Taking into consideration that the five variables mentioned above could be significantly correlated, we use the orthogonalization procedure proposed in Chapter 2, to calculate their orthogonal counterparts. Our results prove to be robust, and the conclusions remain the same, when we repeat the MCSD tests for the uncorrelated components.

The third essay (Chapter 4) examines the validity of different asset pricing models in explaining abnormal returns obtained in the foreign exchange (FX) market. For that purpose, it employs Serban's (2010) strategy that combines mean reversion and momentum, a strategy that is originally implemented for the stock market by Balvers and $\mathrm{Wu}$ (2006). The similarities between the two markets allow us to consider the same models when gauging whether the abnormal returns documented in the FX market are compensation for risk. We analyze the Consumption Capital Asset Pricing Model (CCAPM), Yogo's (2006) Extended CCAPM, CAPM, International CAPM, the Fama-French Model, and a Monetary-based Model. We find, using the Hansen's (1982) Generalized Method of Moments (GMM) procedure, that Yogo's (2006) Extended CCAPM is the best fitted model: it stands as the only model for which the $J_{T^{-}}$ test does not reject the null of validity. Moreover, it gives an $R^{2}$ value (between the predicted and the actual mean excess returns) of 99 percent in the first stage GMM estimation.

This dissertation concludes in Chapter 5, with a summary of the main contributions that these three papers make to the literature. 


\section{Chapter 2: Orthogonalized Equity Risk Premia and}

\section{Systematic Risk Decomposition}

\subsection{Introduction}

Under the traditional single-factor Sharpe (1964) and Lintner (1965) Capital Asset Pricing Model (CAPM), the market beta captures a stock's systematic risk for all rational, risk-averse investors. Therefore, a decomposition of the market beta is sufficient to break down the systematic risk of a stock. ${ }^{1}$ For example, Campbell and Vuolteenaho (2004) break the market beta of a stock into a 'bad' component that reflects news about the market's future cash flows and a 'good' component that reflects news about the market's discount rates. In an earlier paper, Campbell and Mei (1993) show that the market beta can be decomposed into three sub-betas that reflect news about future cash flows, future real interest rates and a stock's future excess returns, respectively. Acharya and Pedersen (2005) develop a CAPM with liquidity risk by separating the market beta of a stock into four sub-betas that reflect the impact of illiquidity costs on the systematic risk of an asset. In many cases, the analysis of decomposed market beta has been applied to examine the size and/or book-to-market anomalies. Although the beta-decomposition is useful to describe the structure and source of systematic variation of returns on risky assets, it is complicated under multi-factor frameworks. ${ }^{2}$

The purpose of this paper is to develop an optimal procedure to identify the underlying uncorrelated components of common factors by a simultaneous orthogonal transformation of sample data, such that the linear dependence is removed, and the systematic variation of stock

\footnotetext{
${ }^{1}$ According to the CAPM, the systematic risk is measured by $\left(\beta_{j} \sigma_{R M}\right)^{2}$. Since the market risk premium is the only factor faced by all investors, $\beta_{j}$ is sufficient to determine the systematic risk.

${ }^{2}$ Campbell and Mei (1993) show that the complication is due to the possible covariance between the risk price of one factor and the other factors.
} 
returns becomes decomposable. We empirically compare our approach with two popular orthogonalization methods, Principal Component Analysis and the Gram-Schmidt process, and unsurprisingly find that our technique has the essential advantage of maintaining maximum resemblance with the original factors. ${ }^{3}$

In the past two decades, one of the most extensively studied areas of financial research has concentrated on alternative common risk factors, in addition to the market risk premium, that could characterize the cross-section of stock expected returns. Fama and French (1992, 1993, 1996, 1998) document that the company's market capitalization - size and the company's value, which is characterized by ratios of book-to-market $(\mathrm{B} / \mathrm{M})$, earnings to price $(\mathrm{E} / \mathrm{P})$ or cash flows to price $(\mathrm{C} / \mathrm{P})$, together predict the return on a portfolio of stocks with much higher accuracy than the market beta alone, or the traditional CAPM. ${ }^{4}$ In addition to the size and value effects, Jegadeesh and Titman (1993, 2001), Rouwenhorst (1998), Chan, Jegadeesh and Lakonishok (1996) reveal that short-term past returns or past earnings predict future returns. Average returns on the best prior performing stocks (i.e. winners) exceed those of the worst prior performing stocks (i.e. losers), attesting the existence of momentum in stock prices. Conversely, DeBondt and Thaler $(1985,1987)$ reveal a contrarian effect such that stocks exhibiting low long-term past returns outperform stocks with high long-term past returns. DeBondt and Thaler $(1985,1987)$, Chopra, Lakonishok, and Ritter (1992), and Balvers et al. (2000) suggest a profitable contrarian strategy of buying the losers and shorting the winners.

Due to the common effects such as size, value, momentum and contrarian, additional factors, besides the market risk premium, must be considered for the determination of the return

\footnotetext{
${ }^{3}$ For instance, Baker and Wurgler $(2006,2007)$ employ Principal Component Analysis to develop measures of investor sentiment, shown to have significant effects on the cross-section of stock prices. Boubakri and Ghouma (2010) remove the multicollinearity between their variables using the Gram-Schmidt algorithm.

${ }^{4}$ Fama and French $(1992,1996,1998)$ show that the investment strategy of buying the small/value and shorting the big/ growth stocks produces positive returns.
} 
generating process for risky assets. Therefore, multi-factor market models have been widely employed by both financial academics and practitioners. Under the multi-factor framework, the expected excess return on a risky asset is specified as a linear combination of beta coefficients and expected premia of individual factors. Fama and French (1993) explicitly demonstrate that if there are multiple common factors in stock returns, they must be in the market return, or in other well-diversified portfolios. This indicates that returns of common factors are correlated with the market, and often with each other. Consequently, in the multiple linear regression setting, although the beta coefficient corresponding to an individual factor provides a sensitivity measure of an asset's return to the factor's variation, it may not catch precisely the systematic variation of the asset with respect to that factor. For instance, low beta might not indicate low systematic risk. The volatility of an asset's returns is determined jointly not only by the betas, but also by the variances and covariances of the factors' premia. Therefore, to provide a clear image of the separate roles of common factors in stock returns, determining the factors' underlying uncorrelated components becomes necessary.

This paper proposes an optimal simultaneous orthogonal transformation of sample returns on factors. The data transformation allows us to identify the underlying uncorrelated components of common factors. Specifically, the inherent components of factors retain their variances, but their cross-sectional covariances are zero. In addition, a multi-factor regression using the orthogonalized factors has the same coefficient of determination ( $R$-square, i.e. the ratio of systematic variation to the overall volatility of a risky asset) as that using the original, nonorthogonalized factors. Since the coefficient of determination is a measure of the systematic risk of an asset, extracting the core, stand alone components of common factors enables us to decompose the systematic risk by disentangling the $R$-square, based on factors' volatility and 
their corresponding betas. Different from the Fama and French (1993) approach (which is in fact very similar to the Gram-Schmidt process), our methodology is democratic, that is, free of sequence bias. They clearly demonstrate that since the market return is a mixture of the multiple common factors, an orthogonalization of the market factor is necessary so that it can capture common variation in returns, left by other factors such as size or value. We argue that not only the market factor, but all factors need to be orthogonally transformed to eliminate the dependence problem among them. Although Fama-French's orthogonalization procedure for the market factor is straightforward, their method would involve selection of the leader (i.e. starting factor) and sequence biases, if one applied it to orthogonalize more than one variable in the model. Specifically, a different selection of the leader factor or a different orthogonalization sequence generates different transformation results. Marcelo and Quiros (2006) employ the Fama and French (1993) orthogonalization approach to generate an illiquidity-based risk factor.

Using Monte Carlo simulations, we demonstrate that our orthogonal transformation is robust, in that it produces unbiased estimates of the population systematic risk even for small samples. By applying our methodology to Kenneth French's data sets, we show empirically that the return variation of assets is now decomposable by factors. ${ }^{5}$ We find that, generally, the market, size and value factors are the largest sources of systematic risk (not always in that order), while other factors such as momentum and contrarian play relatively small roles in stock volatility determination.

The paper is organized as follows. In Section II, after an illustration of systematic risk decomposition problems in multi-factor models, we present our procedure of symmetric orthogonal transformation and risk-decomposition. Next, in Section III, we illustrate the

\footnotetext{
${ }^{5}$ Kenneth French's Data Library is publicly accessible at http://mba.tuck.dartmouth.edu/pages/faculty/ken.french/ data_library.html.
} 
procedure empirically, using sample data from Kenneth French's Data Library. The final section of the paper provides brief concluding remarks.

\subsection{Orthogonalization Procedure}

Empirically, suppose a risky asset $j$ 's return generating process can be linearly determined by a set of $K$-common factors (returns or macro-variables, denoted by $f_{k}$ ) [e.g. the market $(R M)$, size $(S M B)$, value $(H M L)$, momentum (Mom), and long-term reversal (Rev) premia], as shown in the following regression model:

$$
r_{j, t}=\alpha_{j}+\sum_{k=1}^{K} \beta_{k_{j, t}} f_{k, t}+\varepsilon_{j, t}
$$

where the residual term $\varepsilon_{j}$ is assumed to be uncorrelated with $f_{k}$, but $f_{k}$ are not independent from one another. ${ }^{6}$

The systematic variation of asset $j$ 's returns can then be measured by:

$$
\sigma_{s r_{j}}^{2}=\sum_{l}^{K} \sum_{k}^{K} \beta_{k_{j}} \beta_{l_{j}} \operatorname{Cov}\left(f_{k}, f_{l}\right)
$$

while the coefficient of determination or $R$-square is the ratio of systematic variation to the total return variation $\left(\sigma_{s r_{j}}^{2} / \sigma_{j}^{2}\right)$.

It is important to note that under the multi-factor framework, the systematic risk depends not only on the beta coefficients but also on the factors' variance-covariance. Thus, beta coefficients alone are inappropriate measures for systematic variation. One of the goals of this paper is to develop a decomposable systematic risk measure.

\footnotetext{
${ }^{6}$ For instance, the market factor is a hodgepodge of the multiple common factors, and the factor portfolios of size, value, momentum and contrarian are all formed using securities in the same market, and thus their returns are not uncorrelated.
} 
As shown in (2), $\sigma_{s r_{j}}^{2}$ is not decomposable due to the mutual correlation between factors. ${ }^{7}$ Kennedy (2008) points out that the total $R$-square cannot be allocated unequivocally to each explanatory variable, unless we have zero multicollinearity between the variables. To be able to achieve zero multicollinearity, thus eliminating the impact of factors' covariances, the underlying component of each factor's returns needs to be identified by an orthogonal transformation of sample returns. We argue that, even though numerous orthogonalization techniques are available, the optimal alternative for finding the proper orthogonal proxies of the original factors is the socalled symmetric procedure, as adapted in this paper (henceforth denoted as SW/L). For instance, the popular Principal Component Analysis (PCA), often used for dimensionality reduction, though similar to our procedure in some aspects, cannot offer by itself a meaningful bijective correspondence from the original to the orthogonalized sets of factors, if the number of variables is larger than two. And even in the cases where we have only two explanatory variables, if they are significantly correlated, it is difficult to maintain a strong resemblance after transformation. Table 2.I considers all the possible combinations of pairs out of the five factors mentioned above and, using two measures of similitude, compares these two methods, together with the classical Gram-Schmidt (GS) process. A major deficiency of this last procedure is that it requires a choice of the initial starting factor, which will not be transformed, thus failing to give all factors equal footing. We are nevertheless interested to see whether the deviations in the second factor overpower the overall movements attested by the first two methods.

\footnotetext{
${ }^{7}$ For simplicity and without losing generality, henceforth we will only refer to common factors as factor portfolio returns, but the model can also be applied to other systematic factors (e.g. macro-economic or fundamental variables).
} 
Table 2.I

\section{Method Comparison with Respect to Resemblance Criteria}

This table considers all the possible combinations of pairs out of five stock-market factor portfolios: RM, SMB, HML, Mom and Rev, and reports the correlation coefficients (Panel A), and the Frobenius norm values of the deviations (Panel B) between the non-orthogonalized and the orthogonalized forms. The orthogonalized factors are obtained using each of the following methods: the Schweinler-Wigner/ Löwdin (1970) symmetric procedure, as adapted in this paper (SW/L), Principal Component Analysis (PCA), and the Gram-Schmidt process (GS). RM, SMB and $H M L$ are the Fama/French factors: $R M$ is the market risk premium; $S M B$ is Small Minus Big, while $H M L$ is High Minus Low. Mom is the momentum factor, while Rev is the long-term reversal factor. All five factors follow the description and are obtained from Kenneth French's data library at http://mba.tuck.dartmouth.edu/pages/faculty/ken.french/. The sample period is January 1931 to December 2008. The Frobenius norm of a real matrix is defined as the square root of the sum of the squares of its elements.

Panel A: Correlation Coefficients

\begin{tabular}{llllll}
\hline & \multicolumn{2}{c}{ SW/L } & \multicolumn{2}{c}{ PCA } & GS \\
\hline$R M \& S M B$ & 0.992 & 0.978 & 0.986 & 0.874 & 0.941 \\
$R M \&$ \&ML & 0.996 & 0.990 & 0.987 & 0.922 & 0.970 \\
$R M \&$ Mom & 0.987 & 0.982 & 0.909 & 0.709 & 0.946 \\
$R M$ \& Rev & 0.995 & 0.989 & 0.988 & 0.920 & 0.968 \\
$S M B$ \& HML & 0.999 & 0.999 & 0.869 & 0.913 & 0.994 \\
$S M B$ \& Mom & 0.996 & 0.998 & 0.957 & 0.990 & 0.991 \\
$S M B$ \& Rev & 0.976 & 0.979 & 0.590 & 0.871 & 0.908 \\
HML \& Mom & 0.972 & 0.984 & 0.746 & 0.952 & 0.925 \\
HML \& Rev & 0.947 & 0.945 & 0.904 & 0.450 & 0.787 \\
Mom \& Rev & 0.994 & 0.990 & 0.970 & 0.882 & 0.975 \\
\hline
\end{tabular}

Panel B: Frobenius Norm Values of the Deviation Matrix

\begin{tabular}{lccc}
\hline & SW/L & PCA & GS \\
\hline$R M \& S M B$ & 30.518 & 57.877 & 35.994 \\
$R M \& H M L$ & 22.171 & 51.239 & 29.428 \\
$R M \&$ \&om & 38.748 & 128.797 & 54.975 \\
$R M \&$ Rev & 22.824 & 50.529 & 28.768 \\
$S M B \& H M L$ & 7.465 & 70.009 & 17.464 \\
$S M B \&$ Mom & 12.920 & 36.675 & 30.671 \\
$S M B$ \& Rev & 31.769 & 123.197 & 47.165 \\
$H M L \&$ Mom & 37.327 & 88.974 & 63.458 \\
$H M L \&$ Rev & 51.105 & 116.381 & 71.404 \\
Mom \& Rev & 21.661 & 63.158 & 28.691 \\
\hline
\end{tabular}


Panel A presents the correlation coefficients between the original and the transformed factors. It is easily noticeable that SW/L outperforms both PCA and GS. For instance, its lowest correlation of 0.945 is more than double the minimum correlation for PCA, 0.450 , and about 20 percent larger than that of GS, 0.787 , all for $H M L \& R e v .{ }^{8}$ Also, given that GS does not modify the first factor, which can be interpreted as perfect correlation, while the correlation corresponding to the second factor is always higher than the lower coefficient for PCA, we can conclude that GS dominates PCA in all ten cases. Panel B reports, on a comparative scale, the Frobenius norm of the $T \times K$ matrix whose elements are the deviations of the orthogonalized, from the original sets of data where, in these cases, $T=936$ months (from January 1931 to December 2008) and $K=2$ factors. Since we want the original factors to be disturbed as little as possible, the results confirm the superiority of our symmetric procedure, which has the lowest (square root of the) sum of squared deviations, in all ten cases. Similar to Panel A, the principal component scores are further from the values of the original variables, compared to the GS transformation. This is very severe especially when the original variables show significant covariance. That is why, some researchers, for ease of interpretation of the factor loading pattern, prefer to perform rotations, once the PCA is completed.

\subsection{A. Methodology}

For convenience purposes, we present the transformation procedure in a matrix format. Let $f_{T \times 1}^{k}=\left[f_{1}^{k}, f_{2}^{k}, \cdots, f_{T}^{k}\right]^{\prime}$ be the sample returns of the $k$-th factor, for $k=1,2, \ldots, K$, and

\footnotetext{
${ }^{8} \mathrm{HML}$ and $\mathrm{Rev}$, in their original form, exhibit the highest correlation among all pairs of factors, over the period January 1931 - December 2008 (see Table 2.IV).
} 
$F_{T \times K}=\left[f_{t}^{k}\right]_{t=1, \ldots, T}^{k=1, \ldots, K}$ their corresponding $T$ by $K$ matrix. ${ }^{9}$ Our purpose is to derive from $F_{T \times K}$ a matrix of mutually uncorrelated and variance-preserving vectors, denoted by $F_{T \times K}^{\perp}=\left[f_{t}^{k^{\perp}}\right]_{t=1, \ldots, T}^{k=1, \ldots, K}$, so that the systematic return variation can be estimated by the following decomposable form:

$$
\hat{\sigma}_{s r_{j}}^{2}=\sum_{k=1}^{K}\left(\hat{\beta}_{k_{j}}^{\perp} \hat{\sigma}_{f^{k}}^{\perp}\right)^{2}=\hat{\sigma}_{j}^{2}-\hat{\sigma}_{\varepsilon_{j}}^{2},
$$

where $\hat{\sigma}_{s r_{j}}^{2}$ is the estimate of $\sigma_{s r_{j}}^{2}, \hat{\beta}^{\perp}$ and $\hat{\sigma}^{\perp}(=\hat{\sigma})$ are the estimates of beta and standard deviation from sample data after the orthogonal transformation, and $\hat{\sigma}_{j}^{2}$ and $\hat{\sigma}_{\varepsilon_{j}}^{2}$ are the estimated variance of asset $j$ 's returns and its residual variance, respectively. Importantly, both the intercept and the error term in equation (2.1) stay the same after transformation.

To obtain $F_{T \times K}^{\perp}$, we employ a methodology attributed to Löwdin (1970) - in the quantum chemistry literature, and to Schweinler and Wigner (1970) - in the wavelet literature. This is a democratic (or egalitarian) procedure as opposed to a sequential approach that is sensitive to the order in which vectors are selected. ${ }^{10}$ This distinctive characteristic is essential for a proper decomposition, as we need to treat all the factors on an equal footing. Thus, the orthogonal transformation of all factors has to be conducted jointly and simultaneously. ${ }^{11}$

As pointed out earlier in the paper, we choose the symmetric form of orthogonalization, which minimizes the overall difference between the original and the orthogonal vectors, thus maximizing the resemblance between the two sets of data. ${ }^{12}$ We apply it to the demeaned

\footnotetext{
${ }^{9}$ The factors are assumed to be linearly independent (i.e. $F_{T \times K}$ is full rank, where $T$ is the number of time periods, and $K$ is the number of factors).

${ }^{10}$ The classical sequential orthogonalization procedure is the Gram-Schmidt process. For a comparison between the two approaches, see for instance Chaturvedi, Kapoor and Srinivasan (1998) and Löwdin (1970).

${ }^{11}$ Compared to orthogonal rotation techniques employed in factor analysis or principal component analysis (e.g. varimax, quartimax or equamax), our procedure has the advantage of guaranteeing a bijective transformation of the original variables (i.e. a one-to-one and onto correspondence between the original and the orthogonalized sets).

${ }^{12}$ For an elaborate explanation, see Srivastava (2000) or Löwdin (1970).
} 
original factors, which ensures that the resulting vectors are not only mathematically orthogonal, but also uncorrelated.

Let $\vec{F}_{T \times K}=\left[\vec{f}_{t}^{k}\right]_{t=1, \ldots, T}^{k=1, \ldots, K}=\left[f_{t}^{k}-\bar{f}^{k}\right]_{t=1, \ldots, T}^{k=1, \ldots, K}$ be the demeaned matrix of $F_{T \times K}$. We define a linear transformation $S_{K \times K}$ of the set $\vec{F}_{T \times K}$ to $\vec{F}_{T \times K}^{\perp}$, as follows:

$$
\vec{F}_{T \times K}^{\perp}=\vec{F}_{T \times K} S_{K \times K}
$$

To obtain $S_{K \times K}$ (and then $\vec{F}_{T \times K}^{\perp}$ ), the first step is to calculate the variance-covariance matrix of the factors sample returns $\left(\Sigma_{K \times K}\right)$, and take $M_{K \times K}=(T-1) \Sigma_{K \times K}$, that is:

$$
M_{K \times K}=\left[\begin{array}{cccc}
\left(\vec{f}^{1}\right)^{\prime}\left(\vec{f}^{1}\right) & \left(\vec{f}^{1}\right)^{\prime}\left(\vec{f}^{2}\right) & \cdots & \left(\vec{f}^{1}\right)^{\prime}\left(\vec{f}^{K}\right) \\
\left(\vec{f}^{2}\right)^{\prime}\left(\vec{f}^{1}\right) & \left(\vec{f}^{2}\right)^{\prime}\left(\vec{f}^{2}\right) & \cdots & \left(\vec{f}^{2}\right)^{\prime}\left(\vec{f}^{K}\right) \\
\vdots & \vdots & \vdots & \vdots \\
\left(\vec{f}^{K}\right)^{\prime}\left(\vec{f}^{1}\right) & \left(\vec{f}^{K}\right)^{\prime}\left(\vec{f}^{2}\right) & \cdots & \left(\vec{f}^{K}\right)^{\prime}\left(\vec{f}^{K}\right)
\end{array}\right] .
$$

The matrix $\vec{F}_{T \times K}^{\perp}$ will be orthonormal if

$$
\left(\vec{F}_{T \times K}^{\perp}\right)^{\prime} \vec{F}_{T \times K}^{\perp}=\left(\vec{F}_{T \times K} S_{K \times K}\right)^{\prime} \vec{F}_{T \times K} S_{K \times K}=S_{K \times K}^{\prime}\left({\overleftrightarrow{F^{\prime}}}_{T \times K}^{\prime} \vec{F}_{T \times K}\right) S_{K \times K}=S_{K \times K}^{\prime} M_{K \times K} S_{K \times K}=I_{K \times K}
$$

or equivalently,

$$
S_{K \times K} S_{K \times K}^{\prime}=M_{K \times K}^{-1}
$$

The general solution of equation (2.7) is $S_{K \times K}=M_{K \times K}^{-1 / 2} C_{K \times K}$, where $C$ is an arbitrary orthogonal matrix. For $C_{K \times K}=I_{K \times K}$, where $I_{K \times K}$ is the identity matrix, the orthogonalization procedure is called symmetric. To be able to calculate $S_{K \times K}$, we identify an orthogonal matrix $O_{K \times K}$ (i.e. 
$O_{K \times K}^{\prime}=O_{K \times K}^{-1}$ ) that brings $M_{K \times K}$ to a diagonal form $D_{K \times K}$ (i.e. $\left.O_{K \times K}^{-1} M_{K \times K} O_{K \times K}=D_{K \times K}\right) .{ }^{13}$ Thus, $M_{K \times K}$ can be factorized as:

$$
M_{K \times K}=O_{K \times K} D_{K \times K} O_{K \times K}^{-1},
$$

where the $k$-th column of $O_{K \times K}$ is the $k$-th eigenvector of the matrix $M_{K \times K}$, and $D_{K \times K}$ is the diagonal matrix whose diagonal elements are the corresponding eigenvalues $(\lambda)$, i.e., $D_{k k}=\lambda_{k}$, where $k$ goes from 1 to $K$. Note that equation (2.7) could also be solved using the Cholesky factorization (often employed, for instance, in the Generalized Least Squares estimation), but the procedure would produce orthogonal factors whose values depend on their sequence (i.e. the algorithm would not be democratic). ${ }^{14}$ Also note that the GLS estimation, different from our procedure, transforms not only the independent variables, but also the dependent variable and the error term.

Solving for $S_{K \times K}$ from equations (7) and (8), we obtain the symmetric matrix:

$$
\begin{gathered}
S_{K \times K}=O_{K \times K} D_{K \times K}^{-1 / 2} O_{K \times K}^{\prime}, \\
\text { where: } D_{K \times K}^{-1 / 2}=\left[\begin{array}{cccc}
1 / \sqrt{\lambda_{1}} & 0 & \cdots & 0 \\
0 & 1 / \sqrt{\lambda_{2}} & \cdots & 0 \\
\vdots & \vdots & \ddots & \vdots \\
0 & 0 & \cdots & 1 / \sqrt{\lambda_{K}}
\end{array}\right] \text {. }
\end{gathered}
$$

Finally, we rescale the factors to the original variance, using the following transformation:

\footnotetext{
${ }^{13}$ If $C_{K \times K}=O_{K \times K}$ instead, the orthogonalization is termed canonical. This form is not appropriate in our case, as it does not maintain the resemblance with the original data.

${ }^{14}$ For example, Dewachter and Lyrio (2006) use the Cholesky factorization to compute the orthogonalized components of four macroeconomic factors aimed to provide a description of the yield curve.
} 


$$
S_{K \times K} \mapsto S_{K \times K} \sqrt{T-1}\left[\begin{array}{cccc}
\sigma_{1} & 0 & \cdots & 0 \\
0 & \sigma_{2} & \cdots & 0 \\
\vdots & \vdots & \ddots & \vdots \\
0 & 0 & \cdots & \sigma_{K}
\end{array}\right]
$$

where $\sigma_{i}$ represents the standard deviation of factor $i$, for $i=1,2, \ldots, K$.

Hence, the matrix $S_{K \times K}$ [as transformed in equation (2.11)], when substituted in equation (2.4), gives the symmetric orthogonal transformation of the demeaned factor-matrix $\vec{F}_{T \times K}$.

To obtain $F_{T \times K}^{\perp}$, we perform the following straight-forward transformation:

$\vec{F}_{T \times K}^{\perp}+\mathbf{1}_{T \times 1} \bar{F}_{1 \times K} S_{K \times K}=\vec{F}_{T \times K} S_{K \times K}+\mathbf{1}_{T \times 1} \bar{F}_{1 \times K} S_{K \times K}=\left(\vec{F}_{T \times K}+\mathbf{1}_{T \times 1} \bar{F}_{1 \times K}\right) S_{K \times K}=F_{T \times K} S_{K \times K}=F_{T \times K}^{\perp}$,

where $\mathbf{1}_{T \times 1}$ is a vector of ones and $\bar{F}_{1 \times K}$ is the mean of $F_{T \times K}$.

Hence, the matrix $F_{T \times K}^{\perp}$ is a conversion of matrix $\vec{F}_{T \times K}^{\perp}$, not an orthogonalized matrix per se. However, considering that adding constant terms to orthogonal vectors results in uncorrelated vectors, we can refer to $F_{T \times K}^{\perp}$, for simplicity, as the orthogonalized matrix of $F_{T \times K}$.

To be able to understand what matrix $S_{K \times K}$ (or its inverse) represents, we can write each factor $f^{k}$, where $k=1,2, \ldots, K$, as:

$$
f^{k}=\psi_{1 k} f^{1^{\perp}}+\psi_{2 k} f^{2^{\perp}}+\cdots+\psi_{K k} f^{K^{\perp}},
$$

where the coefficients $\psi_{l k}$ are obtained through the orthogonalization procedure described above (i.e. they are the elements of the inverse of matrix $S_{K \times K}$, in its final form).

If we calculate the covariance between $f^{k}$ and $f^{k^{\perp}}$, we obtain that

$$
\operatorname{cov}\left(f^{k}, f^{k^{\perp}}\right)=\psi_{k k} \times \operatorname{var}\left(f^{k^{\perp}}\right) \Rightarrow \psi_{k k}=\frac{\operatorname{cov}\left(f^{k}, f^{k^{\perp}}\right)}{\operatorname{var}\left(f^{k^{\perp}}\right)}=\frac{\operatorname{cov}\left(f^{k}, f^{k^{\perp}}\right)}{\sigma_{k} \sigma_{k}^{\perp}}=\operatorname{corr}\left(f^{k}, f^{k^{\perp}}\right)
$$


Moreover, it can be shown (see the Appendix) that for any $k$ and $l, \psi_{k l}=\operatorname{corr}\left(f^{k}, f^{l^{\perp}}\right)$. Thus, the inverse of matrix $S_{K \times K}$ is the correlation matrix between the original and the orthogonal factors. So, if we consider $S_{K \times K}=\psi_{K \times K}^{-1}$, where $\psi_{K \times K}=\left[\operatorname{Corr}\left(f^{k}, f^{l^{\perp}}\right)\right]_{\substack{k=1, \ldots, K \\ l=1, \ldots, K}}$, the last equality in equation (2.12) can be rewritten as:

$$
F_{T \times K}^{\perp}=F_{T \times K} \psi_{K \times K}^{-1}
$$

That is, the orthogonal factors are linear combinations of the original factors, with the coefficients taken from the inverse correlation matrix, between the original and the uncorrelated factors. Each orthogonal factor deviates from its original counterpart in such a way that the common variation is partitioned symmetrically and $F_{T \times K}^{\perp}$ optimally resembles $F_{T \times K}$.

To demonstrate the consistency between the decomposable systematic risk estimate, $\sum_{k=1}^{K}\left(\hat{\beta}_{k_{j}}^{\perp} \hat{\sigma}_{f^{k}}^{\perp}\right)^{2}$, and the systematic risk estimate from regression, $\hat{\sigma}_{s r_{j}}^{2}=\hat{\sigma}_{j}^{2}-\hat{\sigma}_{\varepsilon_{j}}^{2}$ as shown in equation (2.3), we note that the orthogonal transformation retains the original sum of squared errors $(S S E)$ of equation (2.1) [i.e. $\min \left\{\varepsilon^{\prime} \varepsilon\right\}$ ]. Mathematically, the space generated by $F^{\perp}$ is the same, by definition, as the one generated by $F .{ }^{15}$ This implies that $\left\{F \tilde{\beta} \mid \tilde{\beta} \in \mathfrak{R}^{5}\right\}=\left\{F^{\perp} \tilde{\beta}^{\perp} \mid \tilde{\beta}^{\perp} \in \mathfrak{R}^{5}\right\}$, meaning that all linear combinations of $F$ span the same space as all linear combinations of $F^{\perp}$. Therefore, the range of the function of $F$ [defined as $\left.(r-F \tilde{\beta})^{\prime}(r-F \tilde{\beta})\right]$ is identical to that of the function of $F^{\perp}$ [defined as $\left(r-F^{\perp} \tilde{\beta}^{\perp}\right)^{\prime}\left(r-F^{\perp} \tilde{\beta}^{\perp}\right)$ ]. Since the lower boundary of the two ranges is the same, $\min \left\{\varepsilon^{\prime} \varepsilon\right\}$ for $F$ is identical to that for $F^{\perp}$.

\footnotetext{
${ }^{15}$ Moreover, by adding a column vector of ones to $F$ and to $F^{\perp}$ (to account for intercepts), the two resulting spaces will still be identical.
} 


\subsection{B. Monte Carlo Simulations}

Since the orthogonal transformation is a numerical data process, an examination of the sampling errors for the robustness of our estimation is important. Table 2.II reports the mean squared errors (MSE) for a set of Monte Carlo simulations. We generate data for a five-factor linear model that has the following structure:

$$
r=0.02+1.2 f_{1}+0.1 f_{2}+0.3 f_{3}-0.2 f_{4}+0.7 f_{5}+e,
$$

where $f_{k}, k=1,2, \ldots .5$, follow two hypothetical forms of distribution, multivariate-normal and multivariate-lognormal, respectively. The loadings in equation (2.16) are arbitrarily chosen so that they make sense economically. Different values will not cause significant changes in the robustness of our estimators. A non-zero covariance matrix of $f_{k}$ is predetermined. In addition, the zero-mean residuals, $e$, follow by turns, one of the two processes: homoscedastic [white noise] and heteroscedastic [GARCH(1,1)].

Table 2.II

\section{The Mean Squared Errors (MSE) of the Decomposable Systematic Risk Estimates}

This table presents the Monte Carlo simulation results (10,000 trials) for the MSE of our decomposed systematic risk estimates. We generate data for a five-factor linear model that has the following structure: $r=0.02+1.2 f_{1}+0.1 f_{2}+0.3 f_{3}-0.2 f_{4}+0.7 f_{5}+e$, where $f_{k}, k=1,2, \ldots, 5$, follow two hypothetical forms of distribution, multivariate-normal and multivariate-lognormal, respectively. The correlation coefficients of the original data range from approximately -0.4 to 0.7 . The residuals, $e$, follow by turns, one of the two processes: homoscedastic [white noise $\sim \mathrm{N}(0,0.21)$ ] and heteroscedastic [GARCH$(1,1)$, with coefficients $0.001,0.5,0.3$ ].

\begin{tabular}{cccccc}
\hline \multicolumn{5}{c}{$M S E=E\left(\sum_{k=1}^{5}\left(\hat{\beta}_{k_{j}}^{\perp} \hat{\sigma}_{f^{k}}^{\perp}\right)^{2}-\sigma_{s r}^{2}\right)^{2}$} \\
\cline { 1 - 2 } Sample & \multicolumn{2}{c}{ Normal $f_{k}, k=1,2, \ldots, 5$} & & \multicolumn{2}{c}{ Log-Normal $f_{k}, k=1,2, \ldots, 5$} \\
\cline { 2 - 3 } \cline { 5 - 6 } \cline { 5 - 6 } & Homoscedastic $(e)$ & Heteroscedastic $(e)$ & & Homoscedastic $(e)$ & Heteroscedastic $(e)$ \\
\hline 50 & 0.02373 & 0.02198 & & 0.00119 & 0.00013 \\
150 & 0.00817 & 0.00720 & & 0.00038 & 0.00004 \\
300 & 0.00404 & 0.00354 & & 0.00019 & 0.00002 \\
500 & 0.00232 & 0.00217 & & 0.00011 & 0.00001 \\
1000 & 0.00121 & 0.00110 & & 0.00006 & 0.00001 \\
\hline
\end{tabular}


We calculate the MSE of decomposable systematic risk estimates for ten thousand trials. The random samples have, by turns, five different sizes: 50, 150, 300, 500, and 1,000. Table 2.II shows that the MSE consistently and roughly proportionally decreases as the sample size increases. Specifically, the MSE drops by more than 80 percent when the sample size is increased from 50 to 300 , and by more than 90 percent when increased from 50 to 500 . The results suggest that our estimate in equation (2.3) is robust, especially for sample sizes over 50.

In addition, we examine the robustness of individual decomposed systematic risk measures with respect to a set of five correlated factors in a hypothetical population with a finite number (twenty-five thousand) of outcomes. The uncorrelated components of the factors in the population are determined numerically by the orthogonal transformation. The population decomposed systematic risk for each factor $k,\left(\beta_{k}^{\perp} \sigma_{f_{k}}^{\perp}\right)^{2}$, is then calculated. Again, we generate tenthousand random samples for each sample size (50, 150, 300, 500, and 1000 observations).

Table 2.III presents the $M S E$ of individual decomposed measures.

Table 2.III

Sampling Errors of Individual Decomposed Systematic Risk Estimates

This table presents the Monte Carlo simulation results (10,000 trials) for the MSE of the individual decomposed systematic risk estimates. We define a population with a finite number of observations $(25,000)$, such that the generated data corresponds to the following five-factor linear model: $r=0.02+1.2 f_{1}+0.1 f_{2}+0.3 f_{3}-0.2 f_{4}+0.7 f_{5}+e$, where $f_{k}, k=1,2, \ldots, 5$, follow a multivariate-normal distribution. The correlation coefficients of the original data range from approximately -0.4 to 0.7 . The distribution of the residuals $(e)$ is normal, with a mean of zero and a standard deviation of 0.21 .

\begin{tabular}{cccccc}
\hline \multicolumn{7}{c}{$M S E=E\left[\left(\hat{\beta}_{k}^{\perp} \hat{\sigma}_{f_{k}}^{\perp}\right)^{2}-\left(\beta_{k}^{\perp} \sigma_{f_{k}}^{\perp}\right)^{2}\right]^{2}$, for $k=1,2, \ldots, 5$} \\
\hline $\begin{array}{c}\text { Sample } \\
\text { Size }\end{array}$ & $f_{1}$ & $f_{2}$ & $f_{3}$ & $f_{4}$ & $f_{5}$ \\
\hline 50 & 0.01268 & 0.00035 & 0.00070 & 0.00090 & 0.00134 \\
150 & 0.00398 & 0.00011 & 0.00022 & 0.00031 & 0.00043 \\
300 & 0.00202 & 0.00005 & 0.00011 & 0.00015 & 0.00021 \\
500 & 0.00123 & 0.00003 & 0.00006 & 0.00009 & 0.00012 \\
1,000 & 0.00058 & 0.00001 & 0.00003 & 0.00005 & 0.00006 \\
\hline
\end{tabular}


Similar to Table 2.II, the MSE decreases, roughly proportionally, as the sample size increases. It drops by approximately two-thirds when the sample size increases from 50 to 150 observations.

\subsection{C. $R$-square Decomposition}

We derive an important extension of equation (2.3), dividing it by the estimated variance of asset $j$ 's returns $\left(\hat{\sigma}_{j}^{2}\right)$. We are then able to decompose the estimate of $R$-square, i.e. the coefficient of determination, as follows:

$$
R_{j}^{2}=\sum_{k=1}^{K} D R_{j, k}^{2} \text {, where } D R_{j, k}^{2}=\left(\hat{\beta}_{k_{j}}^{\perp} \frac{\hat{\sigma}_{f^{k}}}{\hat{\sigma}_{j}}\right)^{2} \text {. }
$$

Note that since the idiosyncratic risk can be measured as $\left(1-R^{2}\right)$, the sum of the individual decomposed systematic risk measures and the idiosyncratic risk equals one. Moreover, from a statistical viewpoint, the decomposition of $R$-square characterizes the segments of goodness-offit. Parts of the total $R$-square can now be allocated unequivocally to each orthogonalized factor, indicating their relative contribution to the variation in the dependent variable (in our case, the return on the risky asset $j$ ).

\subsection{Empirical Illustration}

We apply the orthogonal transformation procedure described in Section II, to monthly returns on five well known equity pricing factors found in Kenneth R. French's Data Library: $R M, S M B$, HML, Mom and Rev. Historical observations suggest that market equity, book-to-market ratio, past short- or long-term returns may be proxies for exposures to various sources of systematic risk, not captured by the CAPM beta, and hence generating return premiums. Risk-based explanations for the return premiums to these factors might consider, for instance, that the 
returns on the $H M L$ and $S M B$ portfolios seem to predict GDP growth, and thus they may be proxies for business cycle risk. ${ }^{16}$

Once the transformation is performed, the decomposed systematic risk and decomposed $R$-square are calculated and analyzed for style and industry portfolios, obtained from the same data library. Table 2.IV reports the distribution moments and the correlation matrix of factors' monthly returns over a sample period from January 1931 to December 2008 for both the original and the orthogonally-transformed data.

\section{Table 2.IV}

\section{Distribution Properties of Factors' Sample Returns: Original vs. Orthogonal}

This table reports the distribution parameters (Panel A) and correlation coefficients (Panel B) for the monthly returns on five stock-market factor portfolios: $R M, S M B, H M L, M o m$ and $R e v$, both non-orthogonalized and orthogonalized. $R M, S M B$ and $H M L$ are the Fama/French factors: $R M$ is the market risk premium; SMB is Small Minus Big, while $H M L$ is High Minus Low. Mom is the momentum factor, while Rev is the long-term reversal factor. All five factors follow the description and are obtained from Kenneth French's data library at http://mba.tuck.dartmouth.edu /pages/faculty/ken.french/. The sample period is January 1931 to December 2008. The orthogonalized measures, denoted by the symbol " ${ }^{\perp}$ ", are obtained using the Schweinler-Wigner/ Löwdin (1970) procedure.

Panel A: Distribution Parameters

\begin{tabular}{|c|c|c|c|c|c|c|c|c|c|c|}
\hline & \multicolumn{5}{|c|}{ Original Returns } & \multicolumn{5}{|c|}{ Orthogonal Returns } \\
\hline & $R M$ & $S M B$ & $H M L$ & Mom & Rev & $R M^{\perp}$ & $S M B^{\perp}$ & $H M L^{\perp}$ & $\mathrm{Mom}^{\perp}$ & $R e v^{\perp}$ \\
\hline Mean & 0.61 & 0.29 & 0.44 & 0.70 & 0.35 & 0.67 & 0.23 & 0.55 & 0.99 & 0.17 \\
\hline Std. Dev. & 5.40 & 3.36 & 3.61 & 4.71 & 3.54 & 5.40 & 3.36 & 3.61 & 4.71 & 3.54 \\
\hline Skewness & 0.30 & 2.29 & 1.91 & -3.04 & 2.95 & -0.24 & 1.44 & 0.63 & -2.04 & 1.97 \\
\hline Kurtosis & 8.34 & 22.99 & 16.11 & 28.33 & 24.22 & 4.82 & 14.89 & 5.54 & 15.45 & 17.40 \\
\hline
\end{tabular}

Panel B: Correlation Coefficients

\begin{tabular}{|c|c|c|c|c|c|c|c|c|c|c|c|}
\hline \multicolumn{7}{|c|}{ Original Returns } & \multicolumn{5}{|c|}{ Orthogonal Returns } \\
\hline Factor & $R M$ & $S M B$ & $H M L$ & Mom & Rev & Factor & $R M^{\perp}$ & $S M B^{\perp}$ & $H M L^{\perp}$ & $\mathrm{Mom}^{\perp}$ & $R e v^{\perp}$ \\
\hline$R M$ & 1 & 0.33 & 0.23 & -0.34 & 0.24 & $R M^{\perp}$ & 1 & 0.00 & 0.00 & 0.00 & 0.00 \\
\hline$S M B$ & & 1 & 0.10 & -0.15 & 0.41 & $S M B^{\perp}$ & & 1 & 0.00 & 0.00 & 0.00 \\
\hline$H M L$ & & & 1 & -0.40 & 0.61 & $H M L^{\perp}$ & & & 1 & 0.00 & 0.00 \\
\hline Mom & & & & 1 & -0.24 & Mom $^{\perp}$ & & & & 1 & 0.00 \\
\hline $\operatorname{Rev}$ & & & & & 1 & $\operatorname{Rev}^{\perp}$ & & & & & 1 \\
\hline
\end{tabular}

\footnotetext{
${ }^{16}$ See, for instance, Liew and Vassalou (2000).
} 
As expected (see Panel A), sample variances are identical before and after the orthogonal transformation. Although the other distributional moments are different between nonorthogonalized and orthogonalized data, that does not affect the effectiveness of our decomposed systematic risk measures. Importantly, after transformation, the risk premiums for all factors will change. In our case, the mean returns of $R M, H M L$ and Mom increased, while for $S M B$ and Rev, they decreased. Note in Panel B of Table 2.IV that the original $R M, S M B, H M L, M o m$, and $\operatorname{Rev}$ are more or less correlated to each other, while after the orthogonal transformation they become uncorrelated.

Importantly, the orthogonal factors maintain a high resemblance to their original counterparts: the correlation coefficients between the original and the orthogonally-transformed returns are very high (i.e. $0.97,0.96,0.92,0.97$ and 0.91 , respectively).

Next, using the orthogonally-transformed data, we estimate the "orthogonal" beta coefficients, from the five-factor regression model for eight style portfolios, characterized by size, value/growth, momentum, and contrarian, respectively. Table $2 . \mathrm{V}$ presents the results for the equal-weighted portfolios. Apparently, the absolute values of the "orthogonal" betas $\left(\hat{\beta}^{\perp}\right)$ are generally higher than those of the "non-orthogonal" betas $(\hat{\beta}) .{ }^{17}$ For instance, the nonorthogonal contrarian beta $\left(\hat{\beta}_{\mathrm{Rev}}\right)$ of the small-cap and contrarian-sensitive portfolio (Small/Low $R e v)$ is 0.42 , but its orthogonal beta $\hat{\beta}_{\operatorname{Rev}}^{\perp}$ equals 0.95 . Since the volatility estimates, $\hat{\sigma}$, are identical with or without orthogonalization, lower $\hat{\beta}$ (as compared to $\hat{\beta}^{\perp}$ ) indicates that the systematic risk is underestimated, if the dependence between factors is ignored.

\footnotetext{
${ }^{17}$ Again, the "orthogonal" betas are the coefficients obtained from the regression on the orthogonally-transformed factors, or simply by multiplying the correlation matrix $(\Psi)$ by the original beta estimates. So, they are not orthogonal per se, but for ease of understanding, we prefer to term them accordingly.
} 


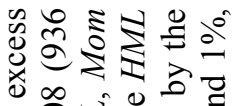
年

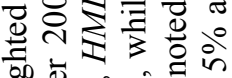
क्ष

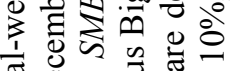

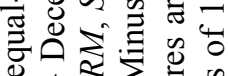

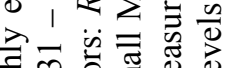

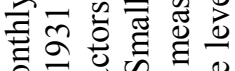
每

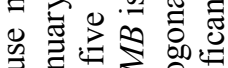

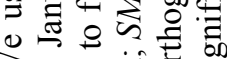

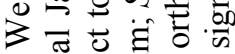

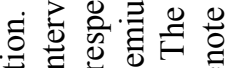

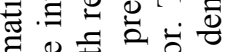

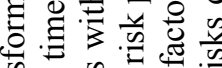

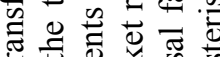
政

可部

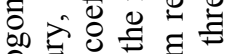
전 ๘ $\cong$

穴 就

政

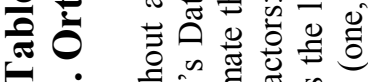

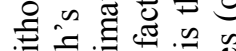

政

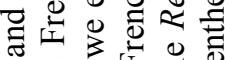

들

政

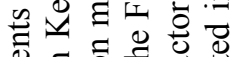

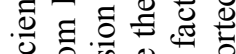

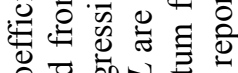

马을

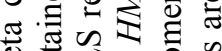

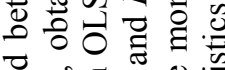

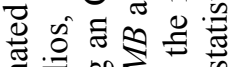

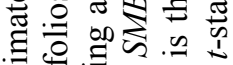

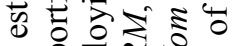

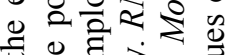

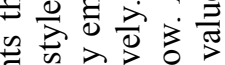

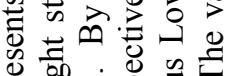

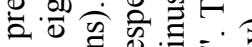

응

婙

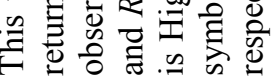

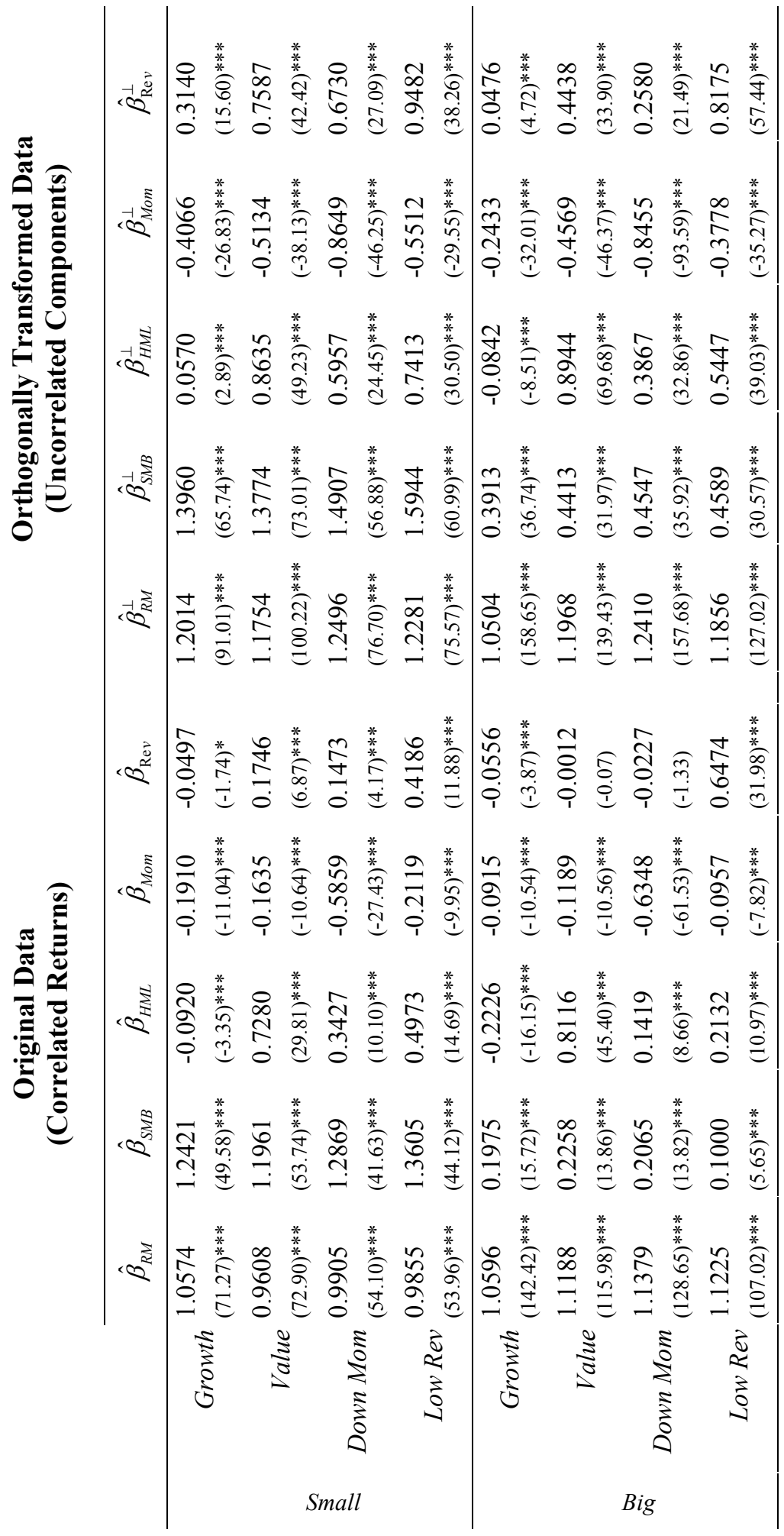


The results presented in Tables IV and V highlight the importance of the orthogonal transformation in determining the proper risk premiums and beta coefficients, and suggest that multi-factor market models should be used cautiously. Paired $t$-tests indicate that, for the entire period (January 1931 to December 2008), the differences between the risk premiums on the orthogonal and the original factors were statistically significant for Mom and Rev (at 1 percent level), $H M L$ (at 5 percent level), $S M B$ (at 10 percent level), and barely significant for $R M$.

We note that although the orthogonal beta $\left(\hat{\beta}^{\perp}\right)$ assesses the sensitivity of an asset's return to the variation in the underlying component of a factor's premium, it alone can not be used as a decomposed risk measurement. The appropriate approach is to take the product of $\hat{\beta}^{\perp}$ square and the factor's volatility $\left(\right.$ i.e. $\left.\hat{\beta}_{f_{j}}^{\perp^{2}} \hat{\sigma}_{f}^{2}\right)$. Table 2 .VI shows the empirical results of systematic risk decomposition. Again, our methodology is applied to the eight style portfolios characterized by size, value/growth, momentum, and contrarian, respectively. We calculate the risk estimates for both the equal-weighted (Panel A) and value-weighted portfolios (panel B). We use an Ordinary Least Squares (OLS) regression model and we calculate the systematic variation $\left(\hat{\sigma}_{s r_{j}}^{2}\right)$, taking the difference between the variance of a portfolio's returns $\left(\hat{\sigma}_{j}^{2}\right)$ and its residual variance $\left(\hat{\sigma}_{\varepsilon_{j}}^{2}\right)$ from the regression. It is clear, from both Panel $\mathrm{A}$ and Panel $\mathrm{B}$, that the sum of decomposed systematic risk measures after the orthogonal transformation is exactly equal to the overall systematic variation $\left(\hat{\sigma}_{s r_{j}}^{2}\right)$. This evidence shows the decomposability of risk measurement through orthogonalization.

Again, due to the correlations between the original factors, as reported in Table 2.IV, the sum of the non-orthogonal measures, $\hat{\beta}_{f_{j}}^{2} \hat{\sigma}_{f}^{2}$, is clearly different from $\hat{\sigma}_{s r_{j}}^{2}$ (and generally much smaller). 

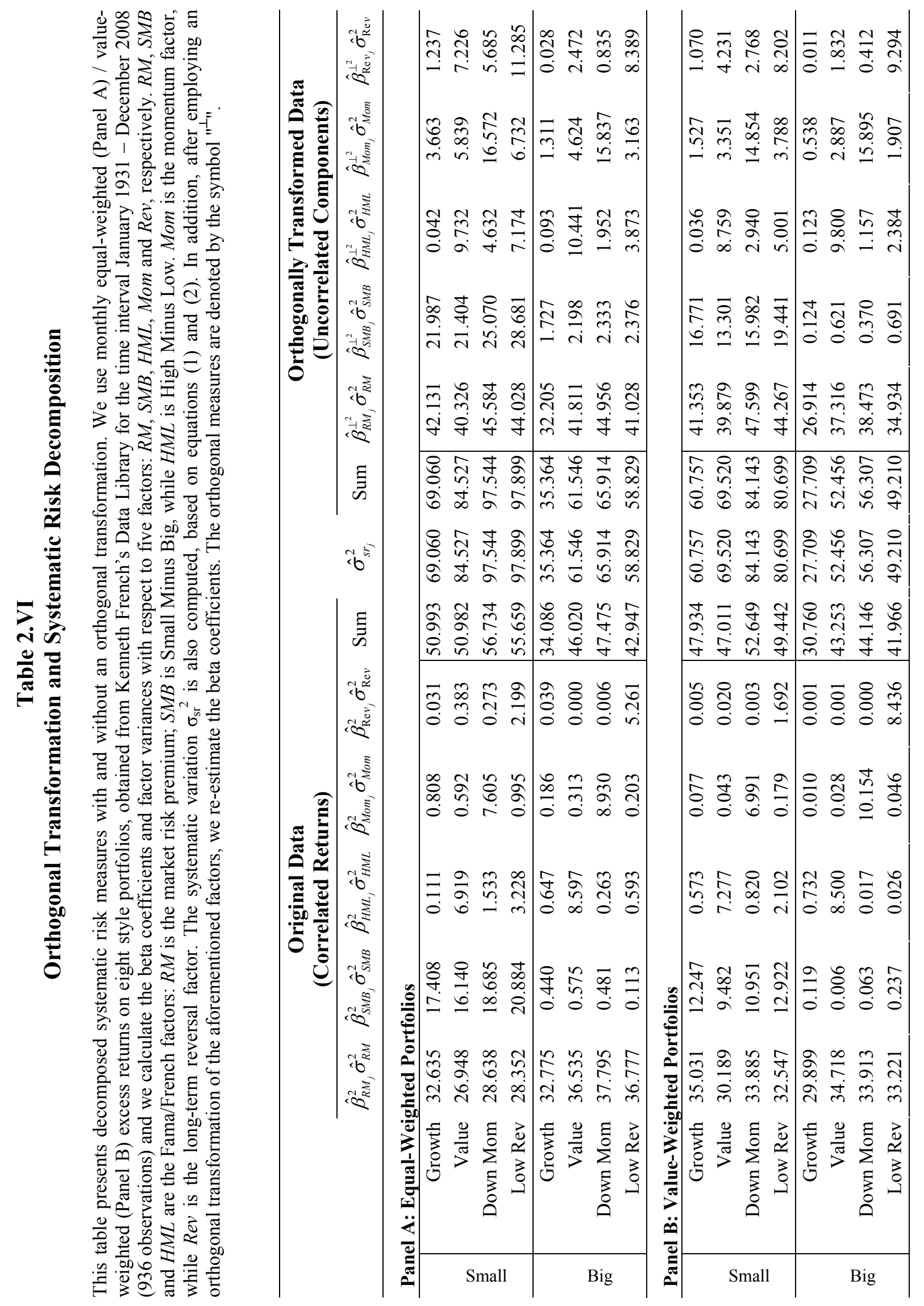
To examine the magnitude of individual decomposed risk measures in relation to the systematic and idiosyncratic risk, we further compute the decomposed $R$-squares, simply dividing $\hat{\beta}_{f_{j}}^{\perp^{2}} \hat{\sigma}_{f}^{2}$ by $\hat{\sigma}_{j}^{2}$. The sum of the decomposed $R$-squares stands for the overall systematic risk, and one minus the $R$-square becomes an assessment of the idiosyncratic risk. In addition, the decomposition of $R$-squares can be used to discriminate against unimportant factors in model specification. Table 2.VII presents the risk decomposition for eighteen style portfolios (both equal-weighted and value-weighted): the six portfolios formed on Size and Book-to-Market, the six portfolios formed on Size and Momentum, and the six portfolios formed on Size and Long-Term Reversal. The percentages of risk contributed systematically from Market (RM), Size (SMB), Value (HML), Momentum (Mom), and Contrarian (Rev) for the equal-weighted (value-weighted) small-cap portfolios are, on average, $53 \%(63 \%), 25 \%(21 \%), 5 \%(5 \%), 6 \%(5 \%)$ and $5 \%(4 \%)$, respectively. This indicates that the systematic return-variation of the small-cap funds is, in a proportion of approximately 80 percent, caused by two sources: the overall market risk and the volatility of the size factor. The idiosyncratic risk of the value-weighted small-cap funds (around 2 percent) seems to be lower than that of the equal-weighted funds (approximately 5 percent).

For large-cap portfolios, on the other hand, roughly 80 percent of volatility comes from the market factor alone, while the size factor is relatively unimportant. Specifically, the decomposed $R$-squares of size are, on average, only 4 percent for the equal-weighted portfolios and under 1 percent for the value-weighted funds. The unsystematic risk is about 3 to 4 percent.

In summary, from the point of view of modeling specification, the conventional single index market model is valid for large-cap stocks, but one needs to consider the size factor for small-cap stocks. 


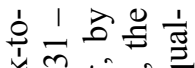

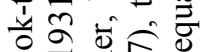

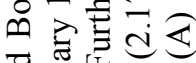

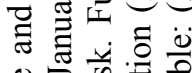

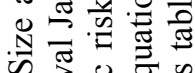

की

б. 氜

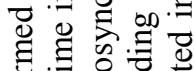

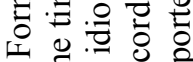

红

웅 范

氖 氜

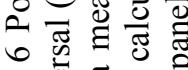

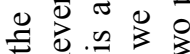

$\therefore$

का है

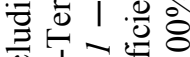

告

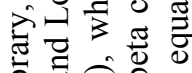

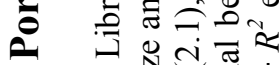

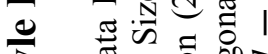

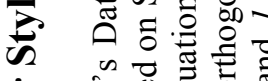

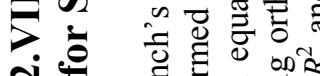

Є

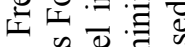

घ윰 तै

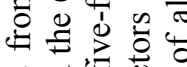

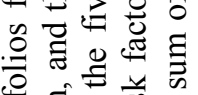

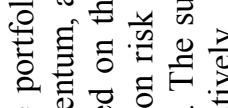

๑可 它

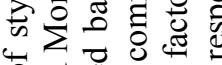

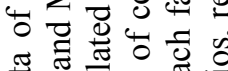

퓨 ส

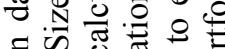

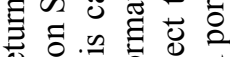

O 00

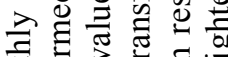

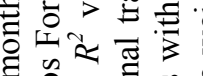

记。

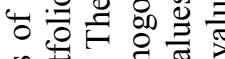

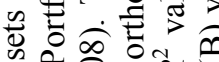

ช 6 웡

吾

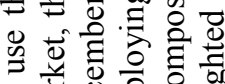
३

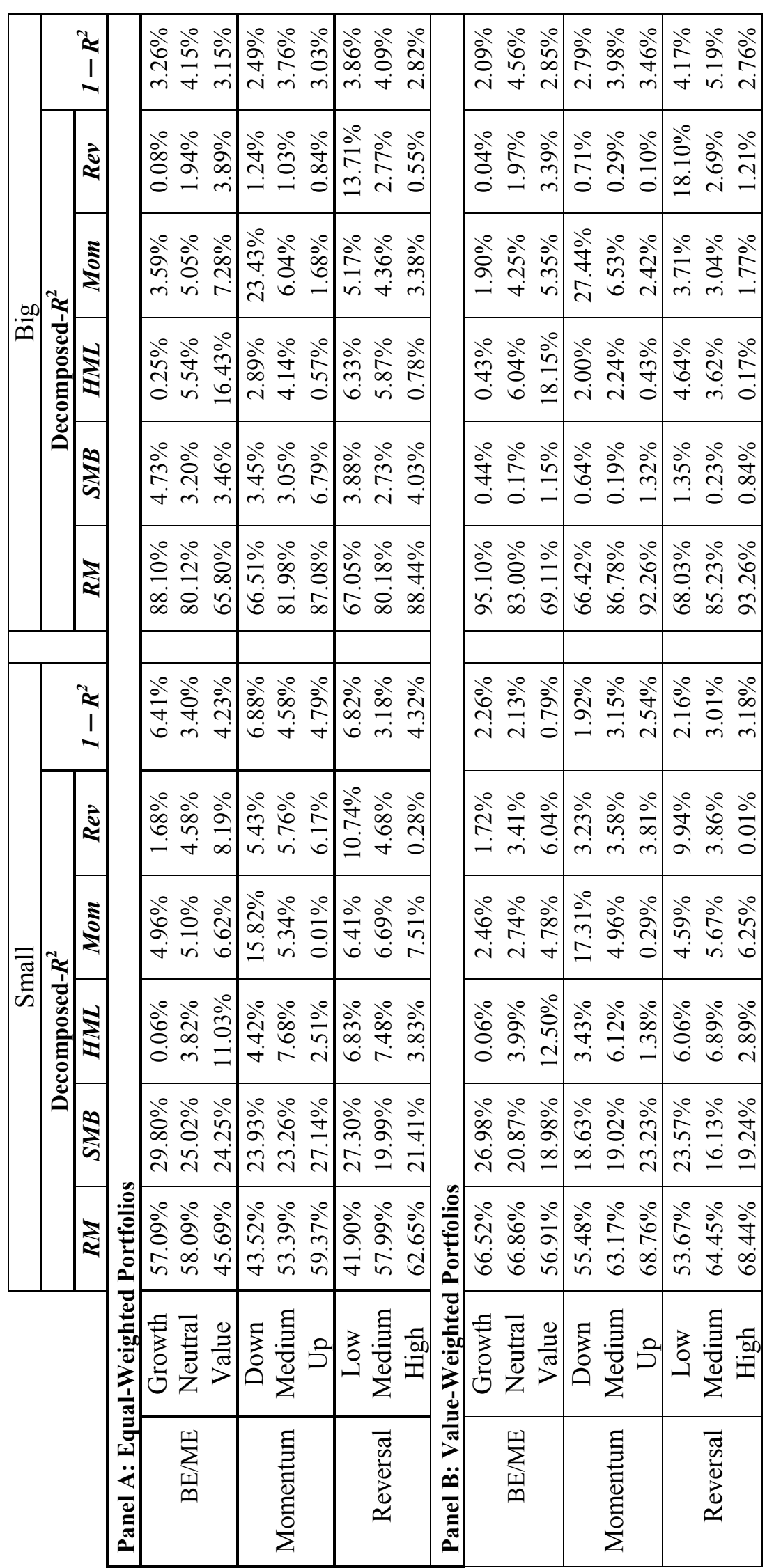


Furthermore, although the value, momentum and contrarian factors seem to be unimportant for average portfolios of both large-cap and small-cap stocks, they do have some impact on the volatility of the style funds that carry their names. For instance, $16.43(18.15)$ percent of the equal-weighted (value-weighted) large-cap/value fund's volatility comes from the value-factor $(H M L)$. The equal-weighted (value-weighted) large-cap/down-momentum fund has 23.43 (27.44) percent of the $R$-square contributed by the momentum factor (Mom). The decomposed $R$-squares of low-reversal portfolios with respect to the Rev factor range from $9.94 \%$ to $18.10 \%$. This indicates that the factor-specification in market models is heterogeneous and varies by different styles of portfolio formation.

When comparing Tables V and VII, it is even more interesting that higher original betas (in absolute value) of one factor versus another factor do not necessarily imply a relatively higher importance of the former. For example, the four small-cap portfolios in Table 2.V have higher betas of $S M B$ compared to $R M$, still their corresponding decomposed- $\mathrm{R}^{2}$ values are lower.

Next, our risk decomposition procedure is applied to monthly returns on 30-industry portfolios. As shown in Table 2.VIII, the unsystematic variation of industry funds is much larger than that of style portfolios. It ranges from 7.76\% (Fabricated Products and Machinery) to 56.23\% (Tobacco Products) for the equal-weighted portfolios and from 13.69\% (Banking, Insurance, Real Estate, Trading) to $71.97 \%$ (Coal) for the value-weighted portfolios. The equalweighted funds have larger $D R_{S M B}^{2}$ than the value-weighted portfolios. This confirms again that the size factor is critical for pricing small-cap stocks. In addition, the value-factor has some weak influences on return variation of equal-weighted industry portfolios. For example, the decomposed $R$-square for the value-factor for Transportation, Utilities, Finance, and Coal are $12.12 \%, 9.00 \%, 8.68 \%$, and $8.51 \%$, respectively. 


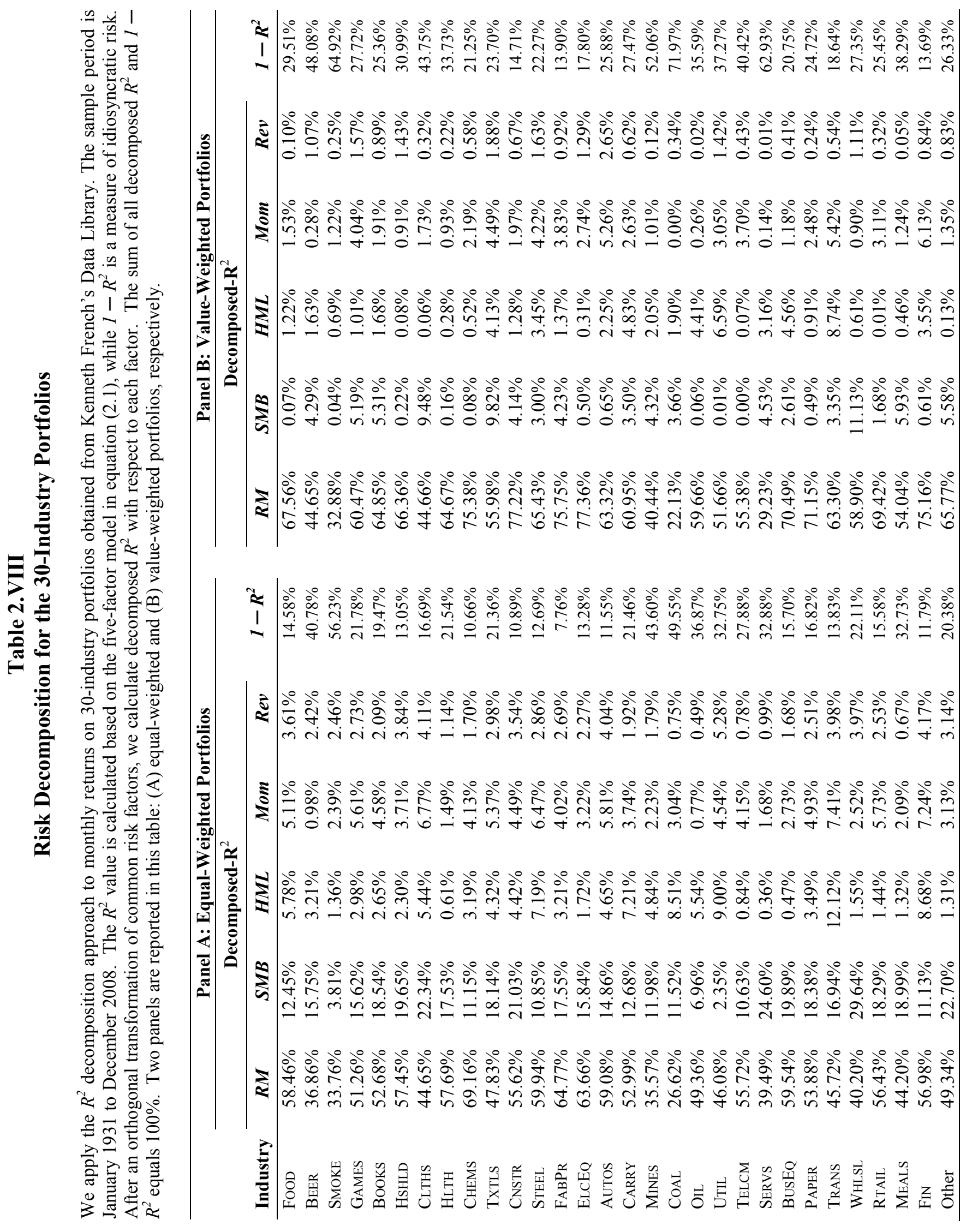


It appears that the impact of the momentum and contrarian factors on the industry portfolios is small and relatively insignificant. Nevertheless, the high unsystematic risk $\left(1-R^{2}\right)$ suggests that other factors, specific to particular industries, may be influential.

From the overall sample analysis for the period ranging from January 1931 to December 2008, more than 85 percent, on average, of style portfolios' return variation is attributed to the $D R^{2}$ of $R M, S M B$ and $H M L$. This indicates that the Fama-French Three-Factor Model quantifies fairly well the risk-return structure of well-diversified equity portfolios. However, it is well known that the volatility of stock portfolios changes over time. ${ }^{18}$ An examination of the time variation of equity risk decomposition is important. Monthly $R$-squares and decomposed $R$ squares are computed based on overlapping regression estimation for every 60-month ( $t-59$ to $t)$ window, over a period ranging from January 1936 to December 2008. We illustrate, in Figure 2.1, the dynamic risk-decomposition for the value-weighted Small/Value and Big/Value style portfolios. In this case, for ease of comparability, they are selected from the Fama and French 25 portfolios formed on size and book-to-market. Again, the volatility is decomposed linearly into six components: market $\left(D R_{R M}^{2}\right)$, size $\left(D R_{S M B}^{2}\right)$, value $\left(D R_{H M L}^{2}\right)$, momentum $\left(D R_{\text {Mom }}^{2}\right)$, contrarian $\left(D R_{\mathrm{Rev}}^{2}\right.$ ), and idiosyncratic risk $\left(1-R^{2}\right)$. In general, the largest component of return variation is captured by the market factor. $R M$ maintains a similar importance when going from Small to Big ( $D R_{R M}^{2}$ for Small and for Big have a high correlation of 77 percent). Conversely, SMB is highly significant for Small and insignificant for Big, while $H M L$ is moderately more significant for Big. These results are in line with Fama and French (1993).

\footnotetext{
${ }^{18}$ For a good analysis of the dynamic nature of stock market volatility and idiosyncratic risk, see Campbell et al. (2001).
} 


\section{Figure 2.1: Decomposed Risk over Time}

Panel A: Decomposed R-square for the Small / Value Portfolio

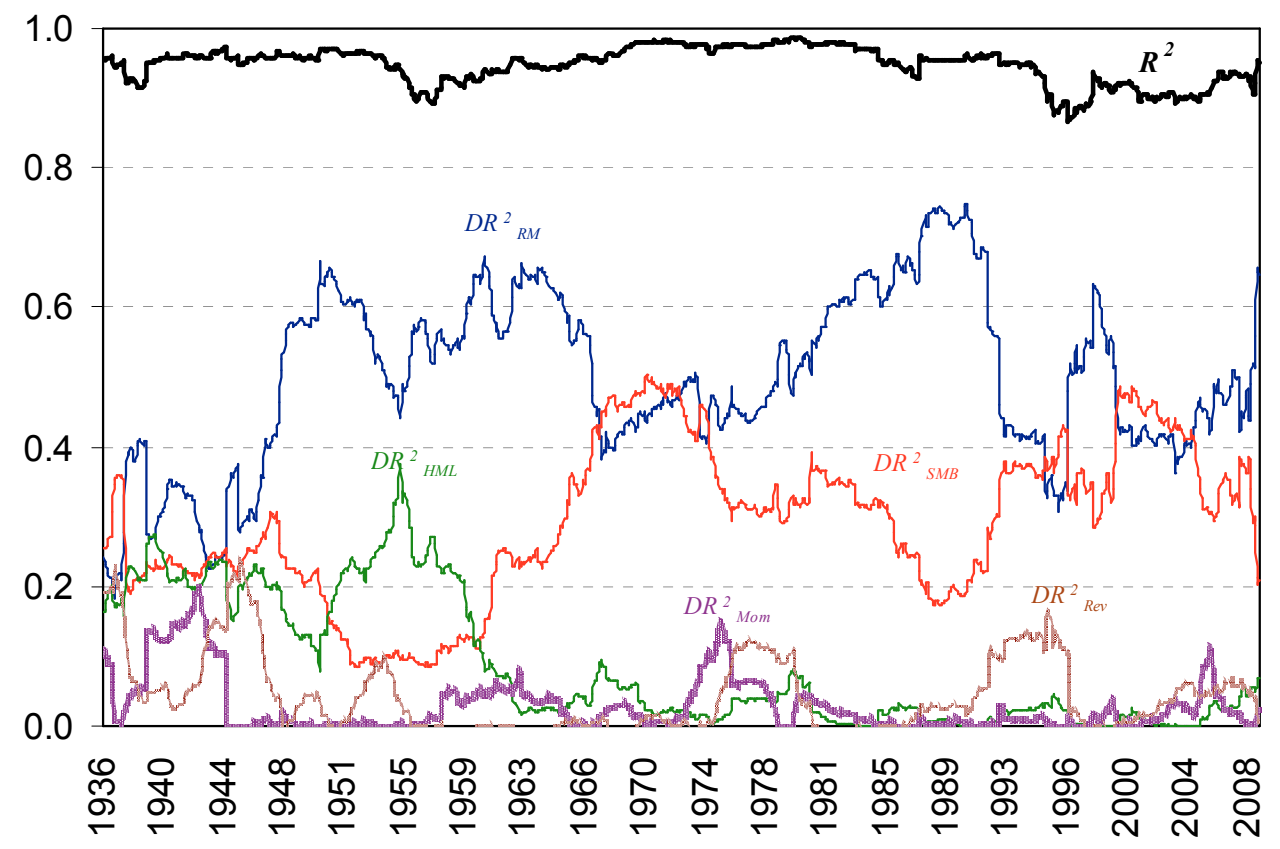

Panel B: Decomposed R-square for the Big / Value Portfolio

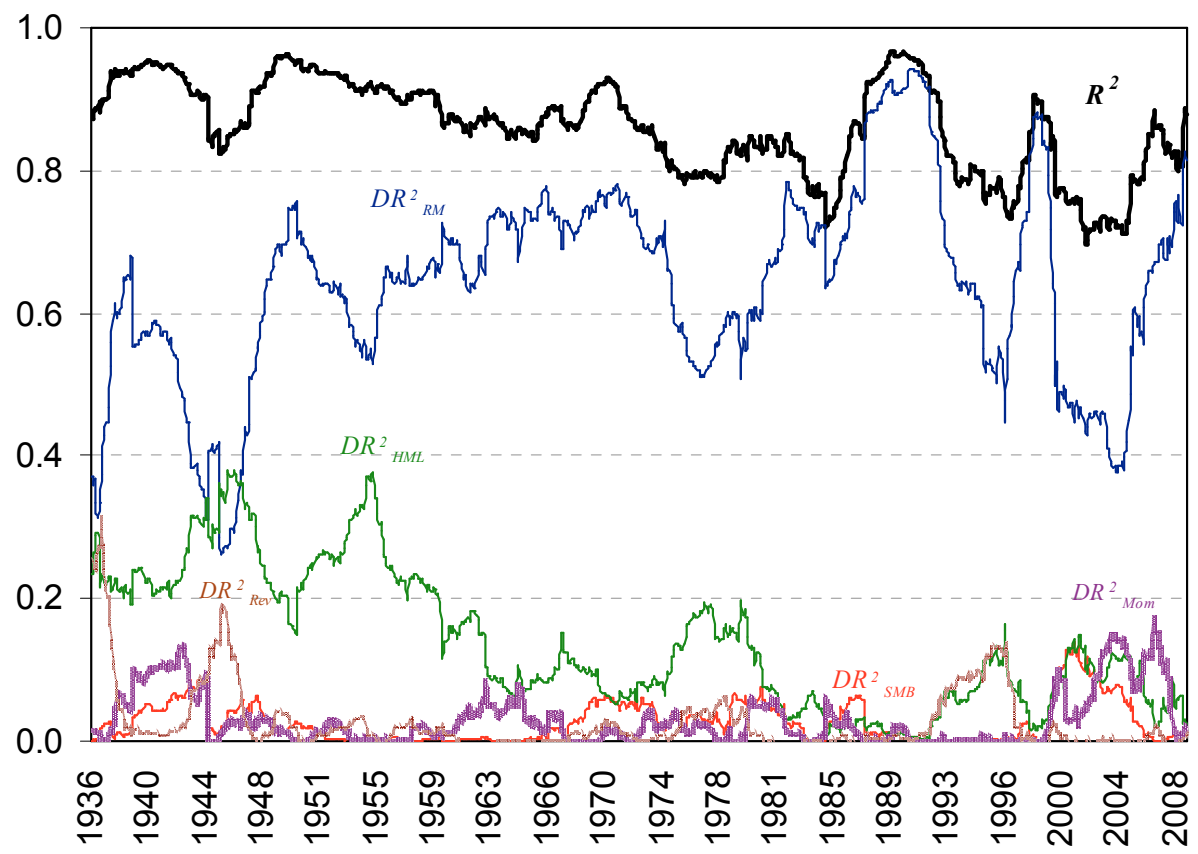

The figure graphs the monthly variation in equity risk decomposition, from January 1936 to December 2008 . The $R^{2}$ and the decomposed- $R^{2}$ (denoted by $D R^{2}$ ) are calculated based on overlapping regression estimation for every 60month ( $t$-59 to $t$ ) window. Specifically, we present our empirical results on $R^{2}$ and $D R^{2}$ for two of the 25 valueweighted portfolios formed on Size and Book-to-Market (i.e. Small/ Value and Big/ Value), obtained from Kenneth French's data library at http://mba.tuck.dartmouth.edu/pages/faculty/ken.french/. 
Additionally, as expected, the idiosyncratic component is consistently higher for Big. In the two cases, both $D R_{M o m}^{2}$ and $D R_{\mathrm{Rev}}^{2}$ have a low contribution: with a few exceptions they fall below 20 percent. From Figure 2.1, it appears that the decomposed components of risk not only are dynamic over time, but they may also exhibit significant correlations. ${ }^{19}$ For example, $D R_{\mathrm{Rev}}^{2}$ (for Small) and $D R_{H M L}^{2}$ (for Big) move inversely with $D R_{R M}^{2}$ (with correlation coefficients of -62 percent and -67 percent, respectively).

\subsection{Conclusions}

Multi-factor models employing additional factors to the market risk premium, such as size, value, momentum and contrarian, have been widely used by financial researchers and professionals. Due to the dependence among factors, decomposing the systematic variation of asset returns, with respect to different factors has been a methodological challenge. This study aims to fill this gap and proposes a simple procedure of decomposing the coefficient of determination or $R$ square. This procedure allows us to examine the marginal contribution of individual factors to an asset's return volatility. The key component of our procedure is a simultaneously orthogonal transformation of data, that is able to extract jointly, the underlying uncorrelated components of individual factors. The covariance between the original factors is eliminated symmetrically, such that we achieve a maximum overall resemblance between the original and the transformed data sets. Experimentally, it appears that the decomposition is robust even for small sample sizes.

The decomposition procedure is further applied to return data on U.S. equity portfolios, obtained from Kenneth French's Data Library. Generally, the return variation of well-diversified equity portfolios is explained, with the highest proportion, by the market risk premium and size

\footnotetext{
${ }^{19}$ Finding the possible reasons for the ups and downs in the individual components over time is beyond the purpose of this paper, and we leave it to future research.
} 
factors (in that order). Nevertheless, the decomposed elements of systematic risk and the systematic risk itself change over time.

As expected, the industry portfolios, both equal and value-weighted, exhibit significantly higher unsystematic risk than well-diversified portfolios. But, the decomposed- $R^{2}$ of the equallyweighted 30-industry portfolios favor market less, and the other factors more, compared to their value-weighted counterparts.

In summary, the paper provides a simple method to extract underlying (i.e. core) uncorrelated components from a set of correlated factors. This allows us to break the systematic variation of asset returns and observe the marginal contribution of risk from individual factors. We note that the orthogonal transformation is numerical, and further research for developing a formal statistical process is necessary. 


\section{Appendix to Chapter 2: The nature of the relationship between the original and the orthogonalized factors}

Considering that each factor $f^{k}$ can be written, according to equation (2.13) as $f^{k}=\psi_{1 k} f^{1^{\perp}}+\psi_{2 k} f^{2^{\perp}}+\cdots+\psi_{K k} f^{K^{\perp}}$, where $k=1,2, \ldots, K$ and the coefficients $\psi_{l k}$ are the elements of the inverse of matrix $S_{K \times K}$, as transformed in equation (2.11), we want to prove that for any $k$ and $l, \psi_{k l}=\operatorname{corr}\left(f^{k}, f^{l^{\perp}}\right)$.

Proof:

The inverse of matrix $S_{K \times K}$ (in its final form), can be written as follows:

$S_{K \times K}^{-1}=\frac{1}{\sqrt{T-1}}\left[\begin{array}{cccc}1 / \sigma_{1} & 0 & \cdots & 0 \\ 0 & 1 / \sigma_{2} & \cdots & 0 \\ \vdots & \vdots & \ddots & \vdots \\ 0 & 0 & \cdots & 1 / \sigma_{K}\end{array}\right]\left[\begin{array}{cccc}\dot{s}_{11} & \dot{s}_{12} & \cdots & \dot{s}_{1 K} \\ \dot{s}_{21} & \dot{s}_{22} & \cdots & \dot{s}_{2 K} \\ \vdots & \vdots & \ddots & \vdots \\ \dot{s}_{K 1} & \dot{s}_{K 2} & \cdots & \dot{s}_{K K}\end{array}\right]=\frac{1}{\sqrt{T-1}}\left[\begin{array}{cccc}\dot{s}_{11} / \sigma_{1} & \dot{s}_{12} / \sigma_{1} & \ldots & \dot{s}_{1 K} / \sigma_{1} \\ \dot{s}_{21} & \dot{s}_{22} / \sigma_{2} & \ldots & \dot{s}_{2 K} / \sigma_{2} \\ \vdots & \vdots & \ddots & \vdots \\ \dot{s}_{K 1} / \sigma_{K} & \dot{s}_{K 2} / \sigma_{K} & \ldots & \dot{s}_{K K} / \sigma_{K}\end{array}\right]$,

where $\dot{s}_{k l}=\dot{s}_{l k}$ (the inverse of a symmetric matrix is symmetric).

So, $\psi_{l k}=\frac{1}{\sqrt{T-1}} \dot{s}_{l k} / \sigma_{l}$, where $k$ and $l$ go from 1 to $K$.

Thus, $f^{k}=\frac{1}{\sqrt{T-1}}\left(\dot{s}_{1 k} / \sigma_{1} f^{1^{\perp}}+\dot{s}_{2 k} / \sigma_{2} f^{2^{\perp}}+\cdots+\dot{s}_{l k} / \sigma_{l} f^{l^{\perp}}+\cdots+\dot{s}_{K k} / \sigma_{K} f^{K^{\perp}}\right)$.

We can now calculate the covariance between $f^{k}$ and $f^{l^{\perp}}$ [Note that for any $i=1,2, \ldots, K$,

$$
\begin{aligned}
& \left.\operatorname{var}\left(f^{i^{\perp}}\right)=\operatorname{var}\left(f^{i}\right)\right]: \\
& \operatorname{cov}\left(f^{k}, f^{l^{\perp}}\right)=\frac{1}{\sqrt{T-1}} \dot{s}_{l k} / \sigma_{l} \operatorname{var}\left(f^{l^{\perp}}\right)=\frac{1}{\sqrt{T-1}} \times \dot{s}_{l k} \times \sigma_{l}
\end{aligned}
$$

Similarly, $\operatorname{cov}\left(f^{l}, f^{k^{\perp}}\right)=\frac{1}{\sqrt{T-1}} \times \dot{s}_{k l} \times \sigma_{k}$.

But, $\dot{s}_{l k}=\dot{s}_{k l} \Rightarrow \frac{\operatorname{cov}\left(f^{k}, f^{l^{\perp}}\right)}{\sigma_{l}}=\frac{\operatorname{cov}\left(f^{l}, f^{k^{\perp}}\right)}{\sigma_{k}}$.

Writing equation (2.13) for factor $l$, we have: 
$f^{l}=\psi_{1 l} f^{1^{\perp}}+\psi_{2 l} f^{2^{\perp}}+\cdots+\psi_{k l} f^{k^{\perp}}+\cdots+\psi_{K l} f^{K^{\perp}}$.

Thus, $\operatorname{cov}\left(f^{l}, f^{k^{\perp}}\right)=\psi_{k l} \times \operatorname{var}\left(f^{k^{\perp}}\right) \Rightarrow$

$\psi_{k l}=\frac{\operatorname{cov}\left(f^{l}, f^{k^{\perp}}\right)}{\operatorname{var}\left(f^{k^{\perp}}\right)}=\frac{\operatorname{from}(*)}{=} \frac{\operatorname{cov}\left(f^{k}, f^{l^{\perp}}\right) \times \sigma_{k}}{\sigma_{l} \times \sigma_{k}^{2}}=\frac{\operatorname{cov}\left(f^{k}, f^{l^{\perp}}\right)}{\sigma_{l} \times \sigma_{k}}=\operatorname{corr}\left(f^{k}, f^{l^{\perp}}\right)$.

Q.E.D. 


\section{Chapter 3: Sentiment Effect and Market Portfolio Inefficiency}

\subsection{Introduction}

Testing market portfolio efficiency relative to different sets of portfolios has been a main theme of financial research. We propose an approach that avoids the major drawbacks of other methods and manages to give clear answers, in a simple and less restrictive way. Using Marginal Conditional Stochastic Dominance (MCSD) tests, we are able to prove the existence and importance of the sentiment effect, and link it to a case of inefficiency of the market portfolio.

Mean-variance efficiency tests are the pioneers in this area. ${ }^{20}$ For instance, Gibbons, Ross, and Shanken (1989) develop a multivariate $F$-test that checks whether the intercepts are jointly equal to zero. This test is easy to implement and offers a nice economic interpretation (in terms of Sharpe ratios), but its theoretical validity depends on the normality assumption of the disturbances. MacKinlay and Richardson (1991), Zhou (1993), and Richardson and Smith (1993) show that this assumption does not hold empirically.

The theory of stochastic dominance, developed initially by Hadar and Russell (1969), Hanoch and Levy (1969), and Rothschild and Stiglitz (1970), and reassessed by Levy and Sarnat (1984) and Levy (1992), was largely augmented by the empirical tests for stochastic dominance efficiency, as developed by Post (2003) or Kuosmanen (2004).

Best, Best and Yoder (2000) show that the U.S. value portfolios second-order stochastically dominate (SSD) the U.S. growth portfolios (for the interval July 1978 - June 1998) and conclude that this result is inconsistent with market portfolio efficiency. Nevertheless, Post and Vliet (2004) underline the sensitivity of the SSD results to sampling variation (as the SSD

\footnotetext{
${ }^{20}$ For an excellent review on the early literature on mean-variance efficiency tests, see Shanken (1996).
} 
rule considers the whole sample distribution), and reject the aforementioned conclusion. They point out that the market portfolio is actually inefficient when extending the period to July 1968 - June 1998.

Chou and Zhou (2006) use a bootstrap method to test the mean-variance efficiency of a given portfolio, and claim that the method provides more reliable and robust results, but in a computationally-expensive manner.

Post and Versijp (2007) apply multivariate statistical tests for stochastic dominance efficiency of a given portfolio and obtain that the market portfolio (proxied by the CRSP allshare index) is significantly mean-variance inefficient relative to ten market beta-sorted portfolios. A strategy of buying low beta stocks, while selling high beta stocks can lead to a higher Sharpe ratio compared to that of the market (i.e. low beta stocks are underpriced and high beta stocks are overpriced in the mean-variance framework). They blame this inefficiency on the tail risk, not captured by variance. The mean-variance beta underestimates the tail risk for low beta stocks and overestimates the tail risk for high beta stocks.

An earlier article by Post and Vliet (2006) concludes that the same proxy for the market portfolio (i.e. the value-weighted CRSP index), is also mean-variance inefficient relative to benchmark portfolios formed on size, value and momentum, for the same time period: January 1933, to December 2002.

We apply the MCSD tests in the context of a multifactor linear model, so we need to turn our attention to this type of models. Multifactor models, alternatives to the traditional Sharpe (1964) and Lintner (1965) Capital Asset Pricing Model (CAPM), have become popular in recent decades. For instance, an extension of the CAPM to a multi-country case is the widely known 
International CAPM. ${ }^{21}$ Other extensions, to a multi-period economy, are the Intertemporal CAPM and Consumption-based CAPM. ${ }^{22}$

A widely cited multifactor model is the Fama and French Three Factor Model (1992, 1993, 1996 and 1998, hereafter FF). The model is considered a special case of the Arbitrage Pricing Theory (APT, as developed by Ross, 1976). It considers the existence of three factors that determine the asset pricing, but those factors are only mimicked by three well diversified portfolios: market, SMB (i.e. Small minus Big, market capitalization) and HML (i.e. High minus Low, book-to-market ratio). FF also claim that a series of the so-called anomalies can be explained using their model. ${ }^{23}$ They see higher returns (i.e. excess returns between dominated and dominating assets) as compensation for taking on more risk (i.e. systematic risk factors that are therefore priced).

The Carhart (1997) model extends the FF model, by including a fourth factor: momentum. The momentum effect of Jegadeesh and Titman (1993, 2001), Chan, Jegadeesh, and Lakonishok (1996), Rouwenhorst (1998), and others, indicates that average returns on the prior best performing stocks (the so-called winners) exceed those of the prior worst performing stocks (the so-called losers), and thus short-term past returns have predictive power over future returns.

Recently, a number of articles have been inspecting the effect of investor sentiment on common stock returns. ${ }^{24}$ Baker and Wurgler $(2006,2007)$ examine investor sentiment as another determinant of stock returns. They construct sentiment indexes (hereafter denoted as BW) and

\footnotetext{
${ }^{21}$ See for example Solnik (1974), Stulz (1981), Adler and Dumas (1983), Black (1990), and DeSantis and Gérard (1998).

${ }^{22}$ See Merton (1973) and Breeden (1979), respectively.

${ }^{23}$ However, a number of studies blame biases in the empirical methodology for the documented anomalies. Lo and MacKinlay (1990), MacKinlay (1995), Knez and Ready (1997), and Loughran (1997) argue that the empirical evidence can actually result from data-snooping biases such that the anomalies are sample dependent. Therefore, they are unlikely to be observed out-of-sample.

${ }^{24}$ See for example Lee, Shleifer and Thaler (1991), Mitchell, Pulvino and Stafford (2002), Qiu and Welch (2004) and Brown and Cliff (2004, 2005).
} 
find that returns are affected by the level of pessimism/ optimism, even when controlled for the Fama and French factors. ${ }^{25}$

Glushkov (2006) tests whether exposure to sentiment is a priced factor, namely whether investors demand premium for holding stocks with more exposure to sentiment. He develops a sentiment factor, taking the first principal component of different measures of investor sentiment (similar to BW). He finds a sentiment beta after controlling for risk factors associated with market, size, value and liquidity. The relationship between sentiment betas and returns turns out to be inverse U-shaped, which means that low and high beta stocks tend to underperform the near-zero beta stocks. The under-performance of extreme beta portfolios (with no significant difference between them), compared to near-zero sentiment beta portfolios, is also manifested for sub-periods, which means, he concludes, that there is no reason to think about sentiment as a risk factor.

This paper applies MCSD tests in order to examine the existence of a sentiment effect and to inspect the efficiency of the market portfolio. Unlike the traditional SSD rules of comparing unconditional return distributions of assets independently, MCSD considers the joint nature between assets and the market. ${ }^{26}$ The MCSD theory, originally developed by Shalit and Yitzhaki (1994), focuses on necessary and sufficient conditions to improve investors' expected utility of wealth, by marginally reallocating the assets in their portfolios (i.e. by increasing the share of the dominating assets on the account of the dominated ones). ${ }^{27}$ Specifically, suppose that the market portfolio can be decomposed into a set of mutually exclusive sub-portfolios according

\footnotetext{
${ }^{25}$ Liu (2006) studies the effect of sentiment on stock market liquidity. She finds that BW is a significant factor for liquidity, but only for some assets (for instance, portfolios with high sentiment beta), not for the market as a whole.

${ }^{26}$ For a comprehensive review of the advantages of the SSD versus conventional mean-variance analysis, see for instance Chow et al. (2008).

27 Jewitt (1987) derives conditions that all risk-averse individuals prefer one particular sub-portfolio over another, given that they hold the rest of the portfolio.
} 
to the stocks' sensitivity to investor sentiment: positively sensitive $\left(\beta_{+}^{s}\right)$, insensitive $\left(\beta_{0}^{s}\right)$, and negatively sensitive $\left(\beta_{-}^{s}\right)$ stocks. Conditional on the return distribution of the given market portfolio, if for instance $\beta_{0}^{s}$ marginally and stochastically dominates $\beta_{+}^{s}$ according to the MCSD criteria, then we conclude that the market portfolio is stochastically inefficient, in that risk-averse investors prefer to hold a re-allocated portfolio by selling $\beta_{+}^{s}$ stocks and purchasing more of $\beta_{0}^{s}$ stocks.

To examine the sentiment effect, we sort all the NYSE, AMEX, and NASDAQ stocks (that do not have missing values during the regression period), according to their sentiment betas, (based on the BW sentiment levels index), after controlling for market, size, value, and momentum factors. Thus, we form three sentiment-beta sorted portfolios. We also construct three sentiment-arbitrage portfolios with positively sensitive vs. insensitive, insensitive vs. negatively sensitive, and positively vs. negatively sensitive stocks, dependent on different levels of investor sentiment. Employing a statistical inference MCSD test developed by Chow (2001), we find that both positively and negatively sentiment sensitive stocks are conditionally and stochastically dominated by sentiment insensitive stocks. Moreover, we find dominance among the sentimentarbitrage portfolios, which proves once again that the market portfolio is inefficient relative to portfolios formed on investor sentiment.

The paper is organized as follows. Section II reviews the MCSD ranking rule and its statistical inference procedures. In section III, we describe the data, the empirical hypothesis and we present our main results. Section IV draws brief conclusions. 


\subsection{Marginal Conditional Stochastic Dominance Test}

Traditional portfolio selection models such as stochastic dominance, mean-variance, and performance measures, rank portfolios unconditionally and independently. These approaches are appropriate for individual asset selection, but they are unable to effectively solve the problem of improving portfolio holding by changing asset allocation in the portfolio. Shalit and Yitzhaki (1994) argue that, in reality, investors usually optimize their portfolios by marginally changing asset allocation, without altering the core portfolio.

Let a diversified core-portfolio, such as a market index portfolio, be decomposed into a set of $n$ mutually exclusive sub-portfolios according to a fundamental metric (sentiment sensitivity, in our case). The return on the core-portfolio can be written as $r_{m}=\sum_{s=1}^{n} w_{s} r_{s}$, where $r_{s}$ is the return of the $s$-th sub-portfolio, and $\sum_{s=1}^{n} w_{s}=1$. As mentioned above, Shalit and Yitzhaki (1994) claim that when investors maximize their expected utility, they normally reallocate securities marginally, without altering their core holdings. So, what is the condition such that investors are willing to marginally change their asset allocation to optimize their utility?

Assume that investors are non-satiated and risk-averse (i.e. their preference functions are such that: $U^{\prime}>0$ and $\left.U^{\prime \prime}<0\right)$. Also, they are maximizing their expected utility, $E(U(W))$, where $W=1+\sum_{s=1}^{n} w_{s} r_{s}$ is the final wealth (assuming an initial wealth of \$1).

Then, a sub-portfolio $p$ dominates another sub-portfolio $q$, given the core-portfolio, if the following inequality holds for all investors:

$$
\frac{d E(U(W))}{d w_{p}}=E U^{\prime}(W)\left(r_{p}-r_{q}\right) \geq 0
$$


Shalit and Yitzhaki (1994) formulate the necessary and sufficient conditions such that inequality (3.1) holds, in terms of Absolute Concentration Curves (ACCs), which are defined as the cumulative expected returns on assets / sub-portfolios, conditional on the return on the coreportfolio. Since the concept of ACC is less familiar in the financial literature, Chow (2001) reformulates these conditions in a relatively simple way, as follows:

Theorem 3.1. For all risk-averse investors, the inequality (3.1) holds if and only if

$$
\begin{aligned}
& \int_{-\infty}^{\tau_{\rho}^{m}} \int_{-\infty}^{\infty} r_{p} f\left(r_{p}, r_{m}\right) d r_{m} d r_{p} \geq \int_{-\infty}^{\tau_{\rho}^{m}} \int_{-\infty}^{\infty} r_{q} f\left(r_{q}, r_{m}\right) d r_{m} d r_{q} \\
& \text { or, } \\
& E\left(r_{p}-r_{q} \mid r_{m} \leq \tau_{\rho}^{m}\right) \geq 0
\end{aligned}
$$

for all $\rho$, where $0 \leq \rho \leq 1 ; E$ is the expectation operator; $\tau_{\rho}^{m}=F_{m}^{-1}(\rho) ; F_{m}^{-1}(\rho)$ is the inverse cumulative density function of $r_{m}$, corresponding to abscissa $\rho$.

From equation (3.1) and Theorem 3.1, it is clear that the existence of MCSD for any pair of sub-portfolios ensures that the core-portfolio is not optimal, because risk-averse investors are able to increase their expected utility through a reallocation between the pair of sub-portfolios. The application of Theorem 1 to the test of market portfolio stochastic efficiency is straightforward. Let the market portfolio be the core-portfolio, while the sub-portfolios are constructed as the sorted mutually exclusive groups of assets according to information about the sentiment metric. Our null hypothesis is that there is no MCSD (implying that the core-portfolio is efficient). Applying MCSD tests to pairwise comparisons of sub-portfolios, if there is at least one MCSD, we then reject the null hypothesis and conclude that the market portfolio is 
inefficient. Notably, when $\rho=1$, the inequalities (2) are equivalent to the difference between the mean returns on sub-portfolios $p$ and $q$.

To test for MCSD, a transformation of inequality (3.2.1) is necessary. Without loss of generality, let $I_{m}^{\tau_{\rho}^{m}}$ be an indicator variable such that $I_{m}^{\tau_{\rho}^{m}}=1$, if $r_{m} \leq \tau_{\rho}^{m}$, and $I_{m}^{\tau_{\rho}^{m}}=0$, otherwise. Then, the inequality (3.2.2) can be written as:

$$
E\left(r_{p} I_{m}^{\tau_{\rho}^{m}}\right) \geq E\left(r_{q} I_{m}^{\tau_{\rho}^{m}}\right)
$$

To apply the statistical inference procedure of MCSD, we begin by selecting a set of target returns, $\left\{\tau_{t}^{m}=\hat{F}_{m}^{-1}\left(\rho_{t}\right) \mid t=1, \ldots k\right\}$, corresponding to the abscissas $\left\{\rho_{t} \mid t=1, \ldots k\right\}$. For instance, in the case of deciles, $k=10$ and $\rho_{1}=0.1, \rho_{2}=0.2, \ldots, \rho_{10}=1.0$. Further, let

$$
\Phi_{p-q}^{\tau_{t}^{m}}=E\left(r_{p} I_{m}^{\tau_{t}^{m}}\right)-E\left(r_{q} I_{m}^{\tau_{t}^{m}}\right)
$$

There are three possible outcomes from the MCSD test: equality $\left(\Phi_{p-q}^{\tau_{t}^{m}}=0\right.$ for all $\left.t\right)$; dominance ( $\Phi_{p-q}^{\tau_{t}^{m}}>0$ for some $t$, but $\Phi_{p-q}^{\tau_{t}^{m}}=0$ for the rest of $t$, or $\Phi_{p-q}^{\tau_{t}^{m}}<0$ for some $t$, but $\Phi_{p-q}^{\tau_{t}^{m}}=0$ for the rest of $t$ ); and non-comparability ( $\Phi_{p-q}^{\tau_{t}^{m}}>0$ for at least one $t$ and $\Phi_{p-q}^{\tau_{t}^{m}}<0$ for at least one $t$ ). Since conventional goodness-of-fit measures (e.g. Chi-square and F-test) are unable to distinguish between dominance and non-comparability when the null hypothesis of equality is rejected, a multiple comparison test becomes necessary. It is also important to note that, using empirical quantiles from the market return sample as targets may involve sampling variation from the population quantiles. However, data snooping bias is limited (Chow, 2001).

By employing the target approach, the statistical inference of MCSD is simple and straightforward. Given a set of $N$ random sample returns, $\left\{\left(r_{p 1}, r_{q 1}, r_{m 1}\right), \ldots,\left(r_{p N}, r_{q N}, r_{m N}\right)\right\}$, the sample estimates of MCSD ordinates can be expressed as: 


$$
\hat{\Phi}_{p-q}^{\tau_{t}^{m}}=N^{-1} \sum_{i=1}^{N}\left(r_{p i} I_{m i}^{\tau_{t}^{m}}\right)-\left(r_{q i} I_{m i}^{\tau_{t}^{m}}\right)
$$

Chow (2001) shows that the sampling distribution of $\sqrt{N}\left(\hat{\Phi}_{p-q}^{\tau_{t}^{m}}-\Phi_{p-q}^{\tau_{t}^{m}}\right)$ is normal, and further provides a full variance-covariance structure of estimates. ${ }^{28}$ Importantly, one may easily perform a statistical inference for MCSD by testing a set of Z-statistics under the null hypothesis $H_{0}:\left\{\Phi_{p-q}^{\tau_{t}^{m}}=0 \mid t=1, \ldots, k\right)$. The test statistic can be written as:

$$
Z_{p-q}^{\tau_{t}^{m}}=\sqrt{N} \frac{\hat{\Phi}_{p-q}^{\tau_{t}^{m}}}{S_{p-q}^{\tau_{t}^{m}}}
$$

for $t=1, \ldots, k$, where $S_{p-q}^{\tau_{t}^{m}}$ is the sample standard deviation. To control for the size of the above multiple comparison procedure, it is necessary to adjust the critical value of the test. Using the Studentized Maximum Modulus $(S M M)$ approach, the asymptotic joint confidence interval of at least $100(1-\alpha)$ percent for a set of MCSD estimates is:

$$
Z_{p-q}^{\tau_{t}^{m}} \pm \operatorname{SMM}(\alpha ; k ; \infty) \quad \text { for } t=1,2, \ldots, k
$$

where $\operatorname{SMM}(\alpha ; k ; \infty)$ is the asymptotic critical value of the $\alpha$ point of the $S M M$ distribution with parameter $k$ and $\infty$ degrees of freedom. Thus, the empirical MCSD rules using the above inference procedure are summarized as follows:

(a) An asset/ sub-portfolio $p$ dominates an asset/ sub-portfolio $q$, if at least one strong inequality holds, $Z_{p-q}^{\tau_{t}^{m}}>+\operatorname{SMM}(\alpha ; k ; \infty)$, and no $Z_{p-q}^{\tau_{t}^{m}}$ statistic has a value less than $-\operatorname{SMM}(\alpha ; k ; \infty)$

(b) An asset/ sub-portfolio $p$ is dominated by an asset/ sub-portfolio $q$, if at least one strong inequality holds, $Z_{p-q}^{\tau_{t}^{m}}<-S M M(\alpha ; k ; \infty)$, and no $Z_{p-q}^{\tau_{t}^{m}}$ statistic has a value greater than

\footnotetext{
${ }^{28}$ It is assumed that sample returns of each portfolio are identically and independently distributed. To generate i.i.d. sample returns, one may randomize the return data.
} 


$$
+\operatorname{SMM}(\alpha ; k ; \infty)
$$

(c) No dominance exists otherwise. ${ }^{29}$

Chow (2001) shows that although the MCSD test is conservative in nature, it has power to detect dominance for samples with more than 300 observations, and is robust under both homoskedasticity and heteroskedasticity assumptions.

\subsection{Empirical Results}

We consider the following setting for a multifactor linear model:

$$
r_{t}^{i}-r_{t}^{f}=\alpha^{i}+\gamma^{i} R M_{t}+s^{i} S M B_{t}+h^{i} H M L_{t}+m^{i} M_{0}+\beta^{i} \operatorname{Sent}_{t}+\varepsilon_{t}
$$

where $r^{i}-r^{f}$ represent the excess returns on all common stocks listed on the NYSE, AMEX, and NASDAQ (that do not have missing values during the regression period), over the one-month Treasury bill rate (from Ibbotson Associates); $R M, S M B$ and $H M L$ are the Fama and French factors: $R M$ is the market risk premium, $S M B$ is Small Minus Big (size), and $H M L$ is High Minus Low (book-to-market), while Mom is the momentum factor; Sent is the Baker and Wurgler (2007) sentiment levels index.

Monthly data, ranging from January 1966 to December 2007, are obtained from the following sources: stock returns - from the CRSP database, market risk premium, size, value and momentum factors - from Kenneth French's data library (at http://mba.tuck.dartmouth.edu/ pages/faculty/ken.french/), and the index of sentiment levels - from Jeffrey Wurgler's website (http://pages.stern.nyu.edu/ jwurgler/). ${ }^{30}$

\footnotetext{
${ }^{29}$ There are two possible cases: (1) all statistics are neither greater than $+S M M$, nor less than $-S M M$. In this case, we fail to reject the null hypothesis that the two distributions are equal, and (2) if at least one statistic is greater than + SMM, and at least one statistic is less than-SMM, then the MCSD ranking crosses, and there is no dominance.

${ }^{30}$ The time period is constrained by the availability of the sentiment measure.
} 


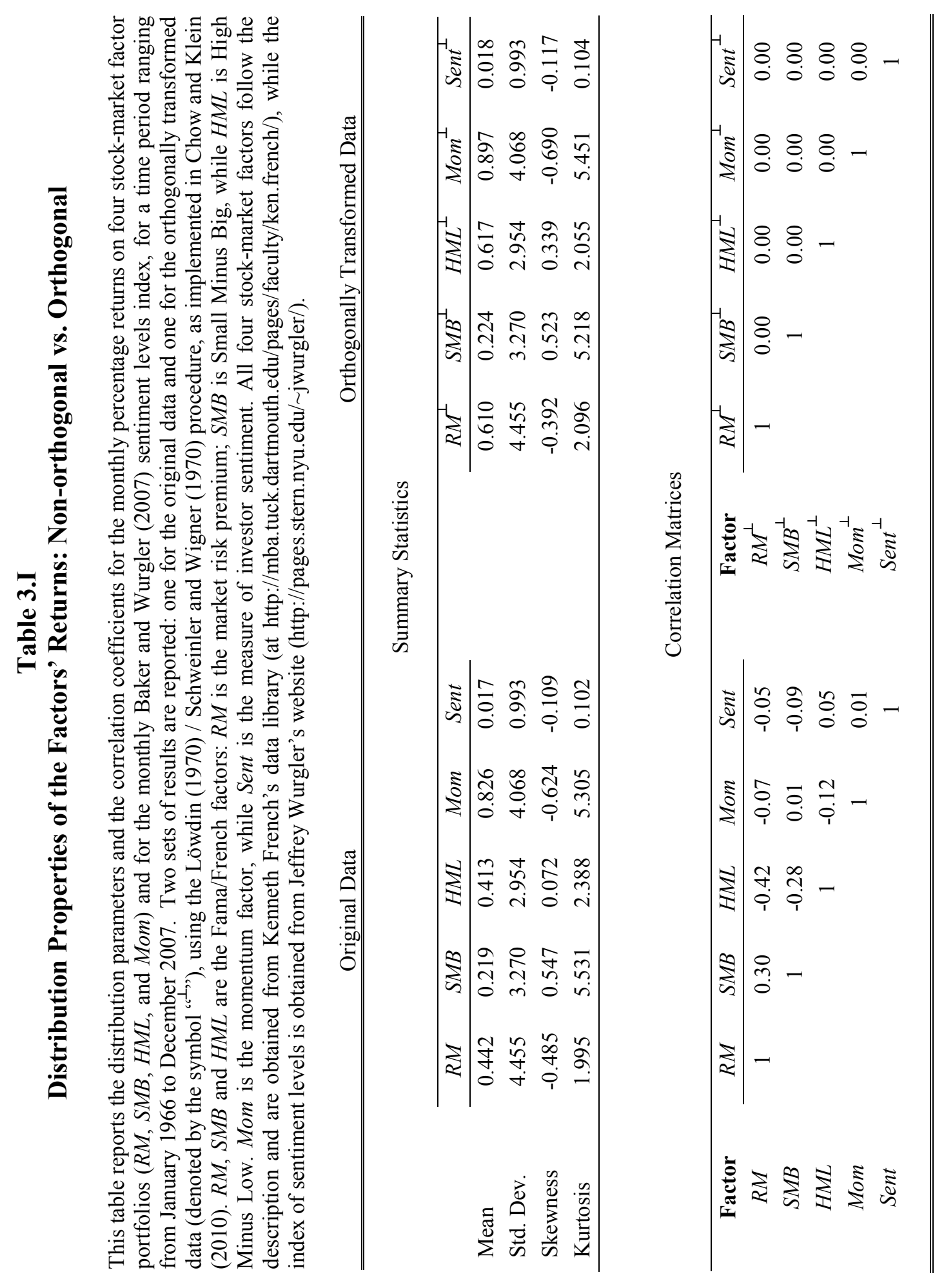


As shown in Table 3.I, the five regressors in equation (3.8) are, to some extent, mutually correlated. Their correlation coefficients range, in absolute value, from 0.01 to 0.42 . However, for other periods or for sub-periods, the coefficients can be more significant. For instance, for the first 95 months of the interval, there is a 0.58 correlation between $R M$ and $S M B$, while for the last 151 months, we have -0.53 between $R M$ and $H M L$. Even more so, the fourth 60 -month subinterval gives a -0.65 correlation between $R M$ and $H M L$.

For more robust results, we also perform a symmetric orthogonal transformation, as in Chow and Klein (2010). The analogous model, in terms of the orthogonally transformed data (denoted by the symbol " ${ }^{\perp}$ "), is as follows:

$$
r_{t}^{i}-r_{t}^{f}=\alpha^{i}+\gamma^{i \perp} R M_{t}^{\perp}+s^{i \perp} S M B_{t}^{\perp}+h^{i \perp} H M L_{t}^{\perp}+m^{i \perp} \operatorname{Mom}_{t}^{\perp}+\beta^{i \perp} \operatorname{Sent}_{t}^{\perp}+\varepsilon_{t}
$$

Note that the average sentiment level is close to zero $(0.017)$ and remains close to zero (0.018) after the orthogonal transformation. The equity premia increase in importance after the orthogonalization, more significantly for $R M$ (from 0.442 , to 0.610 ) and $H M L$ (from 0.413 , to 0.617), and less significantly for $S M B$ (from 0.219, to 0.224) and Mom (from 0.826, to 0.897). Importantly, the orthogonalized factors maintain the standard deviation of their nonorthogonalized counterparts. Also, the intercept and the error term stay the same after transformation.

To form the sentiment-beta portfolios, we run regression (8) (and (9), respectively) for the first twenty-four months, then we sort all assets (that do not have missing values during that particular period) on sentiment betas. The top 25, middle 50 and bottom 25 percent are considered the positively sensitive $\left(\beta_{+}^{s}\right)$, insensitive $\left(\beta_{0}^{s}\right)$, and negatively sensitive $\left(\beta_{-}^{s}\right)$ stocks, respectively. Next, we repeat the procedure using a rolling-window approach (the overlapping interval is twelve months). 


\section{Table 3.II \\ Summary Statistics for Sentiment-Beta Sorted Portfolios}

The table presents summary statistics for the excess returns on three sentiment-beta sorted portfolios and for their orthogonal counterparts (Panel A), and also for pairwise differences between the aforementioned portfolios (Panel B). ${ }^{31}$ The three sentiment-beta sorted portfolios are obtained by regressing the monthly percentage excess returns of all common stocks (listed on the NYSE, AMEX, and NASDAQ), on the five factors mentioned below and then sorting them according to their sentiment betas. The top 25 percent represent the positively sensitive stocks $\left(\beta_{+}{ }^{\mathrm{s}}\right)$, the bottom 25 percent indicate the negatively sensitive stocks $\left(\beta_{-}^{\mathrm{s}}\right)$, while the rest are the insensitive stocks $\left(\beta_{0}{ }^{\mathrm{s}}\right)$.

Monthly data, ranging from January 1966 to December 2007, are obtained from the following sources: stock returns - from the CRSP database, market risk premium, size, value and momentum factors - from Kenneth French's data library (at http://mba.tuck.dartmouth.edu/pages/faculty/ken.french/), and the index of sentiment levels - from Jeffrey Wurgler's website (http://pages.stern.nyu.edu/ jwurgler/).

The orthogonally transformed data (denoted by the symbol " ${ }^{\perp}$,) is obtained using the Löwdin (1970) / Schweinler and Wigner (1970) procedure, as implemented in Chow and Klein (2010).

Panel A: Excess Returns on Sentiment Portfolios

\begin{tabular}{|c|c|c|c|c|c|}
\hline Portfolio & Mean & $t$-statistic & $\begin{array}{l}\text { Standard } \\
\text { deviation }\end{array}$ & Skewness & Kurtosis \\
\hline $\boldsymbol{\beta}_{+}{ }^{\mathbf{s}}$ & $0.836 * * *$ & 2.64 & 6.841 & 0.338 & 4.115 \\
\hline$\beta_{0}{ }^{s}$ & $0.791 * * *$ & 3.52 & 4.857 & -0.190 & 5.135 \\
\hline $\boldsymbol{\beta}_{-}^{\mathrm{s}}$ & $0.819 * * *$ & 2.79 & 6.356 & -0.150 & 2.248 \\
\hline$\left(\beta_{+}{ }^{s}\right)^{\perp}$ & $0.836 * * *$ & 2.65 & 6.824 & 0.339 & 4.163 \\
\hline$\left(\beta_{0}\right)^{\perp}$ & $0.789 * * *$ & 3.52 & 4.854 & -0.191 & 5.105 \\
\hline$\left(\beta_{-}^{s}\right)^{\perp}$ & $0.822 * * *$ & 2.79 & 6.379 & -0.144 & 2.245 \\
\hline
\end{tabular}

Panel B: Pairwise Differences between Sentiment Portfolios

\begin{tabular}{|c|c|c|c|c|c|}
\hline Portfolio & Mean & $t$-statistic & $\begin{array}{l}\text { Standard } \\
\text { deviation }\end{array}$ & Skewness & Kurtosis \\
\hline $\boldsymbol{\beta}_{+}{ }^{\mathrm{s}}-\boldsymbol{\beta}_{0}{ }^{\mathrm{s}}$ & 0.045 & 0.35 & 2.827 & 1.902 & 15.308 \\
\hline $\boldsymbol{\beta}_{+}{ }^{\mathbf{s}}-\boldsymbol{\beta}_{-}{ }^{\mathbf{s}}$ & 0.017 & 0.18 & 2.048 & 1.362 & 11.554 \\
\hline$\beta_{0}^{s}-\beta_{-}^{s}$ & -0.028 & -0.26 & 2.306 & -0.938 & 4.275 \\
\hline$\left(\beta_{+}{ }^{s}\right)^{\perp}-\left(\beta_{0}{ }^{s}\right)^{\perp}$ & 0.046 & 0.36 & 2.814 & 1.933 & 15.569 \\
\hline$\left(\beta_{+}{ }^{s}\right)^{\perp}-\left(\beta_{-}^{s}\right)^{\perp}$ & 0.013 & 0.14 & 2.040 & 1.361 & 11.557 \\
\hline$\left(\beta_{0}^{s}\right)^{\perp}-\left(\beta_{-}^{s}\right)^{\perp}$ & -0.033 & -0.31 & 2.330 & -0.941 & 4.255 \\
\hline
\end{tabular}

Table 3.II reports the descriptive statistics for these three portfolios. Importantly, as shown in Panel B, the pairwise differences between the mean returns on the portfolios (both non-

\footnotetext{
${ }^{31}$ One, two or three asterisks designate significance levels of $10 \%, 5 \%$ and $1 \%$, respectively.
} 
orthogonalized and orthogonalized) are not significantly different from zero. So, we cannot perform any first-order sorting. For each of them, the monthly excess returns are, on average, around 0.8 percent (see Panel A). Note that the orthogonal transformation causes marginal modifications in the construction of the sentiment-beta portfolios, which results in different statistics. Specifically, the variance in the returns on the sentiment-beta portfolios is no longer expected to stay the same after the orthogonalization procedure. The standard deviation of the insensitive stocks, for instance, slightly diverges from 4.857 to 4.854 percent.

At the second order, the MCSD tests find significant dominance (see Table 3.III): both positively and negatively sentiment sensitive stocks are conditionally and stochastically dominated by sentiment insensitive stocks. ${ }^{32}$ The dominance is significant for the first seven targets. ${ }^{33}$ For instance, for the first five targets, conditional on the return on the market portfolio, $\beta_{0}^{s}$ outperforms $\beta_{+}^{s}$ by roughly 0.4 percent per month (for both non-orthogonalized and orthogonalized). That is to say, on the downside of the market, the insensitive stocks surpass the positively-sensitive stocks. These results prove the existence of a sentiment effect. More notably, the market portfolio is found inefficient relative to the sentiment-beta portfolios. ${ }^{34}$ Thus, investors are able to improve their expected utility by marginally changing the weights on their portfolios (i.e. by increasing the share of the insensitive versus the sentiment-sensitive stocks). The dominance fades out towards the upper deciles of the market distribution, but does not reverse, which does not affect the significance of our results.

\footnotetext{
${ }^{32}$ This inverse U-shaped pattern is in line with Glushkov (2006).

${ }^{33}$ The $10^{\text {th }}$ target (i.e. the maximum value of the market) corresponds to the unconditional means, for which we did not find a significant ranking.

${ }^{34}$ We also perform the Gibbons, Ross, and Shanken (1989) test for the entire period, and the results reject the market portfolio efficiency relative to the sentiment-beta portfolios. Nevertheless, the results (not reported) need to be used cautiously, given the empirical failure of the normality assumption.
} 


\section{Table 3.III \\ MCSD Test for Sentiment-Beta Sorted Portfolios}

The table presents the MCSD test results for pairwise comparisons between three portfolios formed by sorting the sentiment betas, based on the Baker and Wurgler (2007) sentiment levels index. We regress the excess returns of all common stocks (listed on the NYSE, AMEX, and NASDAQ), on the factors mentioned below and then sort stocks according to their sentiment betas. The top 25 percent represent the positively sensitive stocks $\left(\beta_{+}{ }^{\mathrm{s}}\right)$, the bottom 25 percent indicate the negatively sensitive stocks $\left(\beta_{-}^{s}\right)$, while the rest are the insensitive stocks $\left(\beta_{0}{ }^{s}\right)$.

Monthly data, ranging from January 1966 to December 2007, are obtained from the following sources: stock returns - from the CRSP database, market risk premium, size, value, and momentum factors - from Kenneth French's data library (at http://mba.tuck.dartmouth.edu/pages/faculty/ken.french/), and the index of sentiment levels - from Jeffrey Wurgler's website (http://pages.stern.nyu.edu/ jwurgler/). Two sets of results are reported: one for the original data (Panel A) and one for orthogonally transformed data (Panel B), using Löwdin (1970) / Schweinler and Wigner (1970) procedure, as implemented in Chow and Klein (2010). The MCSD ordinates, corresponding to empirical quantiles of the market return distribution, are statistically different from zero if their accompanying Z-scores (displayed in parentheses) are greater, in absolute value, than the SMM critical values of $2.560,2.800$ or 3.289 , for significance levels of 10,5 or 1 percent (designated by one, two or three asterisks, respectively). ${ }^{35}$

Panel A: Original Data

\begin{tabular}{|c|c|c|c|c|c|c|c|c|c|c|}
\hline & \multicolumn{10}{|c|}{$\rho$} \\
\hline & 0.1 & 0.2 & 0.3 & 0.4 & 0.5 & 0.6 & 0.7 & 0.8 & 0.9 & 1 \\
\hline$\tau_{\rho}^{m}$ & -4.44 & -2.42 & -1.08 & 0.04 & 1.24 & 2.05 & 3.25 & 4.55 & 6.07 & 16.56 \\
\hline \multirow{2}{*}{$\boldsymbol{\beta}_{+}{ }^{\mathrm{s}}-\boldsymbol{\beta}_{0}{ }^{\mathrm{s}}$} & -0.249 & -0.370 & -0.430 & -0.473 & -0.454 & -0.459 & -0.296 & -0.192 & -0.108 & 0.045 \\
\hline & $(-4.72) * * *$ & $(-6.03)^{* * *}$ & $(-6.63)^{* * * *}$ & $(-6.41)^{* * *}$ & $(-5.89)^{* * *}$ & $(-5.50) * * *$ & $(-2.87)^{* *}$ & $(-1.65)$ & $(-0.88)$ & $(0.35)$ \\
\hline \multirow{2}{*}{$\boldsymbol{\beta}_{+}{ }^{\mathrm{s}}-\boldsymbol{\beta}_{-}^{\mathrm{s}}$} & -0.020 & -0.066 & -0.040 & -0.063 & -0.049 & -0.058 & -0.003 & -0.016 & 0.005 & 0.017 \\
\hline & $(-0.63)$ & $(-1.59)$ & $(-0.87)$ & $(-1.26)$ & $(-0.92)$ & $(-0.99)$ & $(-0.05)$ & $(-0.21)$ & $(0.06)$ & $(0.18)$ \\
\hline \multirow{2}{*}{$\beta_{0}{ }^{s}-\beta_{-}^{s}$} & 0.230 & 0.304 & 0.390 & 0.410 & 0.405 & 0.401 & 0.293 & 0.175 & 0.113 & -0.028 \\
\hline & $(5.41)^{* * * *}$ & $(5.80)^{* * *}$ & $(6.82)^{* * *}$ & $(6.46)^{* * *}$ & $(6.05)^{* * *}$ & $(5.45)^{* * *}$ & $(3.56)^{* * * *}$ & (1.88) & (1.16) & $(-0.26$ \\
\hline
\end{tabular}

Panel B: Orthogonally Transformed Data

\begin{tabular}{|c|c|c|c|c|c|c|c|c|c|c|}
\hline & & & & & $\rho$ & & & & & \\
\hline & 0.1 & 0.2 & 0.3 & 0.4 & 0.5 & 0.6 & 0.7 & 0.8 & 0.9 & 1 \\
\hline$\tau_{\rho}^{m}$ & -4.44 & -2.42 & -1.08 & 0.04 & 1.24 & 2.05 & 3.25 & 4.55 & 6.07 & 16.56 \\
\hline$\left(\beta^{s}\right)^{\perp}-\left(\beta^{s}\right)^{\perp}$ & -0.248 & -0.368 & -0.426 & -0.468 & -0.448 & -0.453 & -0.292 & -0.189 & -0.106 & 0.046 \\
\hline & $(-4.72)^{* * *}$ & $(-6.05) * * *$ & $(-6.62) * * *$ & $(-6.37)^{* * *}$ & $(-5.84) * * *$ & $(-5.46)^{* * *}$ & $(-2.84)^{* *}$ & $(-1.63)$ & $(-0.87)$ & $(0.36)$ \\
\hline$\left(\boldsymbol{\beta}^{\mathbf{s}}\right)^{\perp}\left(\boldsymbol{\beta}^{\mathbf{s}}\right)^{\perp}$ & -0.016 & -0.060 & -0.032 & -0.052 & -0.038 & -0.048 & 0.003 & -0.013 & 0.004 & 0.013 \\
\hline & $(-0.50)$ & $(-1.47)$ & $(-0.69)$ & $(-1.04)$ & $(-0.72)$ & $(-0.83)$ & $(0.04)$ & $(-0.17)$ & $(0.05)$ & $(0.14)$ \\
\hline$\left(\beta^{s}\right)^{\perp}\left(\beta^{s}\right)^{\perp}$ & 0.232 & 0.308 & 0.394 & 0.416 & 0.410 & 0.405 & 0.295 & 0.176 & 0.110 & -0.033 \\
\hline$\left(P_{0}\right)-\left(P_{-}\right)$ & $(5.42)^{* * *}$ & $(5.82)^{* * *}$ & $(6.86)^{* * *}$ & $(6.50)^{* * *}$ & $(6.06)^{* * *}$ & $(5.44)^{* * *}$ & $(3.54)^{* * *}$ & $(1.87)$ & $(1.13)$ & $(-0.31)$ \\
\hline
\end{tabular}

\footnotetext{
${ }^{35}$ All the results in this table are reported as percentages.
} 


\section{Table 3.IV \\ Summary Statistics for Sentiment-Beta Sorted Portfolios Conditional on the Level of Sentiment}

The table presents summary statistics for the excess returns on the portfolios constructed with positively sensitive stocks $\left(\beta_{+}^{\mathrm{s}}\right)$, insensitive stocks $\left(\beta_{0}^{\mathrm{s}}\right)$, and negatively sensitive stocks $\left(\beta_{-}^{\mathrm{s}}\right)$, all with respect to investor sentiment and conditional on the level of sentiment: High / Medium / Low ${ }^{36}$ To obtain these three portfolios, we regress the excess returns of all common stocks (listed on the NYSE, AMEX, and NASDAQ), on the factors mentioned below and then sort stocks according to their sentiment betas. The top 25 percent represent the positively sensitive stocks $\left(\beta_{+}{ }^{\mathrm{s}}\right)$, the bottom 25 percent indicate the negatively sensitive stocks $\left(\beta_{-}^{s}\right)$, while the rest are the insensitive stocks $\left(\beta_{0}{ }^{s}\right)$.

Monthly data, ranging from January 1966 to December 2007, are obtained from the following sources: stock returns - from the CRSP database, market risk premium, size, value, and momentum - from Kenneth French's data library (at http://mba.tuck.dartmouth.edu/pages/faculty/ken.french/), and the index of sentiment levels - from Jeffrey Wurgler's website (http://pages.stern.nyu.edu/ jwurgler/).

Two sets of results are reported: one for the original data (Panel A) and one for orthogonally transformed data (Panel B), using the Löwdin (1970) / Schweinler and Wigner (1970) procedure, as implemented in Chow and Klein (2010).

\begin{tabular}{|c|c|c|c|c|c|c|}
\hline \multicolumn{7}{|c|}{ Panel A: Original Data } \\
\hline Portfolio & $\begin{array}{c}\text { Sentiment } \\
\text { Level }\end{array}$ & Mean & $t$-statistic & $\begin{array}{l}\text { Standard } \\
\text { deviation }\end{array}$ & Skewness & Kurtosis \\
\hline \multirow{4}{*}{$\boldsymbol{\beta}_{+}{ }^{s}$} & High & -0.119 & -0.19 & 7.887 & 0.156 & 2.859 \\
\hline & Medium & $1.326 * * *$ & 3.49 & 5.732 & 0.112 & 1.992 \\
\hline & Low & 1.281 & 1.59 & 7.395 & 1.362 & 7.600 \\
\hline & High & 0.315 & 0.74 & 5.322 & -0.938 & 3.288 \\
\hline \multirow[t]{2}{*}{$\beta_{0}{ }^{s}$} & Medium & $1.009 * * *$ & 3.80 & 4.008 & -0.552 & 2.651 \\
\hline & Low & $1.084 *$ & 1.67 & 5.936 & 1.230 & 6.698 \\
\hline \multirow{3}{*}{$\beta_{-}^{s}$} & High & -0.130 & -0.23 & 7.127 & -0.435 & 1.800 \\
\hline & Medium & $1.307 * * *$ & 3.56 & 5.539 & -0.033 & 1.271 \\
\hline & Low & $1.255^{*}$ & 1.69 & 6.785 & 0.582 & 3.160 \\
\hline
\end{tabular}

Panel B: Orthogonally Transformed Data

\begin{tabular}{|c|c|c|c|c|c|c|}
\hline Portfolio & $\begin{array}{c}\text { Sentiment } \\
\text { Level }\end{array}$ & Mean & $t$-statistic & $\begin{array}{l}\text { Standard } \\
\text { deviation }\end{array}$ & Skewness & Kurtosis \\
\hline \multirow{3}{*}{$\left(\beta_{+}{ }^{s}\right)^{\perp}$} & High & -0.111 & -0.18 & 7.867 & 0.151 & 2.896 \\
\hline & Medium & $1.505 * * *$ & 4.12 & 5.367 & 0.218 & 2.324 \\
\hline & Low & 0.867 & 1.09 & 7.762 & 1.057 & 5.545 \\
\hline \multirow{3}{*}{$\left(\beta_{0}{ }^{s}\right)^{\perp}$} & High & 0.312 & 0.73 & 5.318 & -0.933 & 3.253 \\
\hline & Medium & $1.164 * * *$ & 4.75 & 3.603 & -0.340 & 1.848 \\
\hline & Low & 0.723 & 1.13 & 6.292 & 0.802 & 4.874 \\
\hline \multirow{3}{*}{$\left(\beta_{-}^{s}\right)^{\perp}$} & High & -0.131 & -0.23 & 7.156 & -0.431 & 1.788 \\
\hline & Medium & $1.517 * * *$ & 4.29 & 5.197 & 0.157 & 1.077 \\
\hline & Low & 0.811 & 1.09 & 7.266 & 0.364 & 2.259 \\
\hline
\end{tabular}

\footnotetext{
${ }^{36}$ One, two or three asterisks designate significance levels of $10 \%, 5 \%$ and $1 \%$, respectively.

The sentiment level is High / Medium / Low for values greater than / between / less than the $3^{\text {rd }} / 1^{\text {st }}$ quartile of the Baker and Wurgler (2007) levels index.
} 
If we decompose the time series into three sub-periods: high, medium and low (i.e. corresponding to values greater than/ between/ less than the $3^{\text {rd }} / 1^{\text {st }}$ quartile of the Baker and Wurgler, 2007 levels index), we notice that the higher excess returns on the sentiment-beta portfolios are obtained, on average, during the medium sentiment periods. Less significant results correspond to low, while for high, on average, there are no significant excess returns (see Table 3.IV). For example, for the original data, the insensitive stocks exhibit excess returns of about 1 percent per month for medium and low (statistically significant at $1 \%$ and $10 \%$, respectively), while for high, the excess returns are statistically insignificant, on average. Intuitively, during high sentiment periods, stocks are overpriced, causing lower subsequent returns (and vice versa for medium). Apparently, stocks rebound slower after low sentiment periods, compared to the more sudden rise that follows immediately after medium periods.

What if we condition on the level of sentiment and ignore the medium periods: can we still find significant stochastic dominance between sub-portfolios? The answer is affirmative. Suppose that we check the level of sentiment (in the month that follows the sorting on sentimentbetas), and decide to pursue the following three simple investment strategies for the next twelve months: if the sentiment level is high (i.e. greater than the third quartile of the BW levels index), then long $\beta_{-}^{s}$ and short $\beta_{+}^{s}$, long $\beta_{-}^{s}$ and short $\beta_{0}^{s}$, and finally, long $\beta_{+}^{s}$ and short $\beta_{0}^{s}$. If the sentiment level is low, the strategies reverse signs. Otherwise (i.e. if the sentiment level is neutral), we take no action. Next, we repeat the steps using overlapping intervals (on twelve months). 


\section{Table 3.V \\ Summary Statistics for Sentiment-Arbitrage Portfolios}

The table presents summary statistics for the monthly percentage excess returns on three sentiment-arbitrage portfolios and for their orthogonal counterparts (Panel A), and also, for pairwise differences between the aforementioned portfolios (Panel B). ${ }^{37}$ The three sentiment-arbitrage portfolios are constructed with positively sensitive vs. insensitive, insensitive vs. negatively sensitive, and positively vs. negatively sensitive stocks, based on the Baker and Wurgler (2007) sentiment levels index. We regress the excess returns of all common stocks (listed on the NYSE, AMEX, and NASDAQ), on the factors mentioned below and then sort stocks according to their sentiment betas. The top 25 percent represent the positively sensitive stocks $\left(\beta_{+}{ }^{\mathrm{s}}\right)$, the bottom 25 percent indicate the negatively sensitive stocks $\left(\beta_{-}^{\mathrm{s}}\right)$, while the rest are the insensitive stocks $\left(\beta_{0}{ }^{\mathrm{s}}\right)$.

Monthly data, ranging from January 1966 to December 2007, are obtained from the following sources: stock returns - from the CRSP database, market risk premium, size, value, and momentum factors - from Kenneth French's data library (at http://mba.tuck.dartmouth.edu/pages/faculty/ken.french/), and the index of sentiment levels - from Jeffrey Wurgler's website (http://pages.stern.nyu.edu/ jwurgler/).

The orthogonally transformed data (denoted by the symbol " ${ }^{\perp}$ ") is obtained using the Löwdin (1970) / Schweinler and Wigner (1970) procedure, as implemented in Chow and Klein (2010).

Panel A: Excess Returns on Sentiment-Arbitrage Portfolios

\begin{tabular}{|c|c|c|c|c|c|}
\hline Portfolio & Mean & $t$-statistic & $\begin{array}{l}\text { Standard } \\
\text { deviation }\end{array}$ & Skewness & Kurtosis \\
\hline$\beta_{+}{ }^{s}$ Vs. $\beta_{0}{ }^{s}$ & $0.180 *$ & 1.69 & 2.302 & -2.808 & 35.463 \\
\hline$\beta_{0}{ }^{s}$ vs. $\beta_{-}^{s}$ & $0.179 * *$ & 2.43 & 1.589 & -0.711 & 9.906 \\
\hline $\boldsymbol{\beta}_{+}{ }^{\mathrm{s}}$ Vs. $\boldsymbol{\beta}_{-}^{\text {s }}$ & -0.001 & -0.01 & 1.671 & 1.620 & 27.116 \\
\hline$\left(\beta_{+}{ }^{s}\right)^{\perp}$ VS. $\left(\beta_{0}^{s}\right)^{\perp}$ & 0.170 & 1.59 & 2.316 & -2.722 & 34.262 \\
\hline$\left(\beta_{0}^{s}\right)^{\perp}$ Vs. $\left(\beta_{-}^{s}\right)^{\perp}$ & $0.166 * *$ & 2.20 & 1.630 & -0.660 & 9.199 \\
\hline$\left(\beta_{+}{ }^{s}\right)^{\perp}$ Vs. $\left(\beta_{-}^{s}\right)^{\perp}$ & -0.005 & -0.06 & 1.670 & 1.613 & 26.777 \\
\hline
\end{tabular}

Panel B: Pairwise Differences between Sentiment-Arbitrage Portfolios

\begin{tabular}{|c|c|c|c|c|c|}
\hline Portfolio & Mean & $t$-statistic & $\begin{array}{l}\text { Standard } \\
\text { deviation }\end{array}$ & Skewness & Kurtosis \\
\hline$\left(\beta_{+}{ }^{\mathrm{s}}\right.$ vs. $\left.\beta_{0}{ }^{\mathrm{s}}\right)-\left(\beta_{0}{ }^{\mathrm{s}}\right.$ vs. $\left.\beta_{-}{ }^{\mathrm{s}}\right)$ & 0.001 & 0.01 & 1.671 & -1.620 & 27.116 \\
\hline$\left(\beta_{+}{ }^{\mathrm{s}}\right.$ vs. $\left.\beta_{0}{ }^{\mathrm{s}}\right)-\left(\beta_{+}{ }^{\mathrm{s}}\right.$ vs. $\left.\beta_{-}^{\mathrm{s}}\right)$ & 0.181 & 1.06 & 3.696 & -2.816 & 40.167 \\
\hline$\left(\beta_{0}{ }^{\mathrm{s}}\right.$ vs. $\left.\beta_{-}{ }^{\mathrm{s}}\right)-\left(\beta_{+}^{\mathrm{s}}\right.$ vs. $\left.\beta_{-}{ }^{\mathrm{s}}\right)$ & $0.180 * *$ & 1.69 & 2.302 & -2.808 & 35.463 \\
\hline$\left(\beta_{+}{ }^{\mathrm{s}} \text { vs. } \beta_{0}{ }^{\mathrm{s}}\right)^{\perp}-\left(\beta_{0}{ }^{\mathrm{s}} \text { vS. } \beta_{-}^{\mathrm{s}}\right)^{\perp}$ & 0.005 & 0.06 & 1.670 & -1.613 & 26.777 \\
\hline$\left(\beta_{+}{ }^{s} \text { vs. } \beta_{0}{ }^{s}\right)^{\perp}-\left(\beta_{+}{ }^{s} \text { vs. } \beta_{-}^{s}\right)^{\perp}$ & 0.175 & 1.03 & 3.695 & -2.780 & 39.810 \\
\hline$\left(\beta_{0}{ }^{s} \text { vs. } \beta_{-}{ }^{s}\right)^{\perp}-\left(\beta_{+}{ }^{s} \text { vs. } \beta_{-}{ }^{s}\right)^{\perp}$ & $0.170 *$ & 1.59 & 2.316 & -2.722 & 34.262 \\
\hline
\end{tabular}

${ }^{37}$ One, two or three asterisks designate significance levels of $10 \%, 5 \%$ and $1 \%$, respectively. 
Thus, we have constructed three sentiment-arbitrage portfolios: $\beta_{+}{ }^{s} v s . \beta_{0}^{s}, \beta_{0}^{s} v s . \beta_{-}^{s}$ and $\beta_{+}{ }^{s}$ vs. $\beta_{-}^{s}$ (both non-orthogonal and orthogonal). ${ }^{38}$ Table $3 . V$ reports the summary statistics. Not surprisingly, we see a primary ranking that favors the two portfolios that contain the insensitive stocks, over the portfolio $\beta_{+}^{s} v s . \beta_{-}^{s}$. Mainly, $\beta_{0}^{s} v s . \beta_{-}^{s}$ exhibits monthly average excess returns of 0.179 percent for the original, and 0.166 percent for the orthogonal data.

The MCSD test results (reported in Table 3.VI) confirm the dominance of the portfolios $\beta_{+}{ }^{s}$ vs. $\beta_{0}{ }^{s}$ and $\beta_{0}{ }^{s}$ vs. $\beta_{-}^{s}$ over $\beta_{+}{ }^{s}$ vs. $\beta_{-}^{s}$, while between $\beta_{+}{ }^{s}$ vs. $\beta_{0}{ }^{s}$ and $\beta_{0}{ }^{s} v s . \beta_{-}^{s}$ there is hardly any preference. In these two cases where we find dominance, it persists for the first six/ seven targets (for both original and orthogonal data) and amounts to approximately $0.3 / 0.2$ percent per month. Again, we point out the importance of the sentiment effect in proving the market portfolio inefficiency.

\footnotetext{
${ }^{38}$ Considering that the portfolios are constructed in a similar short/ long fashion, ignoring the transaction costs does not affect the dominance results significantly.
} 


\section{Table 3.VI \\ MCSD Test for Sentiment Arbitrage Portfolios}

The table presents the MCSD test results for pairwise comparisons between three sentiment-arbitrage portfolios constructed with positively sensitive vs. insensitive, insensitive vs. negatively sensitive, and positively vs. negatively sensitive stocks, based on the Baker and Wurgler (2007) sentiment levels index. We regress the excess returns of all common stocks (listed on the NYSE, AMEX, and NASDAQ), on the factors mentioned below and then sort stocks according to their sentiment betas. The top 25 percent represent the positively sensitive stocks $\left(\beta_{+}{ }^{\mathrm{s}}\right)$, the bottom 25 percent indicate the negatively sensitive stocks $\left(\beta_{-}^{\mathrm{s}}\right)$, while the rest are the insensitive stocks $\left(\beta_{0}{ }^{\mathrm{s}}\right)$.

Monthly data, ranging from January 1966 to December 2007, are obtained from the following sources: stock returns from the CRSP database, market risk premium, size, value, and momentum factors - from Kenneth French's data library (at http://mba.tuck.dartmouth.edu/pages/faculty/ken.french/), and the index of sentiment levels - from Jeffrey Wurgler's website (http://pages.stern.nyu.edu/ jwurgler/). Two sets of results are reported: one for the original data (Panel A) and one for orthogonally transformed data (Panel B), using the Löwdin (1970)/ Schweinler and Wigner (1970) procedure, as implemented in Chow and Klein (2010). The MCSD ordinates, corresponding to the empirical quantiles of the market return distribution, are statistically different from zero if their accompanying Z-scores (displayed in parentheses) are greater, in absolute value, than the SMM critical values of 2.560, 2.800 or 3.289, for significance levels of 10,5 or 1 percent (designated by one, two or three asterisks, respectively). ${ }^{39}$

Panel A: Original Data

\begin{tabular}{|c|c|c|c|c|c|c|c|c|c|c|}
\hline & \multicolumn{9}{|c|}{$\rho$} & \multirow[b]{2}{*}{1} \\
\hline & 0.1 & 0.2 & 0.3 & 0.4 & 0.5 & 0.6 & 0.7 & 0.8 & 0.9 & \\
\hline$\tau_{\rho}^{m}$ & -4.44 & -2.42 & -1.08 & 0.04 & 1.24 & 2.05 & 3.25 & 4.55 & 6.07 & 16.56 \\
\hline \multirow{2}{*}{$\left(\beta_{+}{ }^{s}\right.$ VS. $\left.\beta_{0}{ }^{s}\right)-\left(\beta_{0}^{s}\right.$ VS. $\left.\beta_{-}^{s}\right)$} & 0.029 & 0.035 & 0.031 & 0.021 & 0.017 & 0.035 & -0.016 & -0.025 & -0.017 & 0.001 \\
\hline & $(1.05)$ & (1.04) & $(0.82)$ & $(0.52)$ & $(0.42)$ & $(0.79)$ & $(-0.29)$ & $(-0.38)$ & $(-0.25)$ & $(0.01)$ \\
\hline \multirow{2}{*}{$\left(\beta_{+}{ }^{\mathbf{s}}\right.$ vs. $\left.\beta_{0}{ }^{s}\right)-\left(\beta_{+}{ }^{\text {s }}\right.$ vs. $\left.\beta_{-}{ }^{\mathbf{s}}\right)$} & 0.215 & 0.255 & 0.282 & 0.289 & 0.278 & 0.321 & 0.224 & 0.166 & 0.174 & 0.181 \\
\hline & $(3.12)^{* *}$ & $(3.18)^{* *}$ & $(3.31)^{* * *}$ & $(3.26)^{* *}$ & $(3.04)^{* *}$ & $(3.27)^{* *}$ & $(1.71)$ & $(1.10)$ & $(1.08)$ & (1.06) \\
\hline \multirow{2}{*}{$\left(\beta_{0}{ }^{s}\right.$ vs. $\left.\beta_{-}{ }^{s}\right)-\left(\beta_{+}{ }^{s}\right.$ vs. $\left.\beta_{-}^{s}\right)$} & 0.186 & 0.221 & 0.252 & 0.268 & 0.260 & 0.286 & 0.240 & 0.190 & 0.192 & 0.180 \\
\hline & $(3.78)^{* * *}$ & $(4.02)^{* * *}$ & $(4.35)^{* * *}$ & $(4.53)^{* * *}$ & $(4.29)^{* * *}$ & $(4.43)^{* * *}$ & $(2.91)^{* *}$ & (1.98) & $(1.89)$ & (1.69) \\
\hline
\end{tabular}

Panel B: Orthogonally Transformed Data

\begin{tabular}{|c|c|c|c|c|c|c|c|c|c|c|}
\hline & \multicolumn{10}{|c|}{$\rho$} \\
\hline & 0.1 & 0.2 & 0.3 & 0.4 & 0.5 & 0.6 & 0.7 & 0.8 & 0.9 & 1 \\
\hline$\tau_{\rho}^{m}$ & -4.44 & -2.42 & -1.08 & 0.04 & 1.24 & 2.05 & 3.25 & 4.55 & 6.07 & 16.56 \\
\hline \multirow{2}{*}{$\left(\beta_{+}^{s} \text { vs. } \beta_{0}{ }^{s}\right)^{\perp}-\left(\beta_{0}^{s} \text { vs. } \beta_{-}^{s}\right)^{\perp}$} & 0.029 & 0.034 & 0.027 & 0.015 & 0.015 & 0.034 & -0.017 & -0.024 & -0.015 & 0.005 \\
\hline & $(1.05)$ & (1.01) & $(0.73)$ & $(0.38)$ & $(0.35)$ & $(0.76)$ & $(-0.30)$ & $(-0.38)$ & $(-0.22)$ & $(0.06)$ \\
\hline \multirow{2}{*}{$\left(\beta_{+}{ }^{\mathrm{s}} \text { VS. } \beta_{0}{ }^{\mathrm{s}}\right)^{\perp}-\left(\beta_{+}^{\mathrm{s}} \text { VS. } \beta_{-}^{\mathrm{s}}\right)^{\perp}$} & 0.207 & 0.240 & 0.263 & 0.264 & 0.260 & 0.303 & 0.207 & 0.151 & 0.167 & 0.175 \\
\hline & $(3.04)^{* *}$ & $(3.00)^{* *}$ & $(3.11)^{* *}$ & $(3.00)^{* *}$ & $(2.83)^{* *}$ & $(3.07)^{* *}$ & $(1.58)$ & $(1.00)$ & (1.04) & (1.03) \\
\hline \multirow{2}{*}{$\left(\beta_{0}{ }^{\mathrm{s}} \text { VS. } \beta_{-}{ }^{\mathrm{s}}\right)^{\perp}-\left(\beta_{+}^{\mathrm{s}} \text { VS. } \beta_{-}^{\mathrm{s}}\right)^{\perp}$} & 0.178 & 0.206 & 0.236 & 0.248 & 0.245 & 0.269 & 0.224 & 0.175 & 0.182 & 0.170 \\
\hline & $(3.63)^{* * *}$ & $(3.74)^{* * *}$ & $(4.08)^{* * *}$ & $(4.19)^{* * *}$ & $(3.96)^{* * *}$ & $(4.11)^{* * *}$ & $(2.68)^{*}$ & $(1.81)$ & $(1.79)$ & (1.59) \\
\hline
\end{tabular}

${ }^{39}$ All the results in this table are reported as percentages. 


\subsection{Conclusions}

Over the years, financial theorists have been using various tests to gauge the efficiency of a given portfolio. Second (and higher) degree stochastic dominance tests have become more and more popular, due to their appealing characteristics: economically, they entail meaningful assumptions on the utility functions [non-satiation ( $\left.U^{\prime} \geq 0\right)$ and risk aversion $\left.\left(U^{\prime \prime} \leq 0\right)\right]$; statistically, they consider the entire distribution, not only a few moments (as opposed to the mean-variance analysis); another important attribute is the nonparametric approach: the utility function does not have to take any particular form (e.g. quadratic), and the distribution is not restricted (e.g. to normal). Due to the limitations in applying traditional SSD in a portfolio context, the marginal conditional stochastic dominance (MCSD) is considered the appropriate approach. ${ }^{40}$

Under MCSD, the market portfolio (or any other core portfolio) is inefficient if there is a subset of that portfolio that stochastically dominates another subset of the portfolio. Thus, investors are able to improve their expected utility by marginally reallocating the assets in their portfolios (i.e. by altering the relative weights of the dominating/ dominated assets).

In recent decades, part of the financial literature has acknowledged the existence of an investor sentiment effect. Moreover, some researchers have quantified the investor sentiment. We use the Baker and Wurgler (2007) sentiment levels index to show that the insensitive stocks marginally and conditionally dominate the positively and the negatively sensitive stocks, thus proving the market portfolio inefficiency with respect to the sentiment-beta sorted portfolios. Furthermore, we create simple sentiment-arbitrage portfolios, by taking long/ short positions on the sentiment-beta portfolios, conditional on the level of sentiment. Again, we find a dominance

\footnotetext{
40 Shalit and Yitzhaki (1994) argue that one limitation in applying traditional stochastic dominance in portfolio context comes from the case of portfolio-choice problems, where it entails infinite pairwise comparisons of alternative probability distributions. Also, once the investor is faced with new alternatives, the whole optimization procedure must be repeated and sometimes, parts of the portfolio cannot be altered.
} 
pattern between portfolios that confirms the inverse U-shaped outline. For robustness, we apply an orthogonalization procedure, as in Chow and Klein (2010), and obtain similar results as for the original data. 


\section{Chapter 4: Consumption Risk and FX Trading Returns}

\subsection{Introduction}

Following the "forward puzzle", uncovered by Fama (1984), researchers and practitioners have advanced many strategies that create profits in the foreign exchange (FX) markets. The puzzle says that the forward exchange rates represent biased estimators of the future spot exchange rates, which is equivalent to saying that high yielding currencies appreciate with respect to the home currency. The unknown aspect in the abnormal returns obtained through the aforementioned strategies is whether they are just compensation for risk.

Serban (2010) employs a strategy in the FX market, originally constructed for the stock market, which combines mean reversion and momentum. The results confirm the similarities between the two markets, suggesting a very high probability of finding the same risk factors in both markets. This supposition is in line with early studies that show similar empirical regularities in the FX and stock markets (Mussa, 1979). We use the abnormal returns obtained through that particular strategy to test for the validity of different asset pricing models in the FX market.

Given the similarities between equity and FX markets, researchers prefer to use asset pricing models originally developed for the equity markets, rather than create new ones. Villanueva (2007) investigates carry trade strategies for three currency-pairs and an equalweighted carry trade, and examines market risk only for these time series returns. He finds that apart from some strategies involving the German Mark, market risk cannot explain abnormal returns produced by carry trades. Burnside et al. (2010) also investigate risk explanations in carry trades. They use a time-series analysis, as well as the Hansen's (1982) Generalized Method of 
Moments (GMM) procedure for a panel analysis. ${ }^{41}$ In both approaches they find little evidence to support a risk-based explanation.

Mark (1985) is the first to implement the Consumption CAPM (CCAPM) in the FX market, but he rejects the model. However, a follow-up by Hodrick (1989) for UK data does not reject the model. The rest of the literature gives contrasting results.

Lustig and Verdelhan (2007) use consumption-based pricing factors and show that the model explains up to $80 \%$ of the variation in the returns on their portfolios (constructed similarly to the Fama-French portfolios, but sorted by interest rates). The apparent success of the model is intuitively appealing: when the US business cycle decelerates, causing US consumption to decrease, the US investor who holds high-yielding foreign currencies would further decrease her consumption. Therefore, low interest rate currencies provide a hedge against slowdown in domestic consumption, while high interest rate currencies systematically expose the investor to more domestic consumption risk. Figure 4.1 shows how the stock of durables and consumption of nondurables behave over the analyzed time period. It is obvious that they are correlated with periods of recession/economic growth. The Lustig and Verdelhan (2007) procedure is critiqued by Burnside (2007), who blames the weakness of the statistical identification. De Santis and Fornari (2008) use an extended dataset and a slightly different statistical method, and show that durable consumption factors generally give significant coefficients, while nondurables only occasionally. Burnside at al. (2010) cannot get any significance for the CCAPM or Yogo's (2006) Extended CCAPM for carry trade returns. However, all these papers use quarterly data.

\footnotetext{
${ }^{41}$ The panel data analysis consists of payoffs for 1 or 5 carry trade portfolios and the 25 Fama - French portfolios.
} 
Figure 4.1: Durable and Nondurable Consumption

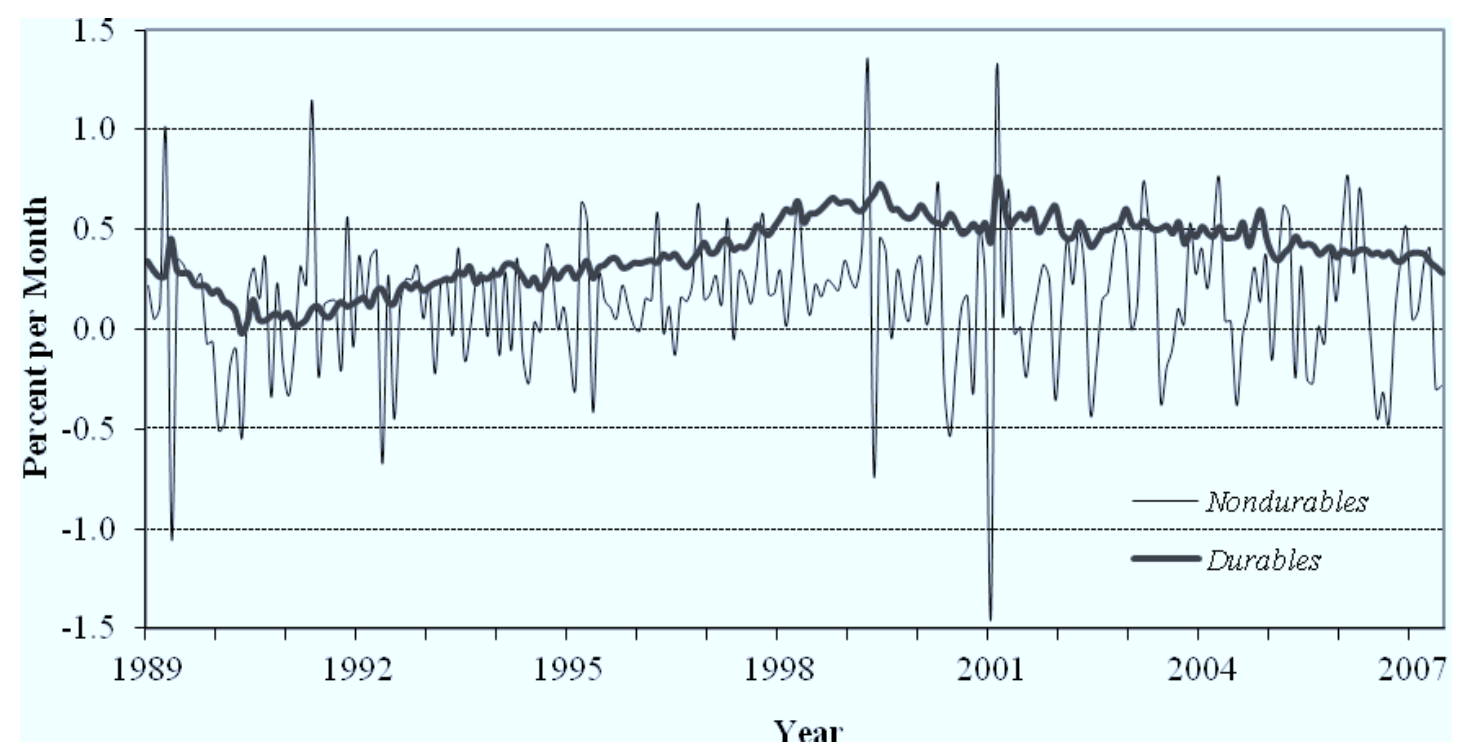

This figure reports the evolution in time, from 1989:09 to 2008:02, for the growth rate of real per capita consumption of nondurables, and for the growth rate of real per capita net stock of durables.

Our paper offers a new perspective on the connection between the current asset pricing models and the FX market by considering trading returns, very similar to equity trading returns. We test the CCAPM and Yogo's extension, as well as a very extensive list of other asset pricing models found in the literature. We find that none of the other models can perform as well as Yogo's CCAPM. Moreover, this model gives an $R^{2}$ of $99 \%$ in the first stage GMM estimation.

To begin with, we present the methodology and data in Section 2. Next, in Section 3, we test the CCAPM, Yogo's CCAPM, and their alternatives. In Section 4 we run robustness checks and, in the fifth and last section, we provide brief conclusions. 


\subsection{Methodology and Data}

\subsubsection{Combining Mean Reversion and Momentum Strategy}

The procedure used in this paper is a momentum - mean reversion combination for the FX market. This strategy was originally implemented for the stock market by Balvers and $\mathrm{Wu}$ (2006), but Serban (2010) finds that it also gives significant returns for the FX market. It starts from the Uncovered Interest Parity (UIP) deviations of currency $i$ with respect to the US dollar, at time $t+1$, denoted as $y_{t+1}^{i}$ (which are different from zero according to Fama, 1984):

$y_{t+1}^{i}=\operatorname{spot}_{t+1}^{i}-$ forward $_{t}^{i}$

where $\operatorname{spot}_{t+1}^{i}$ and forward ${ }_{t}^{i}$ are the log of the spot exchange rate and forward exchange rate, at time $t+1$ and $t$ respectively.

The strategy takes one third of the sample and runs the following pooled regression: ${ }^{42}$

$y_{t}^{i}=-\left(1-\delta^{i}\right)\left(x_{t-1}^{i}-\mu^{i}\right)+\sum_{j=1}^{J} \rho_{j}^{i}\left(x_{t-j}^{i}-x_{t-j-1}^{i}\right)+\varepsilon_{t}^{i}$,

where $x_{t}^{i}=\sum_{s=1}^{t} y_{s}^{i}, \mu^{i}$ is the average return, $J$ is the number of momentum lags, while $\delta$ and $\rho$ are the parameters to be estimated. As one can notice from equation (4.2), we can allow $\delta$ and $\rho$ to vary by country and/or by lag. Intuitively, the first part of the equation represents the mean reversion component, while the second part is the momentum component.

After running the pooled regression, the investor checks which currency has the highest expected return (Max) and which currency has the lowest expected return (Min). Then, she holds

${ }^{42}$ For more details on the procedure, see Balvers and $\mathrm{Wu}(2006)$ and Serban (2010). 
a long position on Max and a short position on Min for $K$ months. However, if all returns are positive, she only holds a long on Max. Conversely, if all returns are negative, she holds a short position on Min.

Then, the investor does the same thing for one third of the sample plus one month, updating the strategy one month at a time. The strategy is shown to give significant mean returns.

\subsubsection{Econometric Procedure}

The linear asset pricing models start from the following equation:

$E\left(y_{t}^{e i}\right)=\beta^{i} \lambda_{t}$

where $y_{t}^{e i}$ is the excess return on asset $i$ at time $t, \lambda_{t}$ represent the risk premia, and the $\beta$ 's are the factor loadings. An alternative setting gives us the opportunity to use the pricing kernel formulation. This way, we are able to test the validity of our model and to compare it with other models. Moreover, as Cochrane (2005) shows, the results of the first stage GMM estimation are very similar to the Fama - MacBeth (1973) two-pass approach, which means that using either the pricing kernel formulation, or the formulation in equation (4.3), will give very similar outcomes. The pricing kernel approach focuses on the prices of risk, $b^{j}$, rather than the beta loadings, as in the following equation:

$$
E\left(y_{t}^{e i}\right)=\sum_{j=1}^{L} b^{j} \operatorname{cov}\left(f_{t}^{j}, y_{t}^{e i}\right)
$$


Note that $L$ is the number of risk factors, while $N$ is the number of assets (i.e., in our case the number of FX portfolios). Note that equation (4.4) is the same as equation (4.3) if $\beta=\operatorname{cov}\left(y_{t}^{e i}, f_{t}\right) V_{f}^{-1}$ and $\lambda=V_{f} b$, with $V_{f}$ being the matrix of variance-covariance of the factors. Note that $\lambda$ represents the risk premia, while $b$ 's are the prices of risk.

In order to test this model, we consider the pricing kernel formulation, with $m$ (the mean discount factor) satisfying the following moment conditions:

$$
E\left(m_{t} y_{t}^{e i}\right)=0
$$

According to Cochrane (2005), we can identify $m$ in a linear factor model as:

$$
m=a-b^{\prime} f,
$$

By normalization, $a$ can be simply equal to one. The imposed moment conditions are in this case:

$$
E\left(y_{t}^{e i}-b^{\prime} f_{t} y_{t}^{e i}\right)=0
$$

We have $L$ factors and this gives us $L$ parameters $b$ to estimate. Equation (4.7) provides $N$ moment conditions. In order to test whether the model is valid or not, we need an overidentification of the parameters. In this case, we require that: $L<N$. That is to say, we need a larger number of portfolios than of factors. The GMM examines the validity of the model, using a test statistic that follows a $\chi^{2}$ distribution with the number of degrees of freedom equal to the difference between the number of moment conditions, and the number of parameters to be estimated (i.e. the number of over-identifications). Consequently, the number of degrees of freedom in this case equals to $N-L$. 
We need to make a few clarifying comments regarding this GMM procedure. First of all, we focus more on the results of the first stage estimation, and less on the second stage. Cochrane (2005) notices that the first stage estimates are consistent and can be more robust from the economic and statistical point of view. The second stage should improve the properties of estimators, but does not necessarily achieve that properly. Rubio and Lozano (2010) notice that OLS and first stage GMM minimize pricing errors better than GLS and second stage GMM, and that the first stage GMM does it better than OLS. Furthermore, many researchers in the GMM literature find that the second stage GMM does not in fact bring anything new to the table compared to the first stage GMM, in that it does not improve efficiency (e.g. Arellano and Bond, 1991; Imbens, 2002). Following other papers, we report in detail the results of the first stage GMM estimation (see Fillat and Garduno, 2005), and just plot the results of the second stage. Fillat and Garduno (2005) also notice that the asset pricing models are rejected too often based on the $J_{T}$-test. Cochrane (2005) reports the same issue (for instance, he finds that the well known Fama - French model is rejected formally by the $J_{T}$-test). Hence, the researcher should also look at other measures of fit, such as the $R^{2}$ and resemblance between the predicted and the actual returns. Our paper takes these comments into consideration.

\subsubsection{Data}

The data set consists of the spot and one-month forward exchange rates. Due to availability reasons, the data come from two sources: for the period December 1978 - December 2001, from the Bank of International Settlements (BIS) database, and for January 2002 - February 2008, 
from Datastream. ${ }^{43}$ We collect monthly data for the Canadian dollar, German mark/Euro, UK pound, and Japanese yen. The focus is on well-developed economies with liquid markets and facile implementation of currency speculation. The US dollar serves as the home currency.

Given that the strategy starts estimating mean returns based on the first third of the sample, and then progresses forward, we lose that third of the sample when obtaining returns on the portfolios. So, our analysis considers the period September 1989 - February 2008 for returns and risk factors. The monthly world market returns are obtained from the Morgan Stanley Capital International (MSCI) Barra. The risk-free rate is the one-month Treasury bill rate (from Ibbotson Associates), obtained from Kenneth French's website. In order to compute the growth rate of M1 per capita, we collect M1 data from the Board of Governors of the Federal Reserve System, and the population data from the U.S. Department of Commerce, Census Bureau. We take the FamaFrench factors: SMB (Small Minus Big), HML (High Minus Low), and RM (market risk premium) from Kenneth French's website. The real per capita growth rates in nondurable consumption and net stock of durables are calculated using data from the U.S. Department of Commerce, Bureau of Economic Analysis. The nondurable consumption includes both nondurable goods and services. The durable stock of the representative consumer, denoted by $D_{t}$, is calculated as in Yogo (2006):

$D_{t}=(1-\varphi) D_{t-1}+E_{t}$

where $\varphi$ is the depreciation rate and $E_{t}$ represents the units of durable consumption at time $t^{44}$

\footnotetext{
${ }^{43}$ It took a few years after the collapse of the Bretton Woods System to establish a floating exchange system and for speculation to be possible. That is why most of the literature considers data on the FX market starting only around 1979.

${ }^{44} \varphi$ is estimated by Yogo (2006) as around 6\% per quarter.
} 

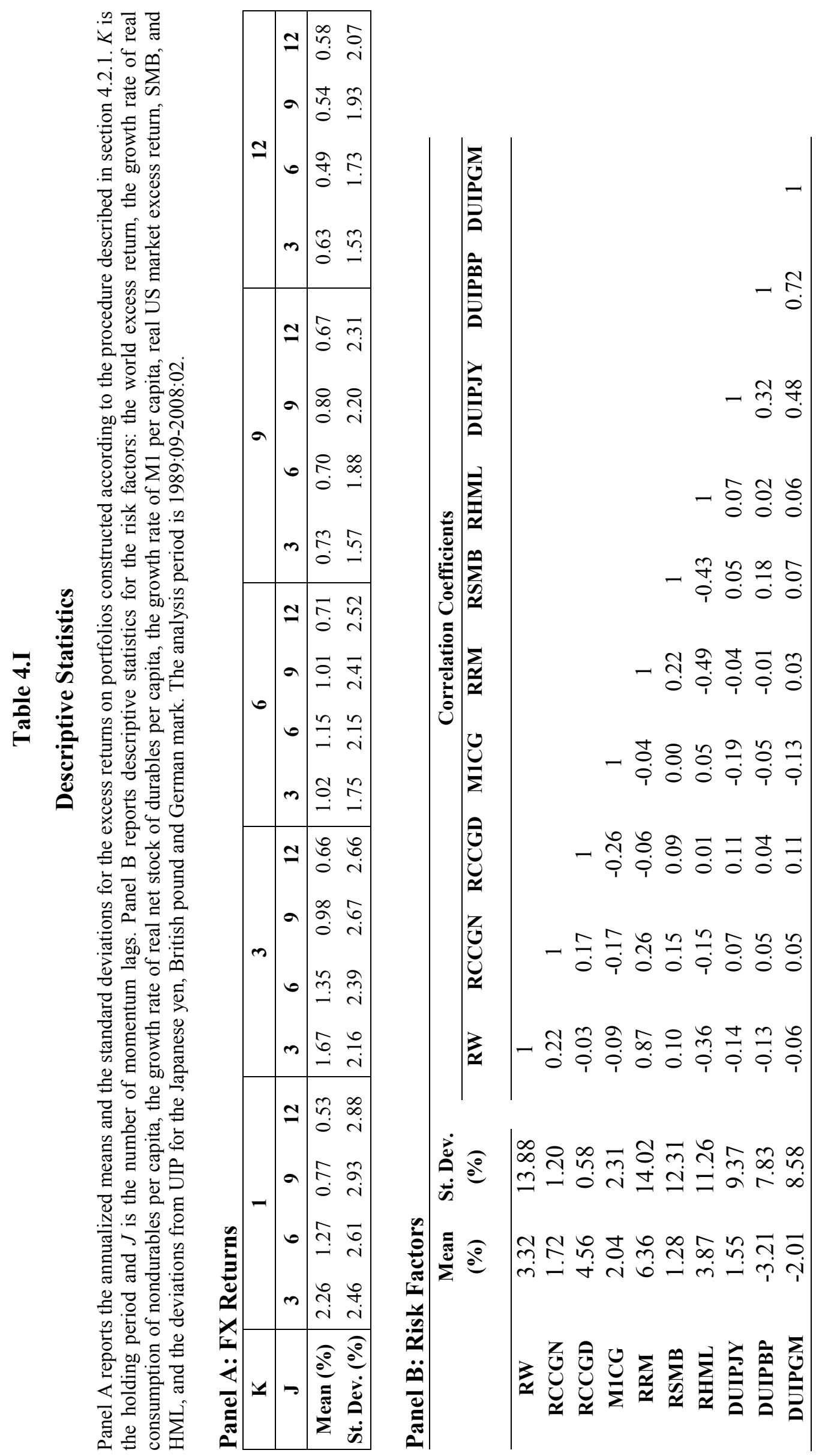
Table 4.I presents annualized descriptive statistics for our data. The highest mean return on the analyzed FX portfolios is $2.26 \%$ obtained for $K=1$ and $J=3$, while the lowest is $0.49 \%$ for $K=12$ and $J=6$. The standard deviation for the FX returns is much smaller (i.e. around 2\%), compared to that of the equity portfolios (i.e. around $11-14 \%$ ), represented by the world and U.S. market, SMB, and HML. As Yogo (2006) notes, and as intuitively expected, the variation in the nondurable consumption growth is larger than that in the durable stock growth. Panel B reports the correlations among the proposed risk factors. The largest coefficient is, as expected, between the world and the U.S. stock market (87\%).

\subsection{Testing the CCAPM, Yogo's CCAPM and Their Alternatives}

\subsubsection{Asset Pricing Models in the FX Literature}

The literature on the FX market suggests different explanations for the abnormal returns generated by the empirical failure of the UIP condition. In the carry trade literature, various authors (mentioned in the introduction) also test for the traditional Sharpe (1964) - Lintner (1965) Capital Asset Pricing Model (CAPM), as well as for the Fama-French (1993) three-factor model. Given that we deal with international markets, we also analyze the International CAPM of Solnik (1974), Stulz (1981), and Adler and Dumas (1983).

Among the pioneers to implement the CAPM in the FX market, Sweeney (1986) uses it to explain returns obtained through trading rule strategies, and finds that the market beta is not significant. Neely et al. (1997) develop a trading rule through a genetic algorithm and find that the world and country risk factors are significant only in two cases (and in one of them, the beta bears the wrong sign). 
Engel (1996) provides a comprehensive survey on models of risk premium in the FX literature. He offers explanations for two large branches of the literature: monetary explanations and consumption-based models. The first proponents of the monetary explanations for the currency risk premia are Hodrick and Srivastava (1986). They develop a two-country setting where individuals need foreign currency (provided by their own governments) in order to purchase goods produced in the other country. Hence, money shocks have an impact on consumption either through the cash-in-advance constraints, or through the "money as a store of value" channel, in the overlapping generations model (Engel, 1996). Even if the role of monetary policy has been well documented in theoretical papers, the literature on carry trades did not find much significance explaining abnormal returns (Burnside et al., 2010; Hollifield and Yaron, 2001). The influence of the monetary policy on the FX market can also be found in a separate branch of the literature, which examines the relationship between market inefficiency and central bank intervention. Szakmary and Mathur (1997) show that central bank interventions are correlated with the profitability of returns generated by moving average rules for three major currencies. However, Neely (2002) supports the conjecture that the intervention is not the cause for the FX market inefficiency.

The monetary model that we use employs two risk factors: the growth rate of M1 per capita and the market factor. We also consider other factors (i.e. federal funds rate, liquidity premium, term spread, and VXO), but the results, not reported in this paper, are very similar to what we obtain for M1. Additionally, we verify factors used in the hedge funds literature, but again, the results are not significantly different from what we report for the monetary aggregate.

However, our interest lies in the most controversial part of the literature, dedicated to the Consumption CAPM (originally derived by Lucas, 1978 and Breeden, 1979). A newer version of 
the model, proposed by Yogo (2006), introduces in the equation the nondurable consumption, the durable stock, and the market risk. Without stating that this is the only extended version of the CCAPM, we consider this approach due to its reported success in the literature (see, for instance, Lustig and Verdelhan, 2007).

\subsubsection{GMM Estimation}

Yogo's (2006) Extended CCAPM writes the expected gross excess return on asset $i$ at time $t$, as:

$$
E\left(y_{t}^{e i}\right)=b_{1} \operatorname{cov}\left(\Delta c_{t}, y_{t}^{e i}\right)+b_{2} \operatorname{cov}\left(\Delta d_{t}, y_{t}^{e i}\right)+b_{3} \operatorname{cov}\left(r_{t}^{m}, y_{t}^{e i}\right),
$$

where $\Delta c_{t}$ is the change in nondurable consumption, $\Delta d_{t}$ is the change in durable stock, and $r_{t}^{m}$ is the market excess return; $b_{1}, b_{2}$, and $b_{3}$ are the prices of risk.

Table 4.II shows the results for the first stage GMM estimation. Only the coefficient of durables stock is statistically different from zero. ${ }^{45}$ And yet, the $J_{T}$-test clearly fails to reject the null hypothesis, meaning that Yogo's CCAPM is a valid model. For comparison purposes only, we also report the results obtained for the traditional CCAPM, the CAPM, the International CAPM, the Fama-French Model and a monetary-based model. According to the $J_{T}$-test, we reject the validity of all these alternatives.

\footnotetext{
${ }^{45}$ Lustig and Verdelhan (2007) find both durables and nondurables prices of risk significantly different from zero, while De Santis and Fornari (2008) only find the durables coefficient statistically significant.
} 


\section{Table 4.II}

\section{GMM One Stage Estimation}

The GMM estimation considers the following moment conditions: $E\left(y_{t}^{e i}-b^{\prime} f_{t} y_{t}^{e i}\right)=0$ (where $y_{t}^{e i}$ is the excess return on the FX portfolios constructed through the procedure described in section 4.2.1 and $f$ are the risk factors). We estimate parameters $b$. This table reports the first-stage estimation, which assumes the weighting matrix to be equal to the identity matrix. The $J_{T}$-test checks the validity of the model. The CCAPM has the growth rate of real per capita consumption of nondurables as the only risk premium. The Extended CCAPM takes into consideration, besides the CCAPM factor, the growth rate of real per capita net stock of durables, and the US market excess return. The CAPM considers the world excess return as the only risk factor. The International CAPM introduces the currency risk to the classic CAPM. The Fama-French model assumes that there are three risk factors: US market excess return, SMB, and HML (in this order). The last model takes market excess return and M1 as the sources of risk. $T$-stats are between round brackets (one, two or three asterisks denote significance levels of $10 \%, 5 \%$ and $1 \%$, respectively), while $p$-values for the $J_{T}$-test are between square brackets. The $R^{2}$ is also reported.

\begin{tabular}{|c|c|c|c|c|c|}
\hline & & $b$ & & $R^{2}$ & $J_{T}$-Test \\
\hline \multirow{6}{*}{$\begin{array}{l}\text { Extended } \\
\text { CCAPM }\end{array}$} & \multirow{2}{*}{ ND } & -0.362 & & \multirow{6}{*}{$99 \%$} & \multirow{6}{*}{$\begin{array}{r}4.725 \\
{[1.00]}\end{array}$} \\
\hline & & $(-0.72)$ & & & \\
\hline & $\mathbf{D}$ & 2.829 & & & \\
\hline & $\mathbf{D}$ & (8.44) & ${ }^{* * *}$ & & \\
\hline & \multirow{2}{*}{$\mathbf{R M}$} & 0.020 & & & \\
\hline & & $(0.66)$ & & & \\
\hline \multirow{2}{*}{ ССАРМ } & & 9.034 & \multirow[b]{2}{*}{${ }^{* * *}$} & \multirow{2}{*}{$48 \%$} & 429.220 \\
\hline & & (3.30) & & & {$[0.00]$} \\
\hline \multirow{2}{*}{ CAPM } & & 0.228 & \multirow[b]{2}{*}{ ** } & \multirow{2}{*}{$-446 \%$} & 4503.825 \\
\hline & & $(2.40)$ & & & {$[0.00]$} \\
\hline \multirow{8}{*}{$\begin{array}{c}\text { International } \\
\text { CAPM }\end{array}$} & \multirow{2}{*}{$\mathbf{R M}$} & 0.287 & \multirow{8}{*}{ * } & \multirow{8}{*}{$-85 \%$} & \multirow{8}{*}{$\begin{array}{r}1523.432 \\
{[0.00}\end{array}$} \\
\hline & & $(0.37)$ & & & \\
\hline & Duin IV & 1.341 & & & \\
\hline & & $(0.96)$ & & & \\
\hline & \multirow{2}{*}{ DuipBP } & -2.867 & & & \\
\hline & & $(-1.66)$ & & & \\
\hline & \multirow{2}{*}{ DuipGM } & 0.637 & & & \\
\hline & & $(0.60)$ & & & \\
\hline \multirow{6}{*}{$\begin{array}{c}\text { Fama- } \\
\text { French } \\
\text { Model }\end{array}$} & \multirow{2}{*}{$\mathbf{R M}$} & 0.609 & & \multirow{6}{*}{$56 \%$} & \multirow{6}{*}{$\begin{array}{r}364.138 \\
{[0.00}\end{array}$} \\
\hline & & $(1.24)$ & & & \\
\hline & CMD & 0.831 & & & \\
\hline & МУБ & $(1.05)$ & & & \\
\hline & \multirow{2}{*}{ HML } & 1.323 & & & \\
\hline & & (1.63) & & & \\
\hline \multirow{4}{*}{$\begin{array}{c}\text { Monetary- } \\
\text { based Model }\end{array}$} & \multirow{2}{*}{$\mathbf{R M}$} & 3.101 & \multirow{4}{*}{${ }^{* * *}$} & \multirow{4}{*}{$47 \%$} & \multirow{4}{*}{$\begin{array}{r}433.647 \\
{[0.00]}\end{array}$} \\
\hline & & $(2.88)$ & & & \\
\hline & \multirow{2}{*}{ M1 } & 0.158 & & & \\
\hline & & $(0.75)$ & & & \\
\hline
\end{tabular}


We present, as well, the $R^{2}$ values for these models, calculated as:

$R^{2}=1-\frac{(\bar{y}-\hat{y})(\bar{y}-\hat{y})}{(\bar{y}-\tilde{y})(\bar{y}-\tilde{y})}$,

where $\bar{y}$ is the actual mean excess return on the portfolios, $\hat{y}$ is the estimated mean return, and $\tilde{y}$ is the average across all portfolios. The results show an $R^{2}$ of $99 \%$ for Yogo's CCAPM, much higher than that of any other alternative. This very high $R^{2}$ is also easily noticeable, looking at the graphical representation of our results in Figures 4.2 and $4.3 .^{46}$ These two exhibits present the mean estimated excess returns on the twenty FX portfolios obtained using the Serban (2010) strategy (on the horizontal axis) and the actual mean excess returns (on the vertical axis) for the first and second stage GMM, respectively. The red line is the $45^{\circ}$ line. All points should be very close to the red line if the excess returns were compensation for risk (i.e. if the models explained a large percentage of the variation in the assets' returns). In both figures it is obvious that Yogo's CCAPM is the best fitted model. One can clearly see that the predicted values of the analyzed returns are very close to the actual values.

\footnotetext{
${ }^{46}$ According to Cochrane (2005), the first stage GMM estimation should be enough for our analysis. We do however check whether the second stage GMM estimation gives significantly different results. We only present them graphically, in Figure 4.3, where it is obvious that Yogo's CCAPM remains the best fitted model. Actually, this extension of the CCAPM is the only one that gives a positive $R^{2}$ in the second stage GMM estimation (97\%).
} 
Figure 4.2: Mean Estimated Returns vs. Mean Realized Returns for the FX Portfolios Obtained through GMM First Stage Approach

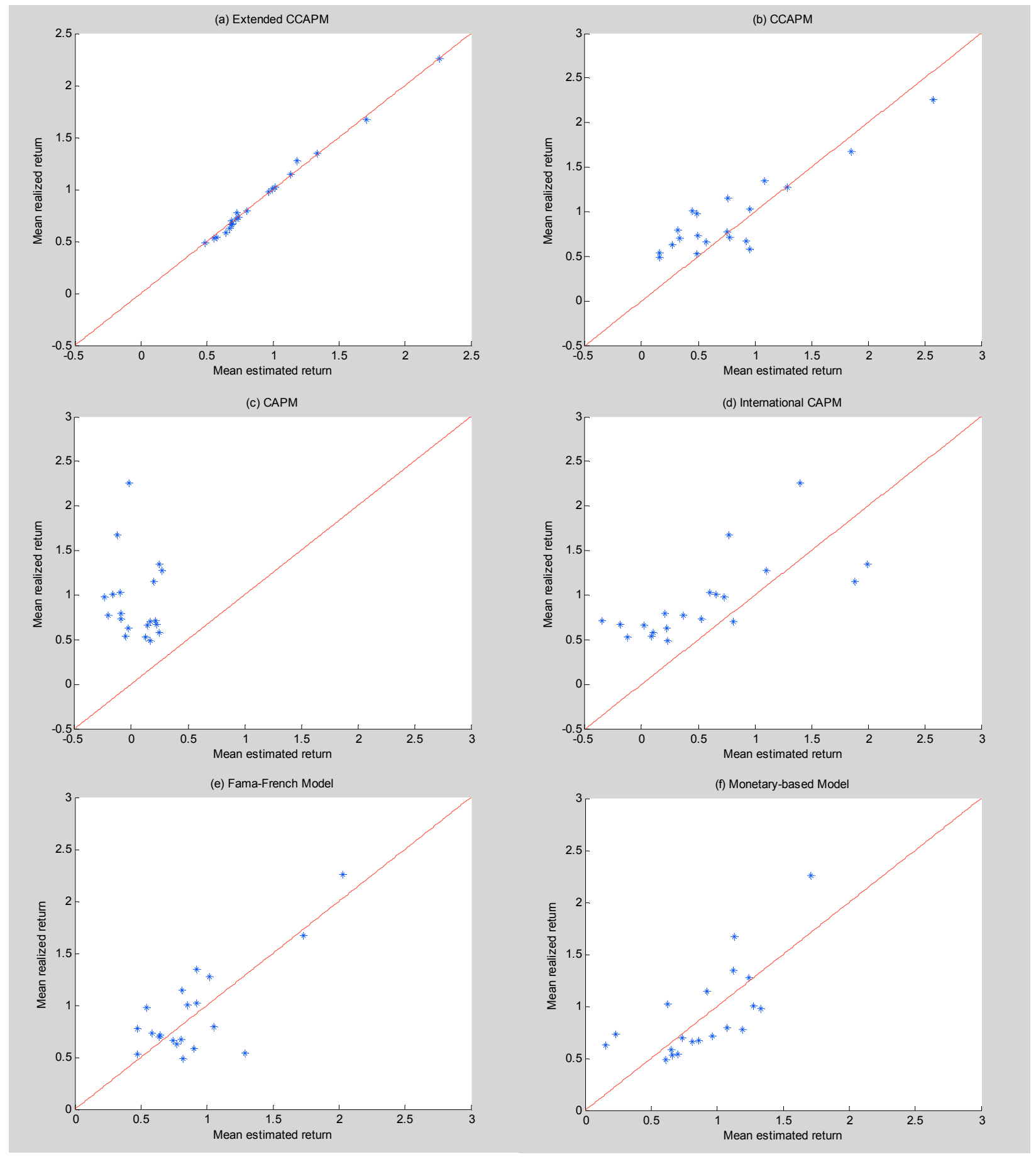

Based on the GMM first-stage procedure, we compute the mean estimated returns for the FX portfolios, constructed as described in section 4.2.1. The relationship between these averages and their corresponding realized averages are represented by the blue stars. The red line is the $45^{\circ}$ line. Each panel shows a different asset pricing model, as described in Section 4.3. 
Figure 4.3: Mean Estimated Returns vs. Mean Realized Returns for the FX Portfolios Obtained through GMM Second Stage Approach

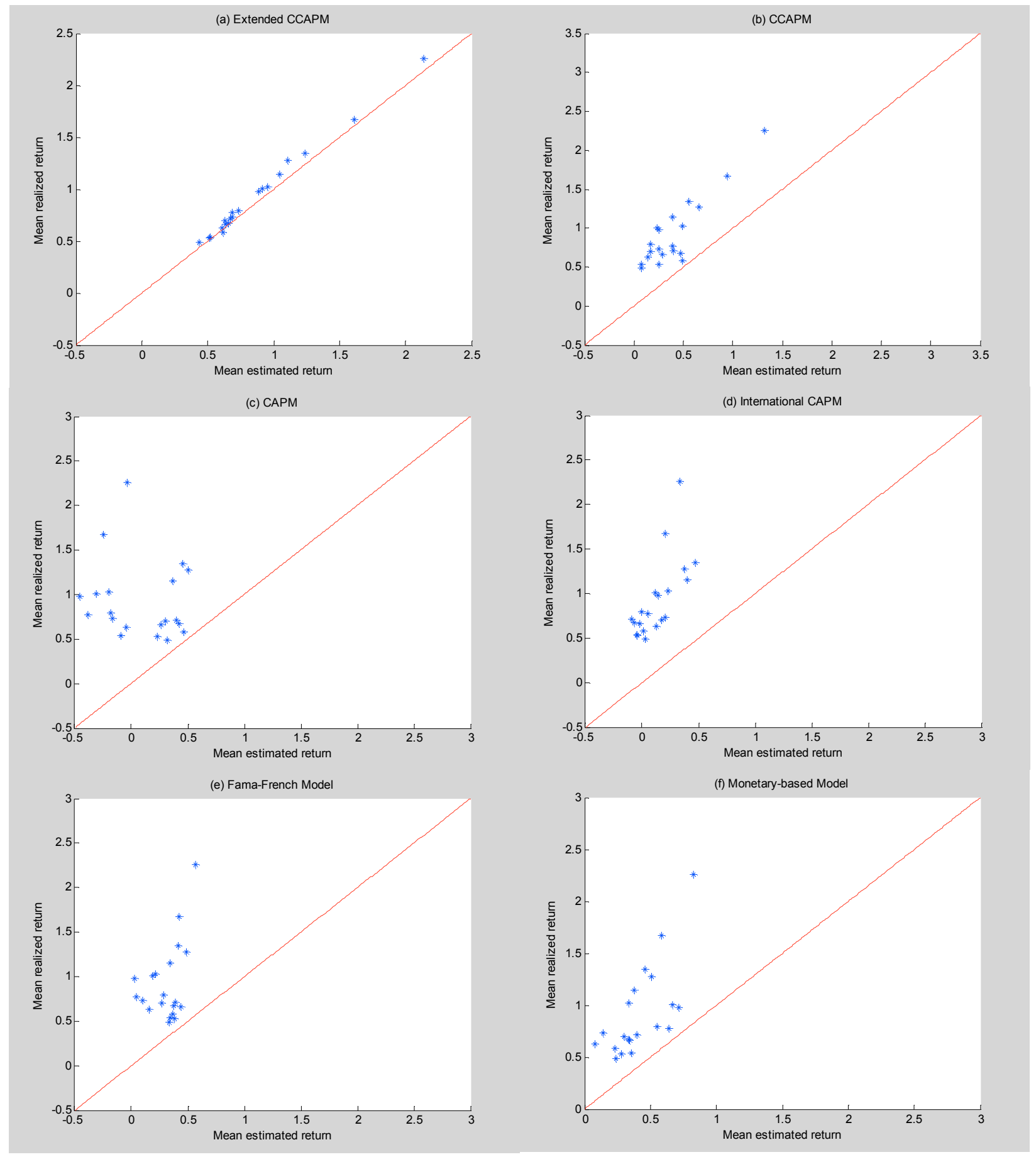

Based on the GMM second-stage procedure, we compute the mean estimated returns for the FX portfolios, constructed as described in section 4.2.1. The relationship between these averages and their corresponding realized averages are represented by the blue stars. The red line is the $45^{\circ}$ line. Each panel shows a different asset pricing model, as described in Section 4.3. 


\subsubsection{Model Comparison}

When comparing asset pricing models, Lewellen et al. (2010) note that one cannot simply look at the cross-sectional measures of fit. If the analyzed portfolios have a strong factor structure, the pricing errors are idiosyncratic and probably not correlated with the factors of the asset pricing model. Consequently, the model betas and the "true" betas are linearly correlated, leading to, for instance, a high $R^{2}$. As reported above, Table 4.II shows a very high $R^{2}$ for Yogo's CCAPM. This could suggest that this model is the best in explaining FX returns. However, a high $R^{2}$ does not necessarily mean that we have identified the "true" model. Comparing different asset pricing models with a different number of factors is not as easy as just comparing measures of fit for these models. Lewellen et al. (2010) give multiple solutions to this problem.

The first is to include other portfolios into the test. We add the 25 Fama-French portfolios sorted by size and value (obtained from Kenneth French's website). These portfolios are known to be explained in large proportion by the Fama-French factors. Table 4.III provides the measures of fit. The only valid model according to the $J_{T}$-test is again Yogo's CCAPM. As for the $R^{2}$, after adding the 25 Fama-French portfolios, the only model that continues to exhibit a positive $R^{2}$ is Yogo's CCAPM (97\%), indicating that this is indeed the model that could explain the FX returns, as predicted by Lustig and Verdelhan (2007). In Figures 4.4 and 4.5, the blue stars represent the $20 \mathrm{FX}$ portfolios, while the green bubbles symbolize the 25 Fama-French portfolios. Again, Yogo's CCAPM shows the best fit in the first stage (Figure 4.4) and second stage (Figure 4.5) GMM estimation. 


\section{Table 4.III}

\section{Models Comparison}

This table reports the comparison among the analyzed models. The CCAPM has the growth rate of real per capita consumption of nondurables as the only risk premium. The Extended CCAPM takes into consideration, besides the CCAPM factor, the growth rate of real per capita net stock of durables, and the US market excess return. The CAPM considers the world excess return as the only risk factor. The International CAPM introduces the currency risk to the classic CAPM. The Fama-French model assumes that there are three risk factors: US market excess return, SMB, and HML (in this order). The last model takes market excess return and M1 as the sources of risk. We study excess returns on the FX portfolios constructed through the procedure described in section 4.2 .1 and the Fama-French 25 portfolios sorted on size and value. We report the $R^{2}$ for the first stage GMM estimation, as well as the $J_{T}$-test and its p-value. The $90 \%$ C.I. (between square brackets) are obtained from 1,000 draws of multivariate normal random factors.

\begin{tabular}{|c|c|c|c|}
\hline & & \\
\hline \multirow{4}{*}{ Extended CCAPM } & \multirow{2}{*}{ FX only } & 0.99 & 4.73 \\
\hline & & {$[-0.81 ;-0.67]$} & {$[1,380.23 ; 1,488.71]$} \\
\hline & \multirow{2}{*}{ FX and $25 F F$} & 0.97 & 34.06 \\
\hline & & {$[-2.95 ;-2.78]$} & {$[4,220.87 ; 4,414.84]$} \\
\hline \multirow{4}{*}{ CCAPM } & \multirow{2}{*}{ FX only } & 0.48 & 429.22 \\
\hline & & {$[-3.37 ;-3.22]$} & {$[3,477.37 ; 3,598.87]$} \\
\hline & \multirow{2}{*}{ FX and $25 F F$} & -2.23 & 3607.41 \\
\hline & & {$[-6.05 ;-5.84]$} & {$[7,644.95 ; 7,884.70]$} \\
\hline \multirow{4}{*}{ CAPM } & \multirow{2}{*}{ FX only } & -4.46 & 4503.83 \\
\hline & & {$[-3.37 ;-3.22]$} & {$[3,477.37 ; 3,598.87]$} \\
\hline & \multirow{2}{*}{ FX and $25 F F$} & -3.73 & 5287.31 \\
\hline & & {$[-6.05 ;-5.84]$} & {$[7,644.95 ; 7,884.70]$} \\
\hline \multirow{4}{*}{ International CAPM } & \multirow{2}{*}{ FX only } & -0.85 & 1523.43 \\
\hline & & {$[-0.04 ; 0.07]$} & {$[766.84 ; 854.55]$} \\
\hline & \multirow{2}{*}{ FX and $25 F F$} & -2.15 & 3517.66 \\
\hline & & {$[-2.27 ;-2.12]$} & {$[3,488.66 ; 3,657.03]$} \\
\hline \multirow{4}{*}{ Fama-French Model } & \multirow{2}{*}{ FX only } & 0.56 & 364.14 \\
\hline & & {$[-0.81 ;-0.67]$} & {$[1,380.23 ; 1,488.71]$} \\
\hline & \multirow{2}{*}{ FX and $25 F F$} & -2.72 & 4159.42 \\
\hline & & {$[-2.95 ;-2.78]$} & {$[4,220.87 ; 4,414.84]$} \\
\hline \multirow{4}{*}{ Monetary-based Model } & \multirow{2}{*}{ FX only } & 0.47 & 433.65 \\
\hline & & {$[-1.82 ;-1.67]$} & {$[2,201.90 ; 2,326.78]$} \\
\hline & \multirow{2}{*}{ FX and $25 F F$} & -0.18 & 1317.58 \\
\hline & & {$[-4.15 ;-3.95]$} & {$[5,532.02 ; 5,754.55]$} \\
\hline
\end{tabular}




\section{Figure 4.4: Mean Estimated Returns vs. Mean Realized Returns for the FX Portfolios and the 25 Fama-French Portfolios (GMM First Stage)}

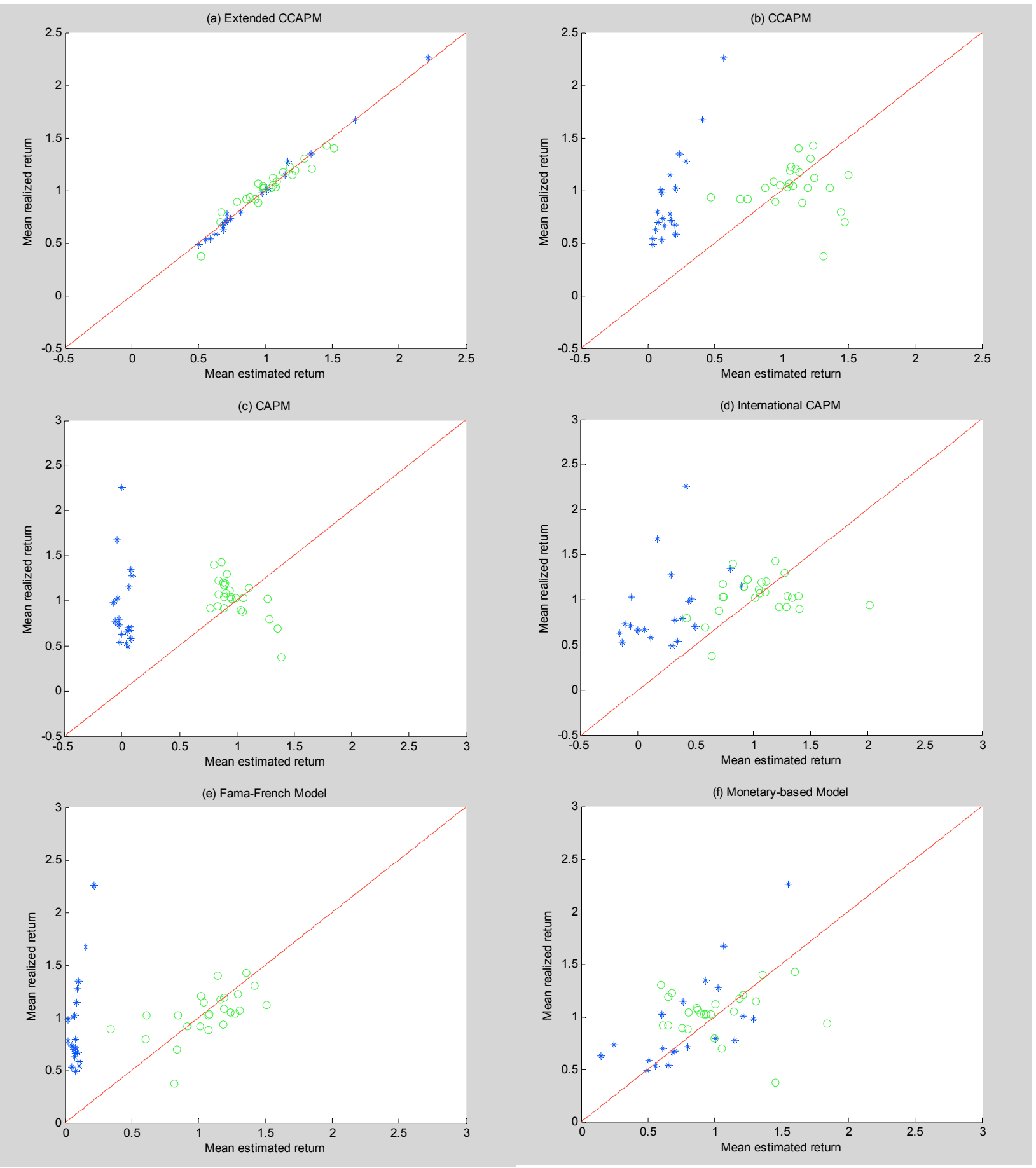

Based on the GMM first-stage procedure, we compute the mean estimated returns for the FX portfolios constructed as described in section 4.2.1 and the mean estimated returns on the 25 Fama-French portfolios, sorted by size and value. The relationship between the FX estimated averages and their corresponding realized averages are represented by the blue stars. We also graph the relationship between the mean estimated returns on the 25 FamaFrench portfolios and their corresponding realized averages, as green circles. The red line is the $45^{0}$ line. Each panel shows a different asset pricing model, as described in Section 4.3. 


\section{Figure 4.5: Mean Estimated Returns vs. Mean Realized Returns for the FX Portfolios and the 25 Fama-French Portfolios (GMM Second Stage)}
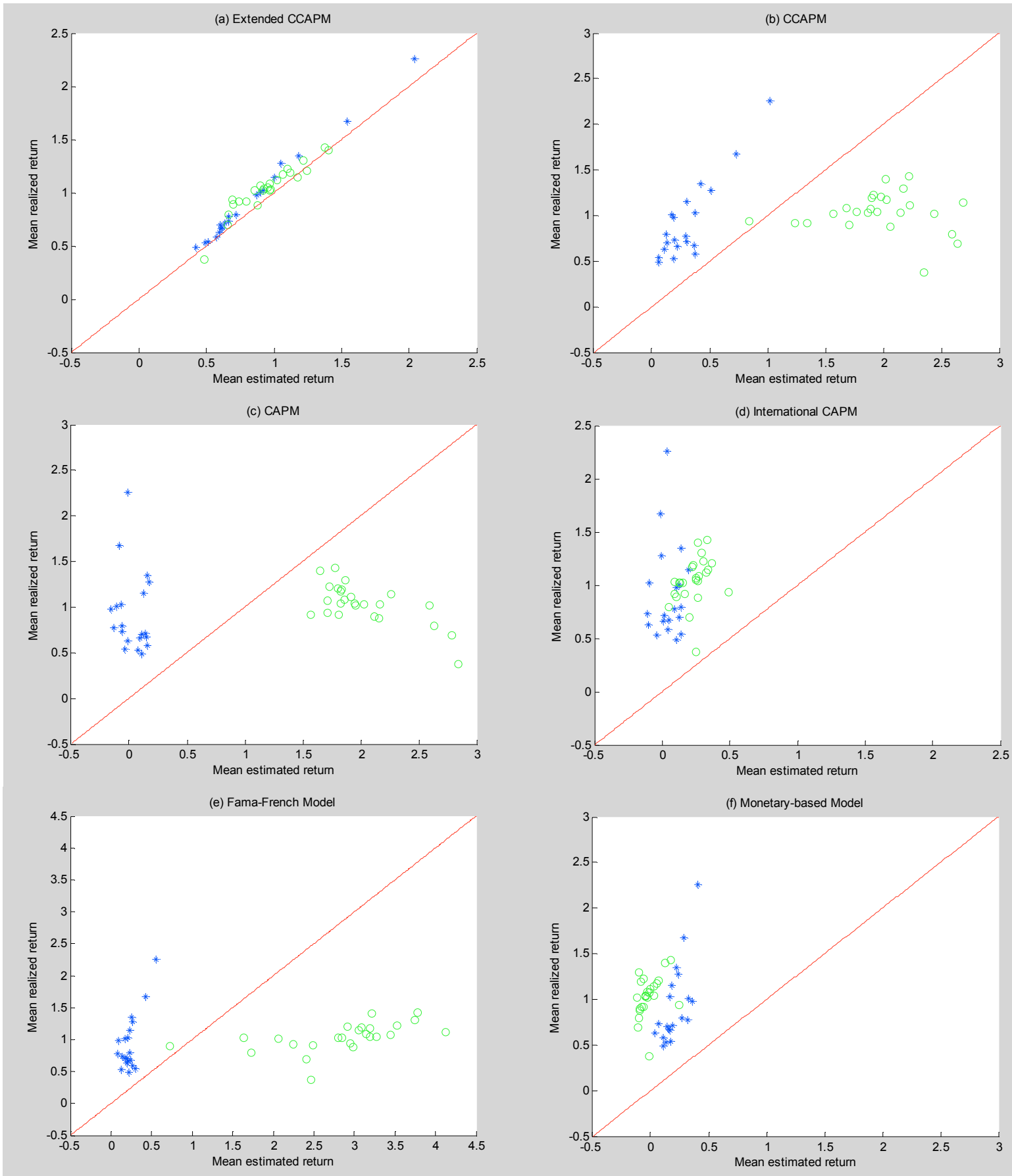

Based on the GMM second-stage procedure, we compute the mean estimated returns for the FX portfolios constructed as described in section 4.2.1 and the mean estimated returns on the 25 Fama-French portfolios, sorted by size and value. The relationship between the FX estimated averages and their corresponding realized averages are represented by the blue stars. We also graph the relationship between the mean estimated returns on the 25 FamaFrench portfolios and their corresponding realized averages, as green circles. The red line is the $45^{0}$ line. Each panel shows a different asset pricing model, as described in Section 4.3. 
A second solution to the issues highlighted in Lewellen et al. (2010) is to check whether the coefficients have an economic significance. We can address this problem by looking again at Table 4.II. This criterion rejects the International CAPM, the Fama-French model, and the relevant component of the Monetary-based model.

The third solution considers confidence intervals (C.I.) for the measures of fit instead of point estimates only. As Lewellen et al. (2010) suggest, researchers should not focus entirely on rejecting or accepting the null, and neglect the power of their tests. A C.I. shows the range of the "true" parameters consistent with the data. We compute the $90 \%$ C.I. for the first stage $R^{2}$ and $J_{T^{-}}$ test, obtained in 1,000 draws of multivariate standard normally distributed factors. The results are reported in Table 4.III. The CAPM and the International CAPM do more poorly than a random choice of factors when it comes to explaining the variation in the returns. The $J_{T}$-test shows a similar picture, in that the models that perform well according to the $R^{2}$ criterion have lower pricing errors (the $J_{T}$-test is below the lower end of the C.I.). Yogo's CCAPM is the top performer from this point of view. We can safely conclude that Yogo's extension of the CCAPM is indeed the best fitted model.

Another alternative for testing the performance of one model compared to another is the $J_{T}$ Difference test (Newey-West, 1987). It tests whether adding extra factors can improve the efficacy of the model. Hence, we are testing whether $b_{1}=\ldots=b_{n}=0$ in:

$$
E\left(y_{t}^{e i}\right)=\sum_{i=1}^{n} b^{i} \operatorname{cov}\left(f_{t}^{i}, y_{t}^{e i}\right)+\sum_{i=n+1}^{L} b^{i} \operatorname{cov}\left(f_{t}^{i}, y_{t}^{e i}\right),
$$


The $J_{T}$ Difference test is the difference between the $J_{T}$-test for the unrestricted model and the $J_{T}$ - test of the restricted model, and follows a $\chi^{2}$ distribution with the number of degrees of freedom equal to the number of restrictions (i.e. $n)$.

Table 4.IV tests whether adding additional factors to the market factor makes statistical sense. Yogo's CCAPM and the monetary model perform better than the CCAPM. Less significantly, so does the Fama-French Model. The International CAPM, however, fails to bring any statistical relevance to the classic CAPM. The last row of the table shows that the factors introduced by Yogo to the traditional CCAPM undeniably carry statistical significance in explaining FX returns.

\section{Table 4.IV \\ $J_{T}$ Difference Test}

This table reports the $J_{T}$ difference tests among the analyzed models. We test if the new factors of risk added by the unrestricted model (the alternative hypothesis) give statistically different from zero parameters. The degrees of freedom represent the number of additional factors of risk in the unrestricted model compared to the restricted model. The last column presents the p-value. The CCAPM has the growth rate of real per capita consumption of nondurables as the only risk premium. The Extended CCAPM takes into consideration, besides the CCAPM factor, the growth rate of real per capita net stock of durables, and the US market excess return. The CAPM considers the world excess return as the only risk factor. The International CAPM introduces the currency risk to the classic CAPM. The Fama-French model assumes that there are three risk factors: US market excess return, SMB, and HML (in this order). The last model takes market excess return and M1 as the sources of risk. We study excess returns on the FX portfolios constructed through the procedure described in section 4.2.1.

\begin{tabular}{llccc}
\hline $\begin{array}{c}\text { Restricted } \\
\text { Model }\end{array}$ & \multicolumn{1}{c}{$\begin{array}{c}\text { Unrestricted model } \\
\text { (Alternative) }\end{array}$} & $\begin{array}{c}\chi^{\mathbf{2}} \text { Difference (Newey } \\
\text { - West, 1987) }\end{array}$ & $\begin{array}{c}\text { Degrees of } \\
\text { freedom }\end{array}$ & p-value \\
\hline CAPM & Extended CCAPM & 201.72 & 2 & 0.000 \\
CAPM & Monetary - based Model & 9.67 & 1 & 0.002 \\
CAPM & Fama-French Model & 5.63 & 2 & 0.060 \\
CAPM & International CAPM & 1.39 & 3 & 0.707 \\
CCAPM & Extended CCAPM & 184.63 & 2 & 0.000 \\
\hline
\end{tabular}




\subsection{Robustness Checks}

In January 1999, the FX market changed drastically with the introduction of the Euro and the demise of currencies that were playing a very important role up to that point in time. Table $4 . \mathrm{V}$ provides GMM results from the first-stage estimation for two sub-periods: prior to January 1999 and after January 1999. The results are not different for the two sub-periods, compared to the whole period considered in Table 4.II. Again, Yogo's CCAPM is not rejected by the $J_{T}-$ test and has a very high $R^{2}$ for both periods (approximately $98 \%$ and $100 \%$, respectively).

\section{Table 4.V}

\section{GMM First Stage - Sub-periods}

This table reports the results of the first-stage GMM approach for the two specified sub-periods. The GMM estimation considers the following moment conditions: $E\left(y_{t}^{e i}-b^{\prime} f_{t} y_{t}^{e i}\right)=0$ (where $y_{t}^{e i}$ is the excess return on the FX portfolios constructed through the procedure described in section 4.2.1 and $f$ are the risk factors). We estimate parameters $b$. The $J_{T}$ test checks the validity of the model. The CCAPM has the growth rate of real per capita consumption of nondurables as the only risk premium. The Extended CCAPM takes into consideration, besides the CCAPM factor, the growth rate of real per capita net stock of durables, and the US market excess return. The CAPM considers the world excess return as the only risk factor. The International CAPM introduces the currency risk to the classic CAPM. The Fama-French model assumes that there are three risk factors: US market excess return, SMB, and HML (in this order). The last model takes market excess return and M1 as the sources of risk. $T$-stats are between round brackets (one, two or three asterisks denote significance levels of $10 \%, 5 \%$ and $1 \%$, respectively), while $p$-values for the $J_{T}$-test are between square brackets. The $R^{2}$ is also reported.

\begin{tabular}{|c|c|c|c|c|c|c|c|c|c|}
\hline & \multicolumn{4}{|c|}{ 1989:09 - 1998:12 } & \multicolumn{4}{|c|}{ 1999:01 - 2008:02 } \\
\hline & & b & & $R^{2}$ & $J_{T}$-Test & $b$ & & $R^{2}$ & $J_{T}$-Test \\
\hline \multirow{3}{*}{$\begin{array}{l}\text { Extended } \\
\text { CCAPM }\end{array}$} & ND & $\begin{array}{r}-0.226 \\
(-0.29)\end{array}$ & \multirow{3}{*}{$* * *$} & \multirow{3}{*}{$98 \%$} & \multirow{3}{*}{$\begin{array}{r}8.814 \\
{[0.95]}\end{array}$} & $\begin{array}{r}0.546 \\
(0.80)\end{array}$ & & \multirow{3}{*}{$100 \%$} & \multirow{3}{*}{$\begin{array}{r}1.027 \\
{[1.00]}\end{array}$} \\
\hline & D & $\begin{array}{r}3.895 \\
(6.70)\end{array}$ & & & & $\begin{array}{r}1.696 \\
(9.22)\end{array}$ & $* * *$ & & \\
\hline & $\mathbf{R M}$ & $\begin{array}{r}0.000 \\
(0.01)\end{array}$ & & & & $\begin{array}{r}-0.050 \\
(-1.01)\end{array}$ & & & \\
\hline \multicolumn{2}{|l|}{ ССАРМ } & $\begin{array}{r}8.921 \\
(2.60) \\
\end{array}$ & $* * *$ & $50 \%$ & $\begin{array}{r}285.836 \\
{[0.00]} \\
\end{array}$ & $\begin{array}{r}6.362 \\
(2.66) \\
\end{array}$ & \multirow[t]{2}{*}{$* * *$} & $-64 \%$ & $\begin{array}{r}477.523 \\
{[0.00]} \\
\end{array}$ \\
\hline CAPM & & $\begin{array}{r}0.431 \\
(3.44) \\
\end{array}$ & $* * *$ & $-489 \%$ & $\begin{array}{r}3349.654 \\
{[0.00]} \\
\end{array}$ & $\begin{array}{r}-0.181 \\
(-1.22) \\
\end{array}$ & & $-284 \%$ & $\begin{array}{r}1121.545 \\
{[0.00]}\end{array}$ \\
\hline \multirow{5}{*}{$\begin{array}{c}\text { International } \\
\text { CAPM }\end{array}$} & $\mathbf{R M}$ & $\begin{array}{r}1.062 \\
(0.74)\end{array}$ & & \multirow{5}{*}{$-99 \%$} & \multirow{5}{*}{$\begin{array}{r}1133.791 \\
{[0.00]}\end{array}$} & $\begin{array}{r}-0.620 \\
(-1.16)\end{array}$ & & \multirow{5}{*}{$91 \%$} & \multirow{5}{*}{$\begin{array}{r}25.007 \\
{[0.07]}\end{array}$} \\
\hline & Duin IY & 2.814 & & & & 0.158 & & & \\
\hline & 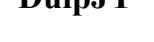 & $(0.87)$ & & & & $(0.12)$ & & & \\
\hline & DuipBP & $\begin{array}{r}-1.082 \\
(-0.56)\end{array}$ & & & & $\begin{array}{r}-2.574 \\
(-1.20)\end{array}$ & & & \\
\hline & DuipGM & $\begin{array}{r}-0.518 \\
(-0.36)\end{array}$ & & & & $\begin{array}{r}1.155 \\
(1.49)\end{array}$ & & & \\
\hline
\end{tabular}




\begin{tabular}{|c|c|c|c|c|c|c|c|c|}
\hline & & \multicolumn{4}{|c|}{ 1989:09 - 1998:12 } & \multicolumn{3}{|c|}{ 1999:01 - 2008:02 } \\
\hline & & $b$ & & $R^{2}$ & $J_{T}$-Test & $b$ & $R^{2}$ & $J_{T}$-Test \\
\hline \multirow{3}{*}{$\begin{array}{l}\text { Fama- } \\
\text { French } \\
\text { Model }\end{array}$} & $\mathbf{R M}$ & $\begin{array}{r}0.864 \\
(2.36)\end{array}$ & ** & \multirow{3}{*}{$-43 \%$} & \multirow{3}{*}{$\begin{array}{r}813.676 \\
{[0.00]}\end{array}$} & $\begin{array}{r}0.369 \\
(0.71)\end{array}$ & \multirow{3}{*}{$48 \%$} & \multirow{3}{*}{$\begin{array}{r}151.035 \\
{[0.00]}\end{array}$} \\
\hline & SMB & $\begin{array}{r}0.325 \\
(0.60)\end{array}$ & & & & $\begin{array}{r}0.511 \\
(1.79)\end{array}$ & & \\
\hline & HML & $\begin{array}{r}0.974 \\
(1.26)\end{array}$ & & & & $\begin{array}{r}0.663 \\
(1.38)\end{array}$ & & \\
\hline \multirow{3}{*}{$\begin{array}{c}\text { Monetary- } \\
\text { based Model }\end{array}$} & & 3.383 & \multirow{3}{*}{$* *$} & \multirow{3}{*}{$75 \%$} & \multirow{3}{*}{$\begin{array}{r}139.627 \\
{[0.00]}\end{array}$} & 2.110 & \multirow{3}{*}{$-31 \%$} & \multirow{3}{*}{$\begin{array}{r}382.922 \\
{[0.00}\end{array}$} \\
\hline & KM & $(2.39)$ & & & & $(1.57)$ & & \\
\hline & M1 & $\begin{array}{r}0.242 \\
(1.15) \\
\end{array}$ & & & & $\begin{array}{r}-0.088 \\
(-0.45)\end{array}$ & & \\
\hline
\end{tabular}

\subsection{Conclusions}

The literature has documented different explanations for the profitability of strategies in the FX market. One of them is the presence of a "peso" problem, particularly appealing to carry trade researchers. Burnside et al. (2010) explain that carry trade positive returns might materialize due to the fact that the rare event of a large appreciation of the foreign currency just does not happen. They find evidence in this regard, rejecting the possibility of a second explanation that these returns are simply compensation for bearing risk.

The appropriate measures of risk are another side of the story. The theoretical background for the sources of risk in the FX market is weak. The only intuitive approaches come from the equity markets, or from consumption/monetary-based models.

We take these issues and give them a new spin. The trading strategy that we use resembles slightly the carry trades, but it is in fact very different from any other strategy in the FX market, and more similar to strategies employed in the stock market. Is it possible that the returns obtained through this approach are due to the "peso" problems? Since this strategy behaves similarly in the stock and FX markets, we can only assume that the reasons for obtaining 
the abnormal returns are the same for the two markets. Hence, the only plausible explanation besides market inefficiency is compensation for risk.

We find that the Fama-French model, International CAPM and monetary explanations do a poor job in explaining these returns. However, Yogo's extension of the CCAPM performs very well. To the best of our knowledge, our paper is one of the most comprehensive studies in the FX literature, analyzing factors of risk. We believe that it helps clarifying which asset pricing models can or cannot be used in the FX literature. 


\section{Chapter 5: Conclusions}

This dissertation addresses various aspects of linear asset pricing models, aiming to improve on the existing literature.

In Chapter 2 we propose an optimal orthogonalization algorithm (adapted from the Schweinler and Wigner (1970)/ Löwdin (1970) symmetric procedure), whose lack of popularity in economics and finance is not easily comprehensible. Mostly used so far in the quantum chemistry and in the wavelet literature, this procedure is not sequence-dependent, a characteristic that can prove to be essential, depending on its application. To understand fully the distinction between a sequence-dependent, and a democratic (i.e. egalitarian) process, we should take a very simple example: the human mind is able to recognize different objects, irrespective of the order in which they appear. If a person sees, for instance, a monitor, a keyboard, and a central unit - in any order - she will understand that she has a computer in front of her. Conversely, if a person sees the following initials: K, R, and F (in this order) she might identify Kenneth Ronald French, or in a different order (R, F, and K) she might think of Rudolf Florian Klein (if, of course, she heard of both of us). This crucial characteristic that our method possesses does not come at the expense of "disturbing" the initial set of factors more than other techniques. On the contrary, it guarantees an optimal resemblance with the original set of variables. As an application, we use this procedure to decompose the coefficient of determination $\left(R^{2}\right)$, which can be considered a standardized measure of systematic risk. Thus, we are able to examine the impact of each individual factor on the return variation of risky assets, and to answer key questions that arise in the literature. For instance, a high $R^{2}$ does not imply a proper diversification: one factor might capture a large proportion of the variation, while the other factors that are considered might be 
insignificant (signaled by small values of the decomposed $R$-squares), and other relevant determinants might be left out.

In Chapter 3 we acknowledge the importance of the Marginal Conditional Stochastic Dominance (MCSD) tests, whose advantages over the traditional mean-variance analysis are thoroughly reviewed in Chow et al. (2008). Using the Baker and Wurgler (2007) index of sentiment levels, we find that both positively and negatively sentiment sensitive stocks are conditionally and stochastically dominated by sentiment insensitive stocks (both for the original and for the orthogonally-transformed factors). This pattern confirms the inverse U-shaped outline attested by Glushkov (2006). Furthermore, we find dominance among sentiment-arbitrage portfolios, constructed with positively sensitive vs. insensitive, insensitive vs. negatively sensitive, and positively vs. negatively sensitive stocks. Thus, we conclude that the market portfolio is stochastically inefficient. The results, besides reaffirming the existence and the importance of a sentiment effect in the US equity market, suggest that fundamental indexation using a sentiment metric may perform better than the capitalization-weighted indexation.

In Chapter 4 we enter the debate on whether the abnormal returns obtained through various strategies conducted in the FX market are compensation for risk, or just some market inefficiency. We use Serban's (2010) strategy that combines mean reversion and momentum, an approach that is initially implemented for the stock market by Balvers and $\mathrm{Wu}$ (2006). We compare a number of asset pricing models (usually employed for the equity market) and we find that Yogo's (2006) Extended Consumption-CAPM is clearly the most accurate in explaining the abnormal returns. This result is in line with Lustig and Verdelhan (2007) who show that consumption growth is a key concept in understanding exchange rates. 


\section{References}

Acharya, V.V. and Pedersen, L.H., 2005, Asset pricing with liquidity risk, Journal of Financial Economics, 77, 375-410.

Adler, M. and Dumas, B., 1983, International portfolio choice and corporation finance: A synthesis, The Journal of Finance, 38, 925-984.

Arellano, M. and Stephen B., 1991, Some Tests of Specification for Panel Data: Monte Carlo Evidence and an Application to Employment Equations, The Review of Economic Studies $58,277-297$.

Baker, M. and Wurgler, J., 2006, Investor sentiment and the cross-section of stock returns, The Journal of Finance, 61, 1645-1680.

Baker, M. and Wurgler, J., 2007, Investor sentiment in the stock market, Journal of Economic Perspectives, 21, 129-151.

Balvers, R.J. and Wu, Y., 2006, Momentum and mean reversion across national equity markets, Journal of Empirical Finance 13, 24-48.

Balvers, R.J., Wu, Y. and Gilliland, E., 2000, Mean reversion across national stock markets and parametric contrarian investment strategies, The Journal of Finance, 55, 745-772.

Best, R.J., Best, R.W., Yoder, J.A., 2000, Value stocks and market efficiency, Journal of Economics and Finance, 24, 28-35.

Black, F., 1990, Equilibrium exchange rate hedging, The Journal of Finance, 45, 899-909.

Boubakri, N. and Ghouma, H., 2010, Control/ownership structure, creditor rights protection, and the cost of debt financing: International evidence, Journal of Banking \& Finance, 34, 2481-2499.

Breeden, D.T., 1979, An intertemporal asset pricing model with stochastic consumption and investment opportunities, Journal of Financial Economics, 7, 265-296.

Brown, G.W. and Cliff, M.T., 2004, Investor sentiment and the near-term stock market, Journal of Empirical Finance, 11, 1-27.

Brown, G.W. and Cliff, M.T., 2005, Investor sentiment and asset valuation, The Journal of Business, 78, 405-440. 
Burnside, A.C., Eichenbaum, M., Kleshchelski, I., and Rebelo, S.T., 2010, Do Peso Problems Explain the Returns to the Carry Trade? Economics Research Initiatives at Duke (ERID) Working Paper No. 45.

Burnside, A.C., 2007, The Cross-Section of Foreign Currency Risk Premia and Consumption Growth Risk: A Comment, NBER Working Papers.

Campbell, J.Y. and Mei, J., 1993, Where do betas come from? Asset price dynamics and the sources of systematic risk, The Review of Financial Studies, 6, 567-592.

Campbell, J.Y., Lettau, M., Malkiel, B.G. and Xu, Y., 2001, Have individual stocks become more volatile? An empirical exploration of idiosyncratic risk, The Journal of Finance, 56, $1-43$

Campbell, J.Y. and Vuolteenaho, T., 2004, Bad Beta, Good Beta, The American Economic Review, 94, 1249-1275.

Carhart, M.M., 1997, On persistence in mutual fund performance, The Journal of Finance, 52, 57-82.

Chan, L.K.C., Jegadeesh, N. and Lakonishok J., 1996, Momentum strategies, The Journal of Finance, 51, 1681-1713.

Chaturvedi, S., Kapoor, A.K. and Srinivasan, V., 1998, A new orthogonalization procedure with an extremal property, Journal of Physics A: Mathematical and General, 31, L367-L370.

Chopra, N., Lakonishok, J., and Ritter, J., 1992, Measuring abnormal returns: Do stocks overreact, Journal of Financial Economics, 31, 235-268.

Chou, P.H. and Zhou, G, 2006, Using bootstrap to test portfolio efficiency, Annals of Economics and Finance, 2, 217-249.

Chow, K.V., 2001, Marginal conditional stochastic dominance, statistical inference, and measuring portfolio performance, Journal of Financial Research, 24, 289-307.

Chow, K.V., Denning, K., and Huang, Z., 2008, Style fund investment: performance and efficiency, International Research Journal of Finance and Economics, 21, 27-47.

Chow, K.V. and Klein, R.F., 2010, Orthogonalized equity risk premia and systematic risk decomposition, Working Paper Series, West Virginia University.

Cochrane, J.H., 2005, Asset pricing (Princeton University Press, Princeton, NJ).

De Bondt, W., Thaler, R., 1985, Does the stock market overreact?, The Journal of Finance, 40, 793-805. 
De Bondt, W., Thaler, R., 1987, Further evidence on investor overreaction and stock market seasonality, The Journal of Finance, 42, 557-581.

De Santis, R.A. and Fornari, F., 2008, Does Business Cycle Risk Account for Systematic Returns from Currency Positioning? The International Perspective, Available at SSRN: http://ssrn.com/abstract $=1140663$.

DeSantis, G. and Gerard, B., 1998, How big is the premium for currency risk?, Journal of Financial Economics, 49, 375-412.

Dewachter, H. and Lyrio, M., 2006, Macro factors and the term structure of interest rates, Journal of Money, Credit, and Banking, 38, 119-140.

Engel, C., 1996, The forward discount anomaly and the risk premium: A survey of recent evidence, Journal of Empirical Finance 3, 123-192.

Fama, E.F., 1984, Forward and spot exchange rates, Journal of Monetary Economics 14, 319338.

Fama, E.F. and French, K.R., 1992, The cross-section of expected stock returns, The Journal of Finance, 47, 427-465.

Fama, E.F. and French, K.R., 1993, Common risk factors in the returns on stocks and bonds, The Journal of Financial Economics, 33, 3-56.

Fama, E.F. and French, K.R., 1996, Multifactor Explanations of Asset Pricing Anomalies, The Journal of Finance, 51, 55-84.

Fama, E.F. and French, K.R., 1998, Value versus Growth: The International Evidence, The Journal of Finance, 53, 1975-1999.

Fama, E.F. and MacBeth, J.D., 1973, Risk, Return, and Equilibrium: Empirical Tests, The Journal of Political Economy 81, 607-636.

Fillat, J. and Garduño, H., 2005, GMM estimation of an asset pricing model with habit persistence, Working Paper, University of Chicago.

Gibbons, M.R., Ross, S.A. and Shanken J., 1989, A test of the efficiency of a given portfolio, Econometrica, 57, 1121-1152.

Glushkov, D., 2006, Sentiment beta, Working paper, Available at SSRN: http://ssrn.com/abstract $=862444$.

Hadar, J. and Russell, W.R., 1969, Rules for ordering uncertain prospects, The American Economic Review, 59, 25-34. 
Hanoch, G. and Levy, H., 1969, The efficiency analysis of choices involving risk, The Review of Economic Studies, 36, 335-346.

Hansen, L.P., 1982, Large Sample Properties of Generalized Method of Moments Estimators, Econometrica 50, 1029-1054.

Hodrick, R.J., 1989, Risk, uncertainty, and exchange rates, Journal of Monetary Economics 23, 433-459.

Hodrick, R.J. and Srivastava, S., 1986, The covariation of risk premiums and expected future spot exchange rates, Journal of International Money and Finance 5, 5-30.

Hollifieldy, B. and Yaron, A., 2001, The foreign exchange risk premium: Real and nominal factors, GSIA Working Papers, Carnegie Mellon University, Tepper School of Business No. 2001-E13.

Imbens, G.W., 2002, Generalized Method of Moments and Empirical Likelihood, Journal of Business \& Economic Statistics 20, 493-506.

Jegadeesh, N. and Titman, S., 1993, Returns to buying winners and selling losers: implications for stock market efficiency, The Journal of Finance, 48, 65-91.

Jegadeesh, N. and Titman, S., 2001, Profitability of momentum strategies: an evaluation of alternative explanations, The Journal of Finance, 56, 699-720.

Jewitt, I., 1987, Risk aversion and the choice between risky prospects: The preservation of comparative statics results, The Review of Economic Studies, 54, 73-85.

Kennedy, P.E., 2008, A guide to econometrics, $6^{\text {th }}$ Edition, Wiley-Blackwell, Malden, MA.

Knez, P.J. and Ready, M.J., 1997, On the robustness of size and book-to-market in crosssectional regressions, The Journal of Finance, 52, 1355-1382.

Kuosmanen, T., 2004, Efficient diversification according to stochastic dominance criteria, Management Science, 50, 1390-1406.

Lee, C.M., Shleifer, A., and Thaler, R.H., 1991, Investor sentiment and the closed-end fund puzzle, The Journal of Finance, 46, 75-109.

Levy, H., 1992, Stochastic dominance and expected utility: survey and analysis, Management Science, 38, 555-593.

Levy, H. and Sarnat, M., 1984, Portfolio and investment selection: Theory and practice, Prentice-Hall International. 
Lewellen, J., Nagel S., and Shanken, J.A., 2010, A skeptical appraisal of asset pricing tests, Journal of Financial Economics 96, 175-194.

Liew, J. and Vassalou, M., Can book-to-market, size and momentum be risk factors that predict economic growth?, Journal of Financial Economics, 57, 221-245.

Lintner, J., 1965, The valuation of risk assets and the selection of risky investments in stock portfolios and capital budgets, Review of Economics and Statistics, 47, 13-37.

Liu, S., 2006, Investor sentiment and stock market liquidity, Working Paper, University of Texas at Austin.

Lo, A.W. and MacKinlay, A.C., 1990, Data-snooping biases in tests of financial asset pricing models, The Review of Financial Studies, 3, 431-467.

Loughran, T., 1997, Book-to-market across firm size, exchange, and seasonality: Is there an effect?, Journal of Financial and Quantitative Analysis, 32, 249-268.

Löwdin, P.O., 1970, On the nonorthogonality problem, Advances in Quantum Chemistry, 5, 185199.

Lozano, M. and Gonzalo, R., 2011, Evaluating alternative methods for testing asset pricing models with historical data, Journal of Empirical Finance 18, 136-146.

Lucas, R.E. Jr., 1978, Asset Prices in an Exchange Economy, Econometrica 46, 1429-1445.

Lustig, H. and Verdelhan, A., 2007, The Cross Section of Foreign Currency Risk Premia and Consumption Growth Risk, The American Economic Review 97, 89-117.

MacKinlay, A.C., 1995, Multifactor models do not explain deviations from the CAPM, Journal of Financial Economics 38, 3-28.

MacKinlay, A.C. and Richardson, M.P., 1991, Using generalized method of moments to test mean-variance efficiency, The Journal of Finance, 46, 511-527.

Marcelo, J.L.M. and Quiros, M.M., 2006, The role of an illiquidity risk factor in asset pricing: Empirical evidence from the Spanish stock market, The Quarterly Review of Economics and Finance, 46, 254-267.

Mark, N.C., 1985, On time varying risk premia in the foreign exchange market: An econometric analysis, Journal of Monetary Economics 16, 3-18.

Merton, R.C., 1973, An intertemporal capital asset pricing model, Econometrica, 41, 867-887.

Mitchell, M., Pulvino, T., and Stafford, E., 2002, Limited arbitrage in equity markets, The Journal of Finance, 57, 551-584. 
Mussa, M., 1979, Empirical regularities in the behavior of exchange rates and theories of the foreign exchange market, Carnegie-Rochester Conference Series on Public Policy 11, 957.

Neely, C.J., 2002, The temporal pattern of trading rule returns and exchange rate intervention: intervention does not generate technical trading profits, Journal of International Economics 58, 211-232.

Neely, C.J., Weller, P., and Dittmar, R., 1997, Is Technical Analysis in the Foreign Exchange Market Profitable? A Genetic Programming Approach, Journal of Financial and Quantitative Analysis 32, 405-426.

Newey, W.K. and West, K.D., 1987, Hypothesis Testing with Efficient Method of Moments Estimation, International Economic Review 28, 777-787.

Post, T., 2003, Empirical tests for stochastic dominance efficiency, The Journal of Finance, 5, 1905-1931.

Post, T. and Vliet, P., 2004, Market portfolio efficiency and value stocks, Journal of Economics and Finance, 28, 300-306.

Post, T. and Versijp, P., 2007, Multivariate tests for stochastic dominance efficiency of a given portfolio, Journal of Financial and Quantitative Analysis, 42, 489-516.

Post, T. and Vliet, P., 2006, Downside risk and asset pricing, Journal of Banking and Finance, 30, 823-849.

Qiu, L. and Welch, I., 2004, Investor sentiment measures, NBER Working Paper Series, 10794, Available at SSRN: http://ssrn.com/abstract=595193.

Richardson, M. and Smith, T., 1993, A test for multivariate normality in stock returns, The Journal of Business, 66, 295-321.

Ross, S., 1976, The arbitrage theory of capital asset pricing, Journal of Economic 13, 341-360.

Rothschild, M. and Stiglitz, J. E., 1970, Increasing risk: I. A definition, Journal of Economic Theory, 2, 225-243.

Rouwenhorst, K.G., 1998, International Momentum Strategies, The Journal of Finance, 53, 267284.

Schweinler, H.C. and Wigner, E.P., 1970, Orthogonalization Methods, Journal of Mathematical Physics, 11, 1693-1694.

Serban, A.F., 2010, Combining mean reversion and momentum trading strategies in foreign exchange markets, Journal of Banking \& Finance 34, 2720-2727. 
Shalit, H. and Yitzhaki, S., 1994, Marginal conditional stochastic dominance, Management Science, 40, 670-684.

Shanken, J.A., 1996, Statistical methods in tests of portfolio efficiency: A synthesis, Handbook of Statistics, 14, 693-711.

Sharpe, W.F., 1964, Capital asset prices: A theory of market equilibrium under conditions of risk, The Journal of Finance 19, 425-442.

Solnik, B., 1974, An equilibrium model of the international capital market, Journal of Economic Theory, 8, 500-524.

Srivastava, V., 2000, A unified view of the orthogonalization methods, Journal of Physics A: Mathematical and General, 33, 6219-6222.

Stulz, R., 1981, A model of international asset pricing, Journal of Financial Economics, 9, 383406.

Sweeney, R.J., 1986, Beating the Foreign Exchange Market, The Journal of Finance 41, 163182.

Szakmary, A.C. and Mathur, I., 1997, Central bank intervention and trading rule profits in foreign exchange markets, Journal of International Money and Finance 16, 513-535.

Villanueva, O., 2007, Forecasting currency excess returns: Can the forward bias be exploited? Journal of Financial and Quantitative Analysis 42, 963-990.

Yogo, M., 2006, A Consumption-Based Explanation of Expected Stock Returns, The Journal of Finance 61, 539-580.

Zhou, G., 1993, Asset-pricing tests under alternative distributions, The Journal of Finance, 48, 1927-1942. 


\section{Rudolf F. Klein}

West Virginia University

College of Business and Economics

Division of Economics and Finance

P.O. BOX 6025, Morgantown, WV 26506
Primary Phone: (434) 321-4773

Alternate Phone: (304) 216-2099

E-mail: Rudolf.Klein@mail.wvu.edu

https://sites.google.com/site/rudolffklein/

\section{Education:}

Ph.D. in Economics, West Virginia University

Graduation: May 2011

Dissertation Title: Analysis of Systematic Risk: Decomposition and Portfolio Efficiency

Dissertation Chair: K. Victor Chow, Ph.D.

B.S. in Economics, Academy of Economic Studies, Bucharest, Romania, September 2003

Thesis Title: Inflation and Disinflation in the Romanian Economy

\section{Areas of Interest:}

Research: Asset Pricing, Portfolio Choice, Portfolio Efficiency, Investor Sentiment, Stochastic Dominance

Teaching: Microeconomics, Macroeconomics, Investments, General Finance, Personal Finance, Financial Markets \& Institutions, Monetary Economics, Business Statistics, Mathematical Economics

\section{Papers Accepted for Review:}

Job Market Paper: Orthogonalized Equity Risk Premia and Systematic Risk Decomposition (with K. Victor Chow): under review at the Quarterly Review of Economics and Finance

\footnotetext{
Abstract: To solve the dependence problem between factors, in the context of linear multi-factor models, this study proposes an optimal procedure to find orthogonalized risk premia, which also facilitates the decomposition of the coefficient of determination. Importantly, the new risk premia may diverge significantly from the original ones. The decomposition of risk allows one to explicitly examine the impact of individual factors on the return variation of risky assets, which provides discriminative power for factor selection. The procedure is experimentally robust even for small samples. Empirically we find that even though on average, approximately eighty (sixty-five) percent of style (industry) portfolios' volatility is explained by the market and size factors, other factors such as value, momentum and contrarian still play an important role for certain portfolios. The components of systematic risk, while dynamic over time, generally exhibit negative correlation between market, on one side, and size, value, momentum and contrarian, on the other side.
} 
Sentiment Effect and Market Portfolio Inefficiency (with K. Victor Chow): under review at Quantitative Finance

Consumption Risk and FX Trading Returns (with Alina Klein): under review at Journal of International Money and Finance

\section{Teaching Experience:}

Adjunct Instructor, Lynchburg College

Intermediate Microeconomics, Spring 2011

Principles of Microeconomics, Spring 2011

Instructor with Full Teaching Responsibilities, West Virginia University

Survey of Finance, Summer 2010 (online)

Investments, Spring 2010

Investments, Fall 2009

Survey of Finance, Summer 2009 (online, 3 sections)

Survey of Finance, Summer 2008 (online)

Principles of Microeconomics, Spring 2008

Survey of Finance, Summer 2007

\section{Academic Position:}

Graduate Teaching Assistant, West Virginia University

Business Finance, Spring 2009

Advanced Bank Management, Spring 2009

Working Capital Management, Fall 2008

Introduction to Business, Fall 2008

Elementary Business and Economics Statistics, Fall 2007

Business Finance, Spring 2007

Trading Financial Instruments, Fall 2006

Business Finance, Spring 2006

Introduction to Management Science, Fall 2005

Applied Business and Economics Statistics, Fall 2005

\section{Awards and Conference Participation:}

"Orthogonalized Equity Risk Premia and Systematic Risk Decomposition", "Sentiment Effect and Market Portfolio Inefficiency", and "Are FX trading returns compensation for risk?" - presented at the Eastern Finance Association Annual Meetings in Savannah, Georgia, April 13 - 16, 2011 
"Sentiment Effect and Market Portfolio Inefficiency" - accepted for presentation at the 2011 meetings of the Midwest Finance Association, in Chicago, IL

Presenter, session chairperson, and discussant at the Midwest Finance Association Conference Las Vegas, NV, February 24-27, 2010

Certificate of Teaching Training, granted by the Academy of Economic Studies, Bucharest, Romania, 2003

Third Prize at the Annual Session of Academic Research, Finance and Insurance Section, Bucharest, Romania, 2001. Paper Title: "Future Account"-Optimal Product in Mixed Personal Insurance in Romania

\section{References:}

Professor Victor Chow

Division of Economics and Finance

West Virginia University

(304) 293-7888

Victor.Chow@mail.wvu.edu

Professor Ronald Balvers

Division of Economics and Finance

West Virginia University

(304) 293-7880

Ronald.Balvers@mail.wvu.edu

Professor Arabinda Basistha

Division of Economics and Finance

West Virginia University

(304) 293-7854

ArBasistha@mail.wvu.edu 